\title{
Nuevos antecedentes estratigráficos y geocronológicos para el Meso-Cenozoico de la cordillera Principal de Chile entre $32^{\circ}$ y $32^{\circ} 30 ’ S$ : implicancias estructurales y paleogeográficas
}

\author{
Pamela Jara ${ }^{1,2}$, Reynaldo Charrier ${ }^{1,3}$ \\ ${ }^{\prime}$ Departamento de Geología y Advanced Mining Technology Center (AMTC), Facultad de Ciencias Físicas y Matemáticas, Universidad \\ de Chile, Avda. Tupper 2007, Santiago, Chile. \\ ${ }^{2}$ Departamento de Ingeniería en Minas, Facultad de Ingeniería, Universidad de Santiago de Chile, Avda. Libertador Bernardo \\ O’Higgins 3363, Santiago, Chile. \\ pamela.jara@usach.cl \\ ${ }^{3}$ Escuela de Ciencias de la Tierra, Universidad Andrés Bello, Salvador Sanfuentes 2357, Santiago. \\ rcharrier@unab.cl
}

\begin{abstract}
RESUMEN. Los intentos por diferenciar y correlacionar las unidades geológicas en la cordillera Principal Andina, entre $31^{\circ} 30^{\prime} \mathrm{S}$ y $33^{\circ} \mathrm{S}$, se han enfrentado a numerosos obstáculos debido a la monotonía litológica de las potentes secuencias de carácter volcánico que las conforman, la complejidad estructural, la falta de datos geocronológicos que las limiten y la errada consideración inicial de un rejuvenecimiento en las edades radiométricas obtenidas. Las unidades reconocidas al oriente de la zona de Falla Pocuro fueron inicialmente atribuidas al Cretácico (Formación Los Pelambres en Chile y Formación Juncal en Argentina). Esta contribución complementa los trabajos previos mediante un levantamiento geológico-estructural desarrollado entre $32^{\circ}$ y $32^{\circ} 30^{\prime} \mathrm{S}$, el que, junto a 8 nuevas dataciones U-Pb en circón, permite reconocer niveles del Cretácico Superior (Formación Salamanca) en el sector occidental de la cordillera Principal, subyacentes a rocas cenozoicas de las formaciones Abanico y Farellones. Las unidades cenozoicas a esta latitud se han subdividido en 3 asociaciones de facies vinculadas al volcanismo Oligoceno Superior-Mioceno. Gran parte de la cordillera Principal en esa latitud se compone de estas unidades cenozoicas, hasta el límite oriental del área de estudio (frontera Chile-Argentina). En el sector occidental de la región, la esencialmente volcánica Formación Abanico presenta las facies más proximales con leve deformación, mientras que las unidades más distales, cerca y allende la frontera, se encuentran intensamente deformadas por eventos ocurridos, uno entre 21 y $18 \mathrm{Ma}$, y otro con posterioridad a $18 \mathrm{Ma}$. Por otra parte, en las cercanías de la Falla Pocuro, la presencia de afloramientos del Cretácico Superior, discordantemente subyacentes a depósitos oligocenos-miocenos levemente deformados, permiten limitar su período de actividad principal previo al depósito de estos.
\end{abstract}

Palabras clave: Andes chileno-argentinos, Estratigrafia, Geocronología, Paleogeografía, Tectónica.

\begin{abstract}
New stratigraphical and geochronological constraints for the Mezo-Cenozoic deposits in the High Andes of central Chile between $32^{\circ}$ and 32 30 'S: Structural and palaeogeographic implications. Attempts to differentiate geological units of the Andean Principal Cordillera, between $31^{\circ} 30^{\prime} \mathrm{S}$ and $33^{\circ} \mathrm{S}$, faced several problems until very recently. The lack of geochronological data or the equivocal interpretation of some existing radiometric ages from thick volcanic and volcaniclastic sequences, along with their structural complexity and lithologic monotony, obscured the recognition and relationships between units. This made a tectonic interpretation difficult as the units cropping-out on the eastern side of the Pocuro Fault zone were initially assigned to Cretaceous formations (Los Pelambres Formation in Chile and Juncal Formation in Argentina). Structural-geological work carried out between $32^{\circ}$ and $32^{\circ} 30^{\prime}$ S, together with 8 new U-Pb zircon datings, allowed us to recognize the presence of Upper Cretaceous levels (Salamanca Formation), underlying volcano-sedimentary younger units of Abanico and Farellones formations. The latter were interpreted as different facies associated with upper Oligocene-Miocene volcanism. Most of the Principal Cordillera at this latitude is composed by these units, at least until the Chile-Argentina border. In the western part of the region, the volcanic Abanico Formation presents the most proximal facies with mild deformation, while more distal units, near and across the border are intensely deformed in two events, one between 21 and $18 \mathrm{Ma}$, and other post $18 \mathrm{Ma}$. On the other hand, in the vicinity of the Pocuro Fault zone, Upper Cretaceous outcrops, underlying oligo-miocene deposits slightly deformed, suggest an oligo-miocene age for the last event of this fault zone.
\end{abstract}




\section{Introducción}

En este trabajo se presentan nuevos antecedentes cronoestratigráficos y estructurales entre las latitudes $32^{\circ}$ y $32^{\circ} 30^{\prime} \mathrm{S}$ (Fig. 1), en la cordillera Principal, entre la zona de Falla Pocuro, por el oeste, y el límite chileno-argentino, por el este (Figs. 1 y 2). Las rocas expuestas corresponden a gruesas sucesiones estratificadas, depositadas en ambiente continental, constituidas por lavas andesíticas porfíricas y depósitos volcanoclásticos, en los cuales se disponen niveles tobáceos y, esporádicamente, sedimentarios.

Los primeros estudios realizados en la región cordillerana comprendida entre $32^{\circ}$ y $33^{\circ} \mathrm{S}$ señalaron la existencia de rocas cenozoicas al este de la zona de Falla Pocuro (Aguirre, 1960; Carter y Aguirre, 1965; Aguirre et al., 1974; Munizaga y Vicente, 1982; Moscoso et al., 1982; Padilla, 1981; Arias, 1984). Sin embargo, la consideración posterior realizada por Rivano et al. (1993) y Rivano (1996), de que las edades cenozoicas obtenidas en esas rocas por el método K-Ar corresponderían a edades rejuvenecidas por eventos termales, implicó que la mayor parte de estos depósitos fueran asignados al Cretácico. Estas unidades fueron designadas como formaciones Los Pelambres y Salamanca, por comparación con la estratigrafía conocida en regiones más al norte (Rivano y Sepúlveda, 1991), mientras que el resto de la sucesión estratificada fue asignada correctamente a la neógena Formación Farellones (Rivano et al., 1993). Esta situación ha dificultado la adecuada correlación de estos depósitos con las unidades cenozoicas descritas para regiones más al oeste y al sur de la región de estudio e impedido su correcta ubicación en el contexto tectono-estratigráfico de los Andes de Chile central.

Considerando que a lo largo de los años se han correlacionado las unidades de la cordillera Principal de Chile central y límite con Argentina según varios puntos de vista desde estratigráficos, cronológicos y estructurales, y que la región de estudio se ubica en la zona de transición entre los segmentos de subducción subhorizontal y normal (Fig. 1), se infiere que los cambios latitudinales en los estilos de

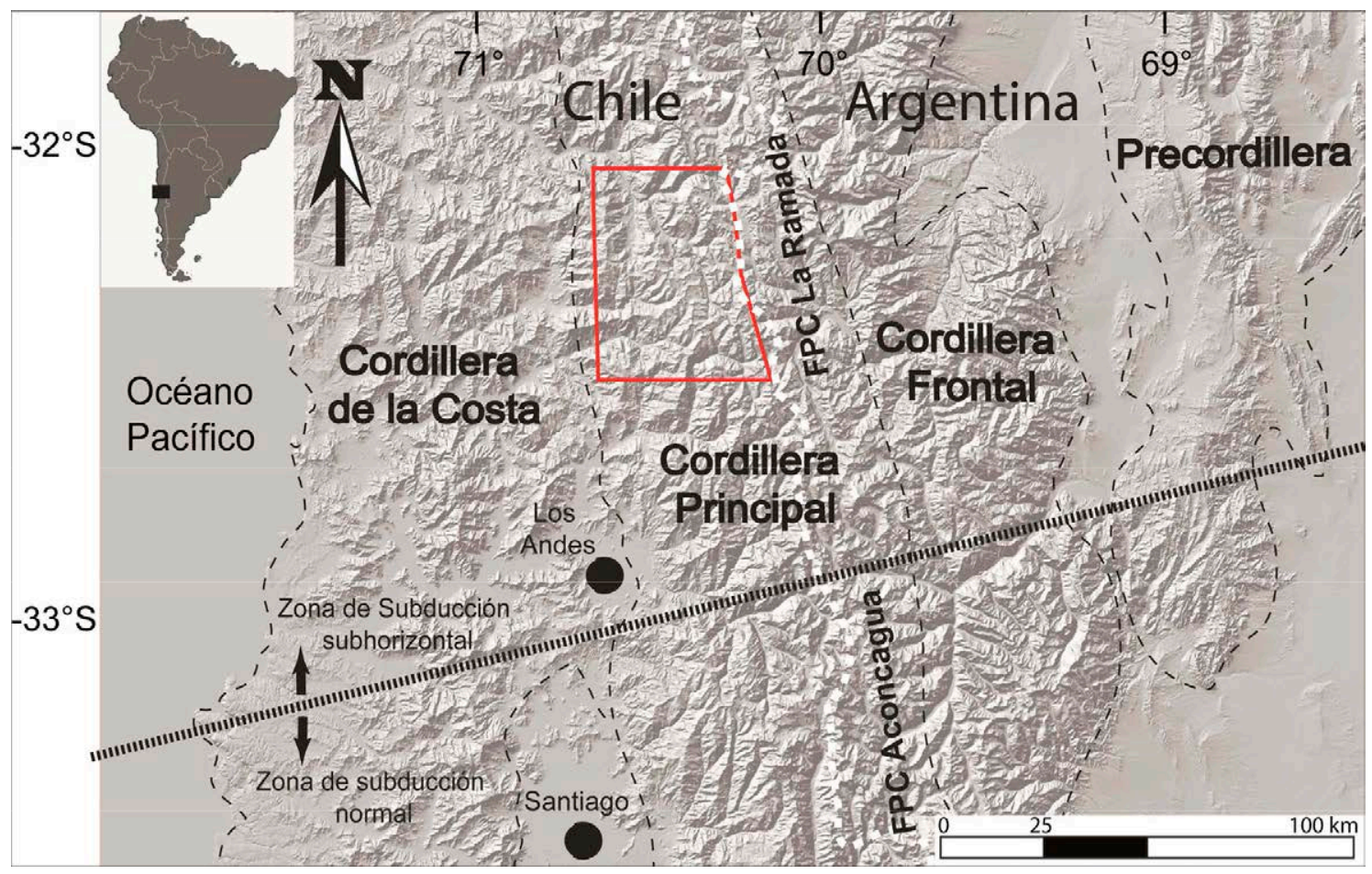

FIG. 1. Modelo de elevación digital de la región Andina en el límite de subducción subhorizontal al norte y subducción normal al sur y límites (línea negra punteada) entre morfoestructuras principales de la región. Se indica en el recuadro rojo la zona de estudio. 


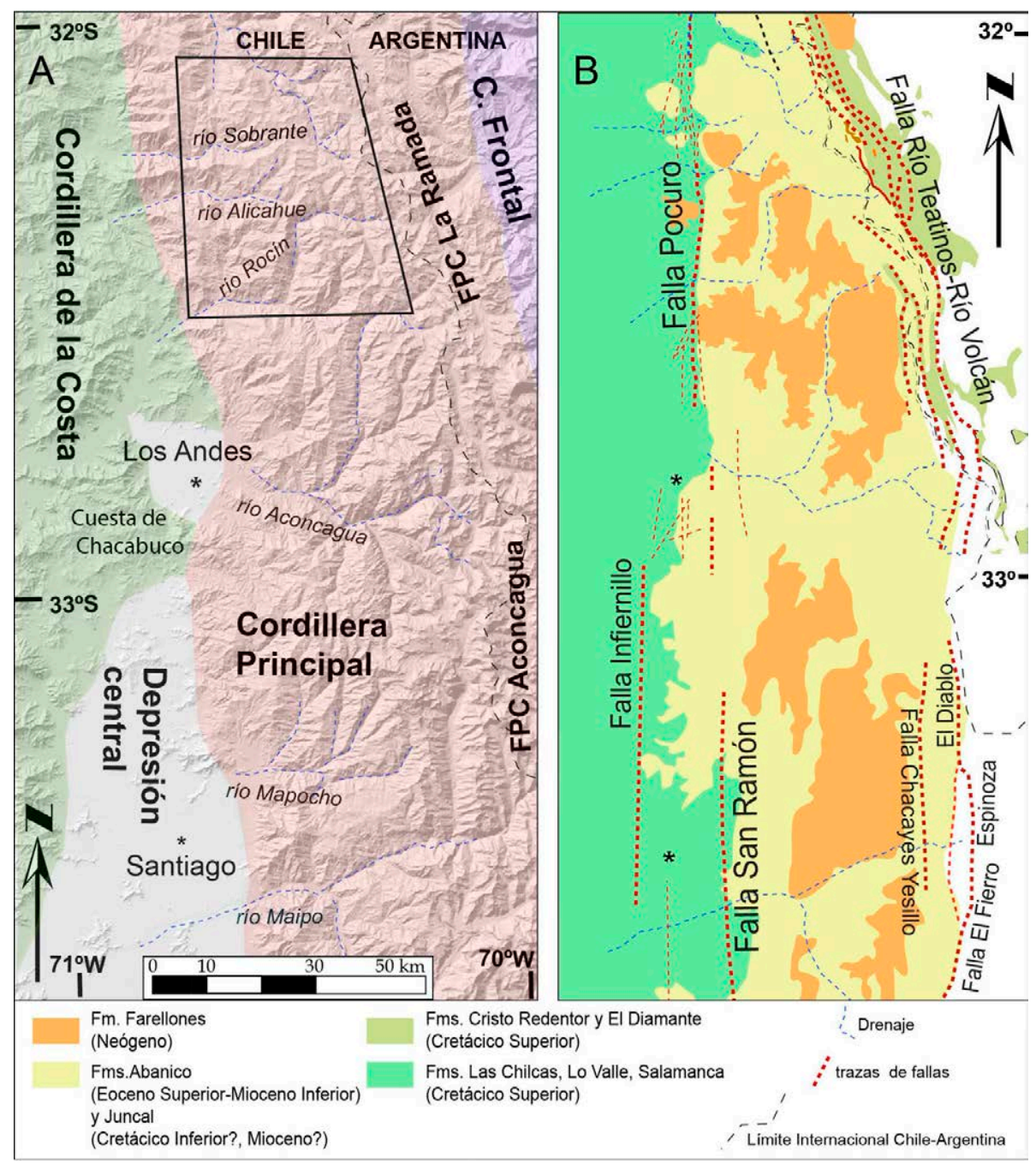

FIG. 2. A. Morfoestructuras regionales en modelo de elevación de la región oriental de la cordillera de la Costa y cordillera Principal chileno-argentina, entre $32^{\circ}$ y $33^{\circ} 30^{\prime} \mathrm{S}$. B. Unidades litológicas y estructuras de importancia regional citadas en el texto, que limitan por el occidente y oriente la región de estudio (recuadro en A). (Compilado de SERNAGEOMIN, 2002; Rivano et al., 1993; Cristallini et al., 1996 y este trabajo).

deformación y características paleogeográficas y consecuentemente estratigráficas han dificultado el reconocimiento de los límites entre estas. Por lo tanto, se hace necesaria una revisión con el fin de aunar criterios para reconocer y definir las unidades que caracterizan la región. Los nuevos antecedentes que aquí se presentan permiten determinar las variaciones latitudinales y transversales en el estilo y la cronología de la deformación a lo largo de esta franja. Por otra parte, trabajos a escala regional, que limitan por el oriente con el área de estudio, realizados en territorio argentino (Cristallini et al., 1995; Cristallini, 1996a, b; Ramos et al., 1996a, b), permiten complementar la información existente y generar un modelo estructural y evolutivo que integre los estudios realizados en ambas vertientes de la cordillera.

El presente estudio aporta nuevos antecedentes estratigráficos y estructurales de la región, que junto a 8 nuevas dataciones $\mathrm{U}-\mathrm{Pb}$ en circón, permiten estudiar las implicancias en la evolución paleogeográfica y su integración al contexto tectónico de los Andes de Chile central. 


\section{Estudios anteriores}

Los primeros levantamientos regionales en la zona estudiada corresponden a los de Aguirre (1960) y Rivano y Sepúlveda (1991). Las unidades litoestratigráficas de la cordillera Principal de Chile central, entre $32^{\circ}$ y $33^{\circ} \mathrm{S}$ (Fig. 3), fueron asignadas a las formaciones Los Pelambres, cretácica inferior; Salamanca, cretácica superior, y Farellones, neógena (Rivano et al., 1990; Rivano y Sepúlveda, 1991; Rivano et al., 1993; Rivano, 1996).

Las rocas volcánicas jurásicas y cretácicas de la actual cordillera Principal en esta latitud se habrían generado en un amplio arco magmático con características extensionales, que se extendía desde la cordillera de la Costa en Chile hasta territorio argentino (Sanguinetti y Ramos, 1993). Dentro de este amplio arco magmático, los miembros volcánicos occidentales de la cordillera de la Costa (formaciones Lo Prado y Veta Negra) representarían un arco volcánico interno, mientras que la esencialmente volcánica Formación Juncal, en territorio argentino, y Los Pelambres, en territorio chileno, representarían al volcanismo más externo de ese arco. Hacia el oeste de la parte externa del arco, en territorio chileno, los depósitos volcano-sedimentarios de la Formación Las Chilcas representarían el intraarco entre estos dos extremos volcánicos (Rivano et al., 1993; Ramos, 1996, entre otros).

Hacia el oeste, la Formación Los Pelambres definida por Rivano (1984), inicialmente atribuida al Cretácico Inferior sobre la base de consideraciones litoestratigráficas y escasos fósiles (Rivano y Sepúlveda, 1991; Rivano et al., 1993), fue correlacionada temporalmente con las formaciones cretácicas Las Chilcas, Lo Prado y Veta Negra (Rivano et al., 1993), que afloran entre el borde oriental de la cordillera de la Costa y el sector más occidental de la cordillera Principal. En este contexto, se completaba para el Cretácico Inferior un esquema de depositación predominantemente subaéreo y continental, con características tectónicas propias de una región en extensión (Levi y Aguirre, 1981; Levi y Nyström, 1982; Coira et al., 1982; Charrier, 1984; Ramos, 1988; Mpodozis y Ramos, 1989, entre otros). Estudios posteriores, basados en asociaciones fosilíferas, muestran que la Formación Las Chilcas se habría desarrollado en un ambiente marino somero con influencias mareales durante el Cretácico Inferior, desvinculada de los sedimentos asociados a la ingresión

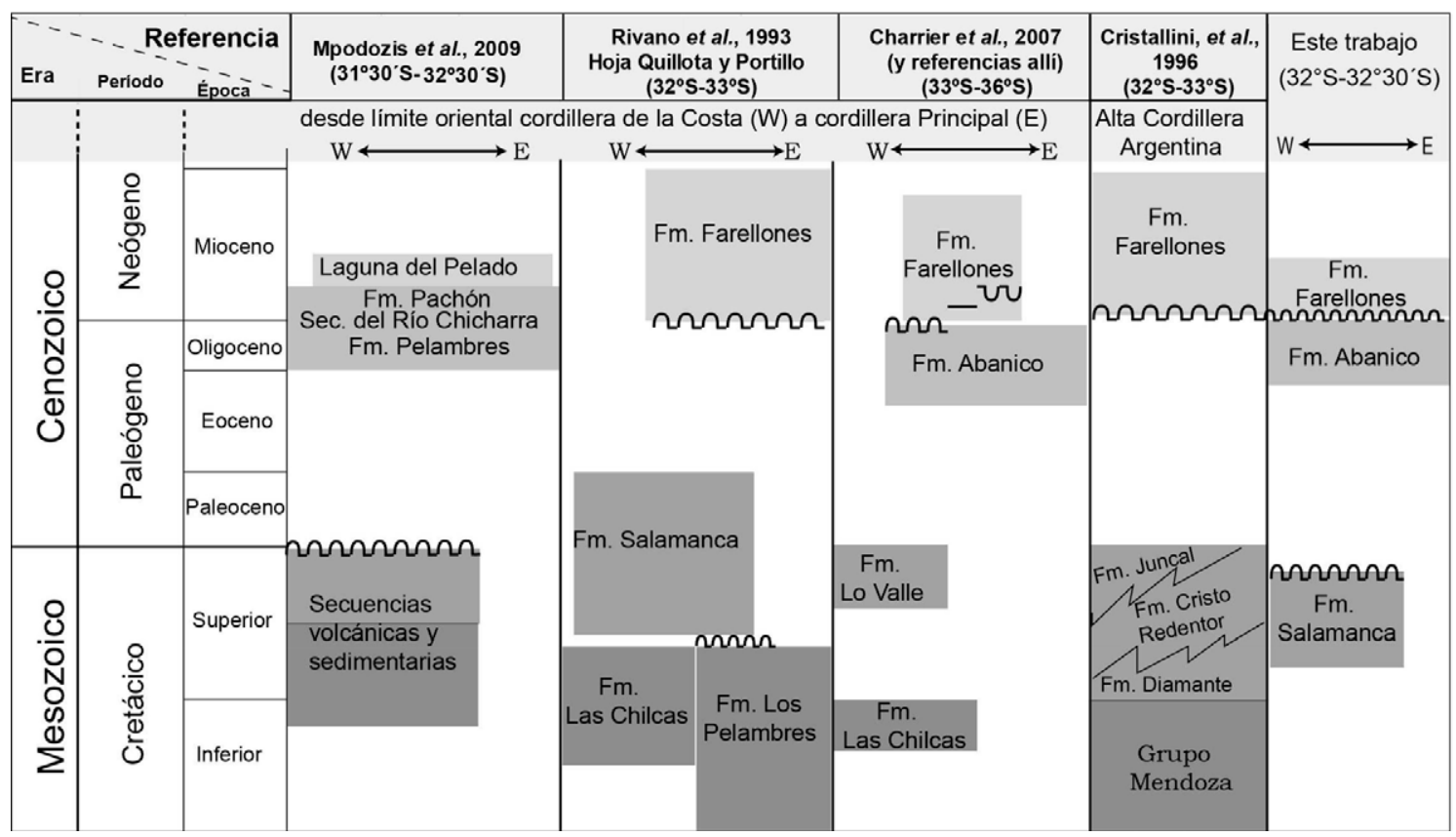

FIG. 3. Cuadro de correlación entre formaciones de edades comprendidas entre el Cretácico Superior y Mioceno, reconocidas desde el límite oriental de la cordillera de la Costa y la cordillera del límite (Chile-Argentina), entre $31^{\circ} 30^{\circ} \mathrm{S}$ y $36^{\circ} \mathrm{S}$. 
marina Atlántica, descartando la comunicación entre los océanos Atlántico y Pacífico a la latitud de $33^{\circ} 30^{\prime}$ S durante el Cretácico Superior (Wall et al., 1999; Sellés y Gana, 2001; Tunik y Álvarez, 2008).

La Formación Los Pelambres fue correlacionada hacia el oriente con la Formación Juncal (Fig. 3) (Rivano et al., 1993), de esa misma edad, reconocida en el sector argentino (Ramos y Cingolani, 1989; Ramos et al., 1990, 1996a, b; Cristallini y Cangini, 1993; Cristallini et al., 1995; Cegarra y Ramos, 1996; Ramos, 1996; Cristallini, 1996a, b; Cristallini y Ramos, 1996); formaciones que en conjunto habrían representado los depósitos orientales del arco externo durante la extensión mesozoica (Ramos, 1996; Ramos et al., 1996a). Este arco externo se habría encontrado al oeste de la cuenca de retroarco en la que se habrían depositado las potentes secuencias marinas del Cretácico Inferior, entre las que se encuentran las facies de plataforma del Grupo Mendoza (Fig. 3) y donde también se desarrollaron intermitentemente centros volcánicos aislados (Ramos y Aguirre-Urreta, 1992).

Cristallini (1996a) señala que la Formación Juncal (Figs. 2 y 3), en el sector limítrofe entre Chile y Argentina, entre $32^{\circ}$ y $33^{\circ} \mathrm{S}$, consiste en conglomerados de matriz tobácea, brechas volcánicas, tobas y areniscas tobáceas de colores violáceos a pardo rojizos, con intercalaciones lávicas y brechas de flujo andesíticas de color verde grisáceo, y señala también que grada hacia el oriente, tanto vertical como horizontalmente, a los depósitos clásticos de la Formación Cristo Redentor (Aguirre, 1960) y Formación Diamante (Yrigoyen, 1976, 1979).

Cristallini y Cangini (1993) dividen los depósitos continentales cretácicos en cuatro facies, donde la Formación Juncal correspondería a las facies volcánicas; la Formación Cristo Redentor a las facies volcanoclásticas proximales y la Formación Diamante, a las facies volcanoclásticas distales (Fig. 3). Las tres formaciones estudiadas por estos autores se encuentran repetidas tectónicamente y afectadas por plegamiento (Cristallini, 1996a).

La deformación que afecta a las rocas de la Formación Juncal, en el sector cordillerano limítrofe entre ambas naciones, se caracteriza por una serie de corrimientos con vergencia oriental y rumbo NNW, descritos como corrimientos fuera de secuencia de la Faja Plegada y Corrida (FPC) de la Ramada (Fig. 2), de gran persistencia en el rumbo y pliegues de escasa longitud de onda, sin participación de niveles salinos (Cristallini, 1996b). La estructura superficial de esta FPC evidencia una deformación compresiva neógena, sin embargo, se reconoce en ella la influencia de una estructuración extensional, de edad triásica superior a jurásica inferior, que habría sido invertida durante el evento compresivo neógeno (Cristallini, 1996b). Según este autor, esta estructuración mesozoica habría permitido la participación del basamento precenozoico en la deformación, y habría dado lugar a una faja plegada y corrida de piel gruesa (FPC de La Ramada) (Cristallini, 1996a, b; Cristallini et al., 1995, 1996), aunque en ella también se han reconocido corrimientos de vergencia oriental que deforman la cobertura cenozoica sin involucrar el basamento, entre las que se reconocen dos eventos de estructuración de piel fina, uno preinversión neógena y otra deformación de piel fina posterior a la inversión. Estos últimos corrimientos fueron interpretados como fallas fuera de secuencia dentro de la faja plegada y corrida de La Ramada (Cristallini et al., 1995, 1996), causadas por una 'línea de fijación' o de bloqueo en la propagación de la faja, tras el levantamiento del basamento mediante fallas inversas de alto ángulo al oriente de la zona de estudio (Cristallini, 1996b).

Dataciones K-Ar en la Formación Juncal entre $32^{\circ}$ y $33^{\circ} \mathrm{S}$ (Ramos y Cingolani, 1989; Cristallini y Cangini, 1993) arrojaron edades terciarias; sin embargo, las correlaciones descritas anteriormente hizo asignarlas al Cretácico Inferior, por lo que se interpretaron como rejuvenecidas. Este rejuvenecimiento se atribuyó a la presencia de cuerpos granodioríticos del Mioceno inferior que intruyen las secuencias anteriormente descritas. Estudios posteriores dan cuenta de la gran cantidad de edades terciarias obtenidas por el método $\mathrm{K}-\mathrm{Ar}$ en rocas asignadas al Cretácico de la Formación Juncal y Cristo Redentor en Argentina (Ramos y Cingolani, 1989; Cristallini y Cangini, 1993) y Formación Los Pelambres en Chile (Rivano et al., 1993), y señalan la evidente necesidad de nuevas dataciones por métodos más apropiados, con el fin de discernir entre las rocas cretácicas rejuvenecidas y aquellas realmente terciarias (Cristallini, 1996a).

La Formación Juncal, cuya localidad tipo se encuentra en territorio chileno (Ramos et al., 1990), fue correlacionada con la Formación Abanico, definida por Aguirre (1960) como una secuencia de volcanitas y sedimentitas clásticas y terrígenas, 
atribuida también inicialmente al Cretácico Superior. A su vez, Rivano (1996) reconoció una continuidad areal, una identidad de facies y una continuidad estructural de la Formación Los Pelambres con la Formación Abanico hacia el sur.

La región de estudio (Fig. 1) se ubica en el límite sur de la zona de subducción subhorizontal Pampeana o Chilena que se desarrolla entre $\sim 27^{\circ}$ y $33^{\circ} \mathrm{S}$ (Cahill e Isacks, 1992; Ramos, 1999; Gutscher et al., 2000; Ramos et al., 2002). Al sur de la zona de estudio (al sur de $33^{\circ} \mathrm{S}$ ), en la parte norte del segmento de subducción normal, los depósitos del Eoceno superior al Mioceno inferior han sido estudiados desde la década del 60 y se ha interpretado el ambiente tectónico en que se habrían originado, mediante la caracterización de los depósitos, las estructuras que los afectan, su geocronología y geoquímica, entre otras metodologías (Aguirre, 1960; Thiele, 1980; Aguirre et al., 2000; Charrier et al., 1996, 2002; Godoy et al., 1996, 1999; Sellés, 1999, 2000; Zurita, 1999; Rivera y Cembrano, 2000; Giambiagi et al., 2002; Giambiagi y Ramos, 2002; Nyström et al., 2003; Fock et al., 2005; Fock et al., 2006a, b; Muñoz et al., 2006; Jara et al., 2009a, b; Maksaev et al., 2003, 2009; Armijo et al., 2009; Farías et al., 2010; Rauld, 2011, entre otros). Estos estudios han permitido asignar las rocas de la Formación Abanico (Fig. 2) al Eoceno Superior a Mioceno Inferior, bien desarrollada en la cordillera Principal, entre los valles del Maipo, frente a Santiago, y del Maule, frente a Talca (Aguirre, 1960; Klohn, 1960; Vergara y Drake, 1978; Thiele, 1980; Charrier, 1981; Vergara et al., 1999; Astaburuaga et al., 2012), y concluir que se habrían acumulado en 'cuencas de intraarco', en ambiente extensional con volcanismo activo y una geoquímica que no representaría un arco volcánico típico (Muñoz et al., 2006; Jordan et al., 2001; Charrier et al., 2002, 2007). La compleja distribución de los depósitos, la geoquímica y la contracción tectónica que reactivó algunas fallas que originalmente tuvieron movimientos normales, han permitido concluir que la 'cuenca de Abanico' habría sido invertida en un proceso compresivo entre 21 y $16 \mathrm{Ma}$ (ver, por ejemplo, Charrier et al., 2002, 2005, 2007). Este evento contraccional se habría producido sin interrupción del volcanismo, cuyos productos se han asignado a la Formación Farellones del Mioceno Medio a Superior (Klohn, 1960; Rivano et al., 1990). El paso de un régimen tectónico extensional a uno compresivo estaría relacionado con variaciones en las condiciones geodinámicas del margen continental durante la evolución Andina (Pardo-Casas y Molnar, 1987; Jordan et al., 2001; Nyström et al., 2003).

La separación entre las formaciones Abanico y Farellones ha sido ampliamente debatida al sur de $33^{\circ} \mathrm{S}$, donde se ha descrito el límite entre ambas mediante discordancia, pseudoconcordancia, concordancia o falla (Aguirre, 1960; Klohn, 1960; Charrier, 1973, 1981; Thiele, 1980; Moscoso et al., 1982; Godoy, 1988, 1991; Godoy y Lara, 1994; Godoy et al., 1999; Charrier et al., 2002). La deformación de la cuenca de Abanico habría generado depósitos sintectónicos y discordancias progresivas, y no habría, necesariamente, afectado a toda la región de manera homogénea; mientras que los procesos de depositación (incluyendo el volcanismo), probablemente continuó durante el período contraccional, lo que explicaría la dificultad de separar las formaciones Abanico y Farellones en algunas regiones (Charrier et al., 2002). Estudios posteriores reconocen una signatura geoquímica diferente para ambas formaciones, lo que relaciona los procesos de adelgazamiento y posterior engrosamiento cortical durante el desarrollo de las formaciones Abanico y Farellones, respectivamente (Charrier et al., 2002; Nyström et al., 2003; Kay et al., 2005; Muñoz et al., 2006).

Charrier et al. (2005) señalan evidencias de la presencia de la cuenca extensional de Abanico entre al menos $33^{\circ} \mathrm{S}$ y $36^{\circ} \mathrm{S}$, aunque sugieren una extensión mayor incluso más allá de $30^{\circ} \mathrm{S}$ hacia el norte y $38^{\circ} \mathrm{S}$ hacia el sur. Sumado a lo anterior, nuevos estudios presentan pruebas de un período extensional en el sector central de la zona de subducción subhorizontal pampeana de los Andes centrales (Winocur, 2010; Winocur y Ramos, 2008, 2012), lo que indica también la existencia de un arco volcánico Oligoceno entre $29^{\circ}$ y $30^{\circ} \mathrm{S}$, que habría estado activo durante un régimen tectónico extensivo.

Al sur de la región de estudio, entre los ríos Rocín y Aconcagua (Fig. 2), Campbell (2005) y Fock (2005) dan cuenta de la presencia de rocas oligocenas a miocenas de la Formación Abanico en la vertiente chilena de la cordillera Principal. Campbell (2005), mediante el uso de trazas de fisión en apatito y circón y edades ${ }^{40} \mathrm{Ar} /{ }^{39} \mathrm{Ar}$, las reconoce al este de la zona de la Falla Pocuro, y describe un período de exhumación importante para estas, entre el Mioceno Superior y Plioceno. Por otra parte, Fock (2005) reconoce 
rocas asignadas a la Formación Abanico incluso al oeste de la Falla Pocuro, en el sector de la Cuesta de Chacabuco $\left(33^{\circ} \mathrm{S}\right)$ y señala que sería la Falla Infiernillo (Fig. 2) la que las pone en contacto con los depósitos mesozoicos al oeste. La Falla Pocuro, al este de la anterior, cortaría depósitos cenozoicos asignados a la Formación Abanico (Aguirre, 1960; Fuentes et al., 2002; Fuentes, 2004; Fock, 2005) y podría ser la falla principal en la cual se arraigan la Falla Infiernillo y los cabalgamientos de vergencia occidental asociados a ella.

La zona de Falla Pocuro corresponde a un rasgo morfoestructural de escala regional que ha sido descrita como una 'megafalla' que destaca como uno de los elementos mayores en la región comprendida entre $32^{\circ} \mathrm{S}$ y $33^{\circ} \mathrm{S}$ (Rivano, 1996). Su traza se puede seguir a lo largo de más de $100 \mathrm{~km}$ con un ancho variable entre 500 a 2.000 m (Rivano et al., 1993). Según Rivano (1996), corresponde a una zona de falla extensiva y en parte de rumbo, con una serie de fallas paralelas menores de rumbo y fallas conjugadas que obliteran la estratificación debido al intenso clivaje de fractura producido. Por otra parte, Campbell (2005) señala que este sistema estructural está formado por fallas inversas de alto ángulo con vergencia al oeste y con rumbo $\mathrm{NS}$ a $\mathrm{N} 20^{\circ} \mathrm{W}$ y estructuras asociadas con rumbo aproximado $\mathrm{N} 50^{\circ} \mathrm{W}$ y $\mathrm{N} 60^{\circ} \mathrm{E}$ a $\mathrm{EW}$. Este último autor menciona que el sistema debió estar activo al menos hasta el Mioceno Inferior sobre la base del uso de trazas de fisión en apatito de intrusivos emplazados y deformados en la traza de la zona de falla, de las cuales obtuvo edades de 23 y $32 \mathrm{Ma}$ en las cercanías del río Rocín. Lo anterior le indica que, producto de la inversión de la cuenca extensional de Abanico, el sistema de fallas se habría invertido y habría reactivado fallas de alto ángulo con movimientos inversos de vergencia al oeste y de rumbo dextral (Campbell, 2005).

En el límite norte de la región de este estudio $\left(32^{\circ} \mathrm{S}\right)$, dataciones geocronológicas recientes (Mpodozis et al., 2009) permitieron reconocer la existencia de unidades del Cretácico Superior y el Mioceno (Fig. 3). A esta latitud, la Falla Pocuro corta unidades cretácicas. Al este de esta falla, Mpodozis et al. (2009) presentan 4 unidades cenozoicas (Fig. 3) que nombran: Secuencia del Río Chicharra (24,9-22,2 Ma), Formación Pachón (22,1-21,6 Ma), Formación Pelambres (33,4-25,2 Ma) y Complejo Volcánico Laguna del Pelado (18,4-18,3 Ma). Estos autores describen el estilo de deformación de cada una de estas unidades y señalan que se encuentran formando dominios estructurales limitados por fallas regionales, de los cuales los más orientales concentran una intensa deformación en las rocas de edad oligocena-miocena. La Secuencia del Río Chicharra corresponde a una serie de lavas andesíticas que recubre una secuencia de volcanitas y sedimentitas continentales del Cretácico Superior (Mpodozis et al., 2009). Las secuencias del Cretácico Superior y la Secuencia del Río Chicharra forman el dominio occidental de Mpodozis et al. (2009), que describen con un estilo estructural típico de la cordillera de la Costa, con suave deformación y formado por secuencias poco inclinadas $\left(<25^{\circ}\right)$, exceptuando algunos niveles del Cretácico Superior. Hacia el este de la anterior, Mpodozis et al. (2009) señalan que las rocas volcánicas y sedimentarias de la Formación Pelambres (Fig. 3) se encuentran intensamente deformadas con sectores con características propias de una zona afectada por deformación dúctil de relativamente elevada temperatura. Indican además, que hacia el este, el dominio oriental (cordillera Frontal) se caracteriza por una deformación de piel gruesa con grandes bloques de basamento con su cobertura solidaria. En este dominio afloran los conglomerados continentales lavas andesíticas y andesítico-basálticas y tobas de la Formación Pachón, la que se encuentra cubierta, en discordancia, por lavas andesíticas y dacíticas del Complejo Volcánico Laguna del Pelado (Mpodozis et al., 2009). La Formación Pachón, en el sector occidental de este dominio, se encuentra involucrada en un angosta faja plegada y corrida de piel delgada (Mpodozis et al., 2009).

Además, la región ha sido afectada por cuerpos intrusivos 'alineados' en franjas separadas según su edad. En el sector occidental, aflora la franja de intrusivos cretácicos, donde se encuentran dioritas, granodioritas, tonalitas y subordinadas monzodioritas de la unidad Fredes (Rivano et al., 1993; Rivano, 1996), del Paleoceno-Eoceno, que forma stocks de 20 a $100 \mathrm{~km}^{2}$ al oeste de la zona de Falla Pocuro (Rivano, 1996). Hacia el este, los intrusivos de la franja neógena se ubican exclusivamente al este de la Falla Pocuro y solo algunos pequeños cuerpos cuarzo-feldespáticos se ubican en la traza de la zona de falla, y otros alineados más al oriente dentro de la región entre $32^{\circ}$ y $33^{\circ} \mathrm{S}$ (Rivano, 1996). En esta franja, los pórfidos dacíticos miocenos de la unidad Tambillos (Rivano et al., 1993; Rivano, 1996) forman cuerpos plutónicos de gran extensión areal al 
norte del río Alicahue y hacia el sur en las cercanías del río Aconcagua. Las monzodioritas, monzonitas, dioritas y subordinados monzogranitos de la unidad Río Cerro Blanco (Rivano et al., 1993; Rivano, 1996) se presentan intruyendo a la Formación Farellones al oriente de las unidades intrusivas de las franjas descritas.

\section{Geología Local}

La región de estudio se ha subdividido en 2 sectores (Fig. 4), según el grado de deformación y el tipo de unidades litoestratigráficas reconocidas en la región: 1. Sector Occidental, cercano a la zona de Falla Pocuro por el oeste y a la laguna de Chepical por el este y 2. Sector Oriental, al este de la anterior y extendido hasta el límite fronterizo Chile-Argentina.

\subsection{Sector Occidental (sector de la zona de Falla Pocuro)}

La zona oeste de este sector, a la latitud del valle del río Sobrante y cerca de $10 \mathrm{~km}$ al oeste de la zona de Falla Pocuro (Fig. 4), se caracteriza por presentar una secuencia de brechas, lavas brechosas y tobas líticas del Cretácico Superior (edad U-Pb en circón en este trabajo) con un espesor estimado de $1.300 \mathrm{~m}$ (Figs. 5 y 6). Sobreyacen discordantemente (Fig. 5A) a esta secuencia, alrededor de $800 \mathrm{~m}$ de lavas andesíticas que fueron inicialmente atribuidas (Rivano et al., 1993) a la Formación Salamanca del Cretácico Superior, pero que sobre la base de los nuevos resultados de este estudio resultan ser más jóvenes que $81 \mathrm{Ma}$ (Fig. 7).

En el valle del río Alicahue ( $\sim 10 \mathrm{~km}$ al sur del valle del río Sobrante), la sucesión (Fig. 6) se compone esencialmente de lavas andesíticas porfíricas e intercalaciones de niveles volcanoclásticos y escasos niveles clásticos y tobáceos. Se estima aquí un espesor de $2.000 \mathrm{~m}$. En este mismo valle, al este de la zona de Falla Pocuro, las rocas que afloran en la parte baja del valle, a una altura entre 1.700 a 2.000 m s.n.m., corresponden a brechas, lavas y tobas. Sobre esta cota, la sucesión consta esencialmente de lavas. La ladera sur del valle del río Alicahue se encuentra conformada de una secuencia de $\sim 800 \mathrm{~m}$ a $1 \mathrm{~km}$ (Fig. 6) de lavas afaníticas y lavas porfíricas andesí-

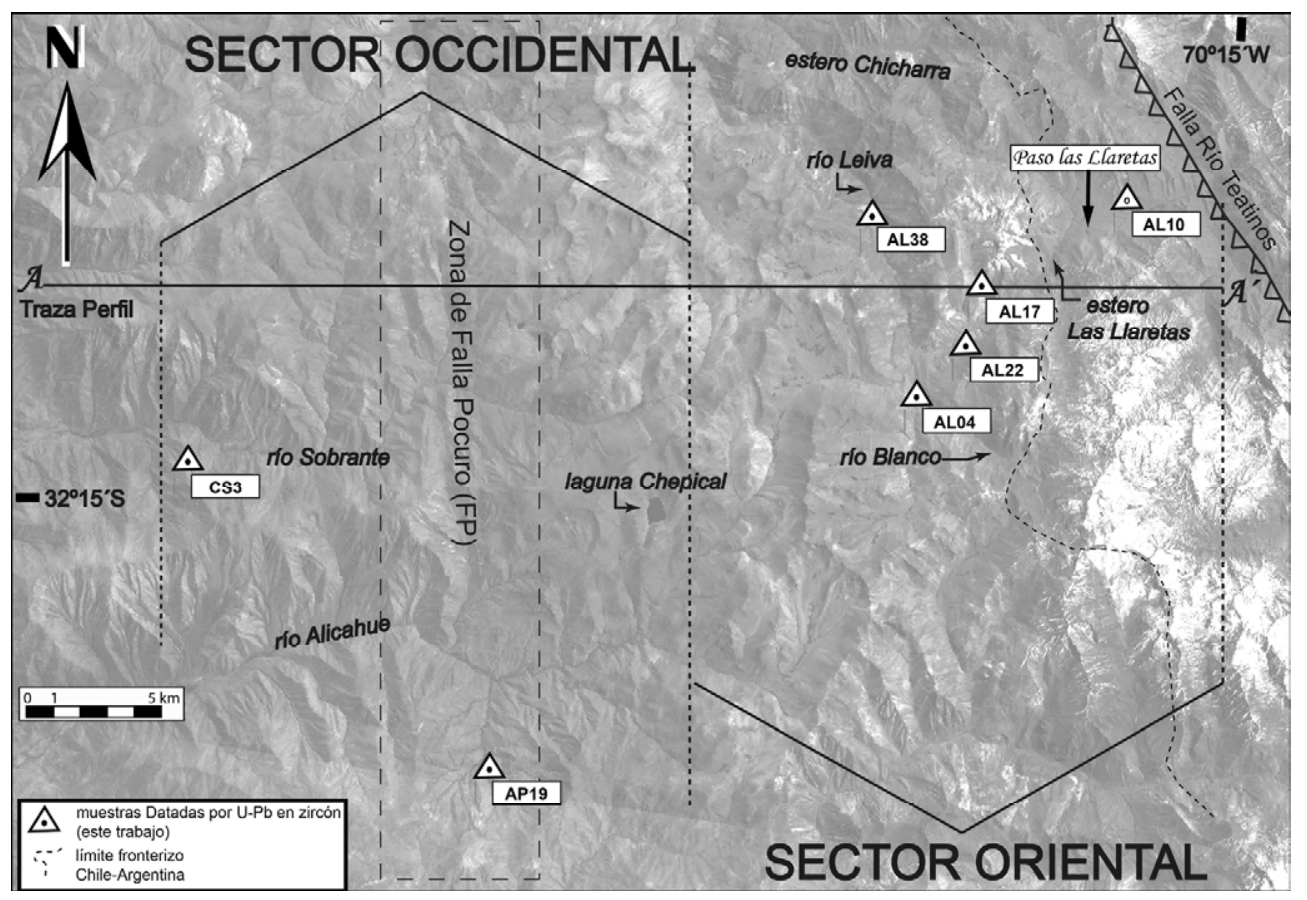

FIG. 4. Región de estudio y límites de sectores definidos para este trabajo. Se indica, además, la ubicación y códigos de las muestras datadas mediante U-Pb en circón y traza de perfil integrado A-A' de figura 11. 


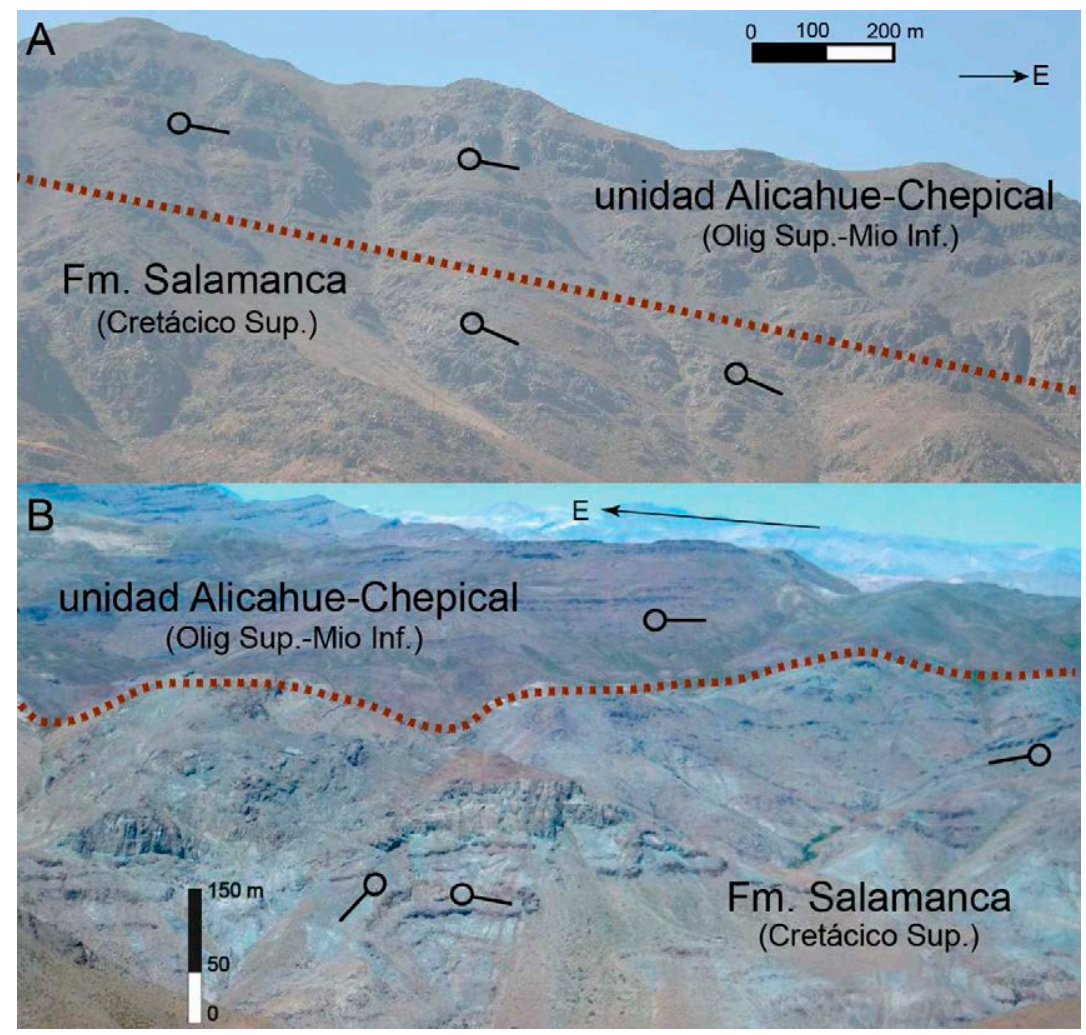

FIG. 5. A. Vista al norte hacia discordancia angular observada en sector del río Sobrante, $\sim 5 \mathrm{~km}$ al oeste de la zona de Falla Pocuro. Los niveles inferiores fueron datados en $81,5 \mathrm{Ma}$, y los superiores han sido incluidos en la unidad de predominio lávico (AlicahueChepical) del Oligoceno Superior-Mioceno Inferior. B. Vista al sur hacia discordancia angular observada en sector del río Alicahue, $\sim 5 \mathrm{~km}$ al este de la zona de Falla Pocuro. Los niveles inferiores fueron datados en 87,7 Ma, y los superiores han sido incluidos en la unidad de predominio lávico (Alicahue-Chepical) del Oligoceno Superior-Mioceno Inferior.

ticas, con intercalaciones de niveles volcanoclásticos de $\sim 1,5 \mathrm{~m}$ de espesor en la parte media de la secuencia. La parte inferior de esta secuencia corresponde a niveles del Cretácico Superior (Fig. 7), sobre la base de una nueva datación U-Pb en circón de 87,7 Ma (este trabajo), mientras que los niveles esencialmente volcánicos de la parte superior corresponden al Oligoceno Superior-Mioceno Inferior (Fig. 5B).

\subsection{Sector Oriental}

El Sector Oriental se caracteriza por la presencia de rocas volcánicas a volcanoclásticas y detríticas (Figs. 6 y 7), que sobre la base de los antecedentes expuestos y nuevas dataciones U-Pb en circón (Apéndice I), se han incluido en tres unidades del Oligoceno superior al Mioceno Inferior de las formaciones Abanico y Farellones.
El estudio de estos niveles, hasta el sector fronterizo (al oeste de la Falla Río Teatinos, Figs. 4 y 6), permitió agruparlas, sobre la base de sus características litológicas, su continuidad areal, deformación y relaciones de contacto, en tres unidades que representan asociaciones de facies relacionadas con el volcanismo Oligoceno a Mioceno. Estas unidades alcanzan, además, las partes altas del Sector Occidental, por ejemplo en la región de la laguna Chepical y las cimas de los cerros en el río Sobrante (Figs. 4, 6 y 7) y fueron denominadas según la localidad en donde es más representativo su predominio litológico: 1. Alicahue-Chepical (predominio lávico), 2. Las Llaretas (predominio volcanoclástico), y 3. Estratos del Pañuelo (predominio detrítico). Es necesario destacar que todas ellas contienen, en mayor o menor cantidad, intercalaciones de los tres tipos litológicos que las caracterizan (Fig. 6). 


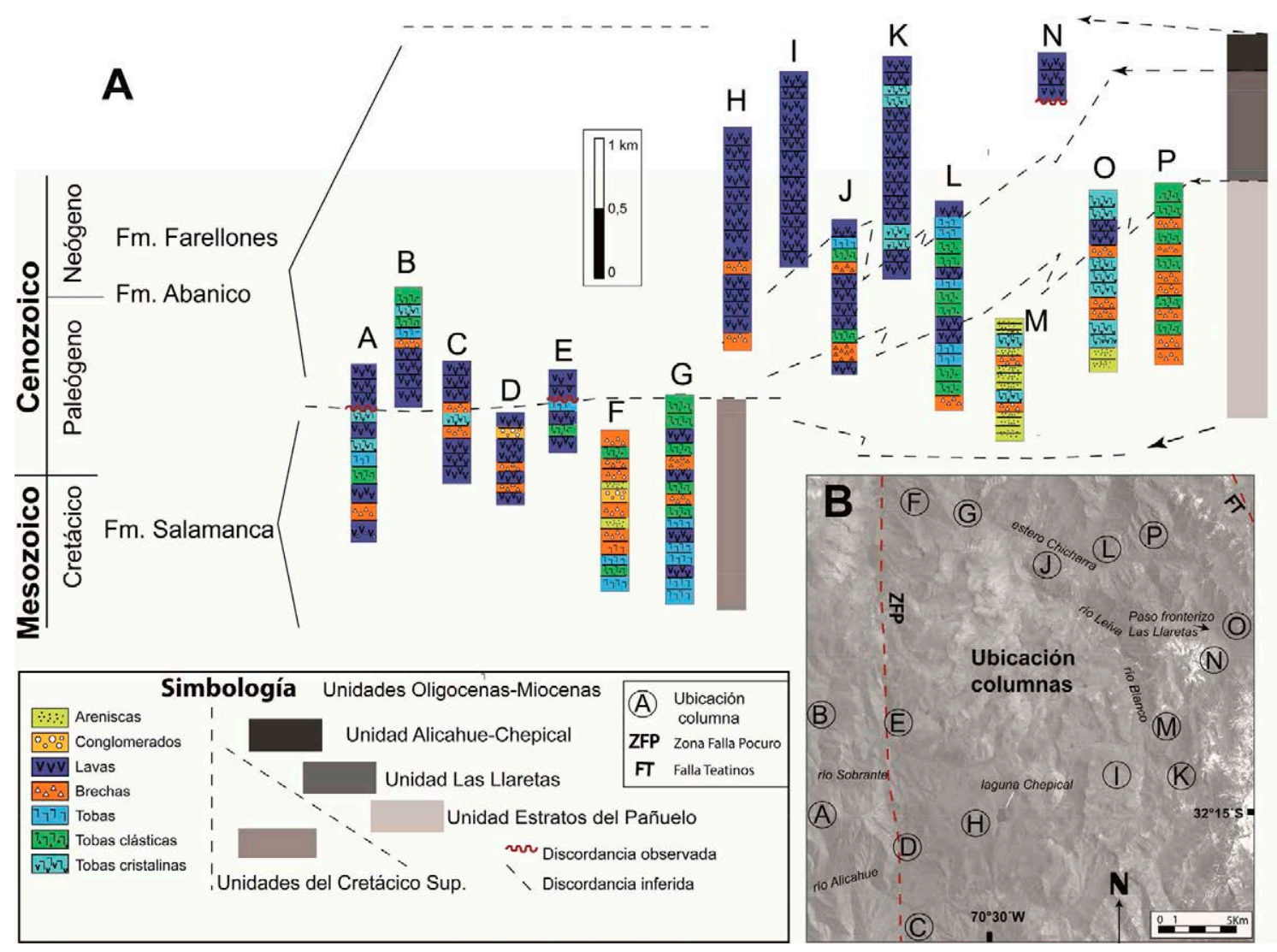

FIG. 6. A. Columnas estratigráficas representativas de las distintas unidades litológicas presentes en la región de estudio. B. Ubicación de columnas A-P.

\subsubsection{Unidad 'Alicahue-Chepical'}

Esta unidad ocupa la región occidental de la zona estudiada (Fig. 7), al este de la zona de Falla Pocuro, y se extiende hacia el oriente por unos 15 $\mathrm{km}$ hasta las inmediaciones del valle del río Leiva (Figs. 4 y 7). Corresponde a una asociación de facies esencialmente volcánica, compuesta en su mayoría de lavas andesíticas porfíricas con intercalaciones volcanoclásticas y escasos niveles de conglomerados y brechas. Se estima un espesor total máximo de $2.000 \mathrm{~m}$ a $2.500 \mathrm{~m}$. Esta unidad corresponde a la sucesión más occidental de las unidades oligocenasmiocenas reconocidas y, en la cercanía de la zona de Falla Pocuro, se dispone discordantemente sobre las rocas volcano-sedimentarias del Cretácico Superior, datadas en 74,7 y 71,4 Ma (Mpodozis et al., 2009) y en $81,5 \pm 1,4$ y $87,7 \pm 0,3 \mathrm{Ma}$ (Fig. 7 y Apéndice I). A su vez, se dispone en contacto discordante, pseudoconcordante o por falla con las unidades más orientales aquí definidas. Las rocas estratigráficamente inferiores de esta sucesión fueron inicialmente atribuidas a las formaciones Los Pelambres y Salamanca (Rivano et al., 1993) y las superiores a la Formación Farellones, separadas entre sí por discordancias angulares. En este estudio, se reconoce que toda la sucesión es del Oligoceno Superior a Mioceno.

\subsubsection{Unidad 'Las Llaretas'}

Esta unidad se encuentra en el sector más oriental, entre el valle del río Leiva y el límite fronterizo (Figs. 4 y 7) y corresponde a una asociación de facies de predominio volcanoclástico, que constituye una sucesión de $600 \mathrm{~m}$ a $1 \mathrm{~km}$ de espesor de tobas, lavas (andesíticas porfíricas y escasas intercalaciones andesítico-basálticas) y escasos niveles de brechas (Fig. 6). Se dispone en pseudoconcordancia bajo la unidad Alicahue-Chepical; sin embargo, la intensa deformación que presenta localmente dificulta, en 


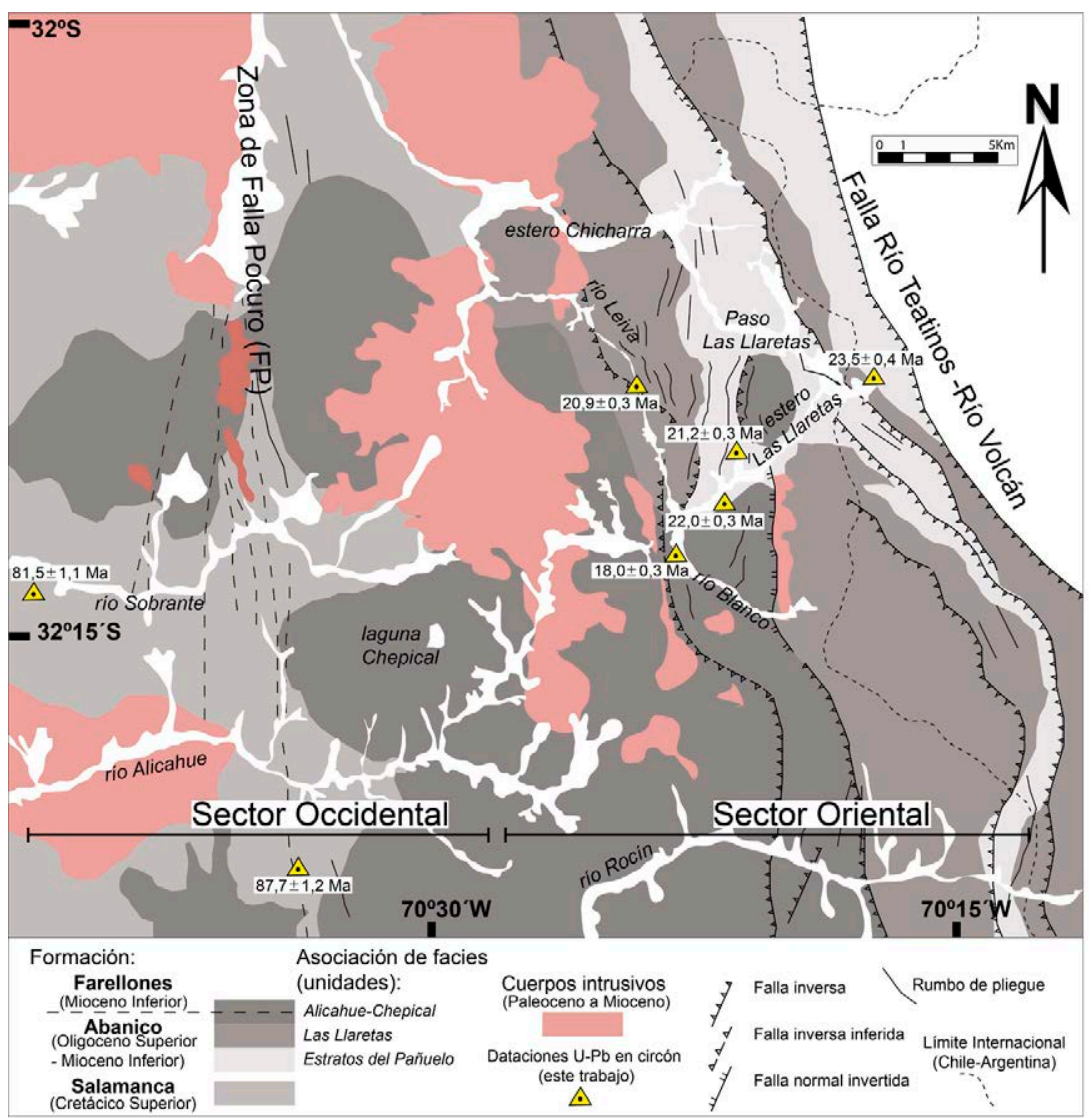

FIG. 7. Distribución de las unidades litológicas reconocidas y ubicación de las muestras datadas en la región de estudio. El rango de edad indicado para las formaciones se basa en las dataciones geocronológicas obtenidas para esta región.

el sector donde ambas unidades se encuentran en contacto, la observación de posibles contactos por falla o discordantes.

\subsubsection{Unidad 'Estratos del Pañuelo'}

Esta unidad se reconoce, al igual que la anterior, en el sector oriental de la zona descrita (Fig. 7). Corresponde a una asociación de facies con predominio detrítico que conforma una secuencia volcano-sedimentaria de un espesor estimado de $\sim 1.000$ a $1.500 \mathrm{~m}$. Se compone esencialmente de areniscas y brechas con intercalaciones de tobas y brechas piroclásticas (Fig. 6). En esta unidad se reconocieron estructuras sin sedimentarias como diques clásticos y 'slumps', además de estratos de crecimiento con relación a 'onlap' (Fig. 8). En algunos sectores se la observa cubierta en discordancia angular por las unidades anteriores (Figs. 7 y 8) y, en otros, se presenta en contacto por falla.

\section{Nuevos antecedentes geocronológicos}

\subsection{Metodología}

En este estudio, 8 muestras fueron datadas mediante U-Pb en circón. 7 de ellas fueron realizadas por medio LA-ICP-MS (laser ablation-inductively coupled plasma-mass spectrometry) en el Department of Geology, Washington State University, Pullman, EE.UU. Para las muestras datadas mediante este método, los minerales pesados fueron separados magnéticamente de la fracción $<350$ micras. Los circones de la fracción no magnética se montaron en epoxi y fueron ligeramente esmerilados y pulidos para exponer la superficie y mantener tanto material como sea posible para los análisis de ablación con láser. Previo al análisis de ablación con láser ICP-MS, se realizaron imágenes de catodoluminiscencia, con el fin de estudiar los circones y determinar su com- 

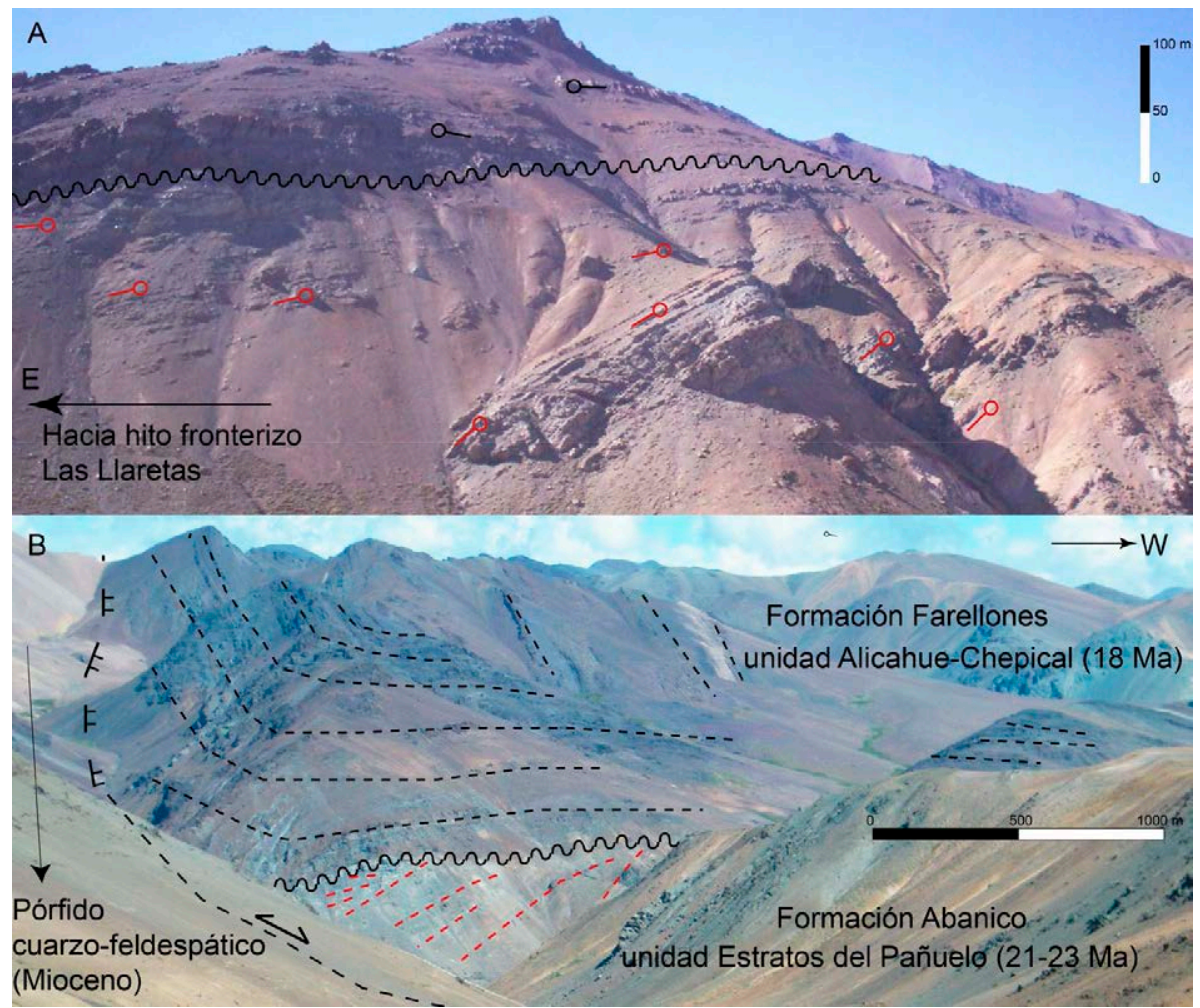

FIG. 8. A. Vista al SSE que muestra la relación de contacto discordante entre la unidad Estratos del Pañuelo (abajo) y la unidad Alicahue-Chepical (arriba). Nótese el cambio de manteo hacia el este de la unidad Estratos del Pañuelo, generando estratos de crecimiento y una relación de 'onlap' en el sector oriental. B. Vista general de la estructura: fallas que limitan por el oriente a las mencionadas en A. Lavas de la unidad Alicahue-Chepical forman hacia el sur un pliegue sinclinal con eje buzante al sur. Ver también mapa de figura 7.

plejidad. La ablación se realizó mediante un láser 'New Wave Nd:YAG UV 213 nm' acoplado a un elemento ThermoFinnigan de 2 colectores, doble enfoque y sector magnético ICP-MS (V. Valencia, comunicación personal, 2011). Los procedimientos de operación y los parámetros son una modificación de Chang et al. (2006). El tamaño láser y la tasa de repetición fueron $30 \mathrm{~nm}$ y $10 \mathrm{~Hz}$, respectivamente. Cada análisis consistió en un análisis de blanco corto seguido de 250 barridos a través de masas 204, 206, $207,208,232,235$ y 238 , que tarda aproximadamente 30 segundos. El fraccionamiento independiente del tiempo se corrigió mediante la normalización de las razones $\mathrm{U}-\mathrm{Pb}$ y $\mathrm{Pb} / \mathrm{Pb}$ de las incógnitas a los estándar para circón (Chang et al., 2006). Para este estudio se utilizaron dos estándar de circón: Peixe, con una edad de $564 \mathrm{Ma}$ (Dickinson y Gehrels, 2003) y el FC-1, con una edad de $1.099 \mathrm{Ma}$ (Paces y Miller, 1993). Las edades U-Pb se calcularon utilizando el programa Isoplot (Ludwig, 2003). Los resultados analíticos se adjuntan en el Apéndice I.

Una octava muestra fue datada mediante $\mathrm{U}-\mathrm{Pb}$ en circón por medio de SHRIMP (Sensitive High Resolution Ion MicroProbe), en la Research School of Earth Sciences de la Australian National University en Canberra. Las técnicas de medición son similares a las descritas por Williams (1998), y las referencias en él. Imágenes de catodoluminiscencia se obtuvieron de los circones seccionados y se utilizan para apuntar a áreas específicas de análisis. Los datos fueron procesados con el SQUID Excel macro y los cálculos de edad mediante ISOPLOT (Ludwig, 2003).

\subsection{Resultados}

La tabla 1 resume la información de las muestras y las edades obtenidas. La descripción de las muestras utilizadas, los resultados analíticos de estas dataciones 
(Apéndice tablas 1 y 2) y los gráficos de concordia y distribución de edades de las muestras datadas (Figs. 1-3 apéndice) pueden observarse en el Apéndice I.

\section{Caracterización estructural de la zona de estudio}

\subsection{Sector Occidental (Zona de Falla Pocuro)}

Este sector se caracteriza, en general, por una deformación leve (capas subhorizontales o inclinadas menos de $10^{\circ}$ ) de los niveles superiores (oligocenosmiocenos) y por la presencia de rocas cretácicas deformadas en la parte baja de los valles, que subyacen discordantemente a las unidades más jóvenes.

A la latitud del valle del río Sobrante (Fig. 4), las rocas cretácicas $(81,5 \pm 1,4 \mathrm{Ma})$ presentan un manteo general de $20^{\circ} \mathrm{E}$ a $25^{\circ} \mathrm{E}$ al oeste de la zona de Falla Pocuro. Una estructura anticlinal en rocas de edad cretácica $(87,7 \pm 0,3 \mathrm{Ma})$ se presenta bien desarrollada al norte del río Sobrante al este de la zona de Falla Pocuro (Fig. 7) mientras que hacia el sur (río Alicahue), solo se observan los flancos erosionados de esta estructura.

Las lavas de la unidad Alicahue-Chepical sobreyacen discordantemente a las rocas cretácicas con manteos entre $5^{\circ} \mathrm{E}$ a $10^{\circ} \mathrm{E}$ (Fig. 5). Esta relación discordante se observa a ambos lados de la zona de Falla Pocuro en esta latitud.

En el valle del río Alicahue (Fig. 4), al oeste de la zona de Falla Pocuro, las rocas se encuentran muy afectadas por la intrusión de abundantes diques y filones que dificultan el reconocimiento de la estratificación, por lo que no fue posible observar la discordancia angular reconocida en el río inmediatamente al norte (Fig. 5A) y al este de la zona de falla en la latitud del río Alicahue (Fig. 5B).

En este mismo valle, inmediatamente al este de la zona de Falla Pocuro, las rocas que afloran en la ladera norte forman pliegues suaves y presentan manteos de $10^{\circ}$ a $30^{\circ}$. La ladera sur del río Alicahue se encuentra conformada por una sucesión de lavas del Cretácico Superior con un manteo general de $\sim 10^{\circ} \mathrm{W}$ y parecen formar el flanco oeste del anticlinal de rumbo $\sim \mathrm{NS}$ observado en el río Sobrante.

\subsection{Sector Oriental}

Las rocas oligocenas a miocenas expuestas en la región inmediatamente al este de la zona de Falla Pocuro, hasta el límite internacional Chile-Argentina, se caracterizan en general por una intensidad de la deformación (plegamiento y fallamiento) creciente hacia el oriente.

Las secuencias de facies de predominio lávico (unidad Alicahue-Chepical, Fig. 6) presentan una deformación suave con leves cambios de manteos $\left(5^{\circ}\right.$ a $\left.10^{\circ}\right)$, en las cercanías de la laguna Chepical, por unos $15 \mathrm{~km}$ hasta las inmediaciones del valle del río Leiva (Figs. 4 y 7), aunque en algunos sectores se observan discordancias locales entre las zonas bajas y las altas. Hacia el este (ver también perfiles en Jara y Charrier, 2011), la deformación es intensa (Figs. 8 y 9), y las rocas de $18 \mathrm{Ma}$ (este trabajo) de esta unidad se encuentran involucradas en una serie de fallas y pliegues de vergencia oriental, con disposiciones de hasta $70^{\circ} \mathrm{W}$ en el sector del río Blanco (Fig. 7).

TABLA 1. UBICACIÓN GEOGRÁFICA Y ESTRATIGRÁFICA, Y EDADES OBTENIDAS EN LAS 8 MUESTRAS DATADAS MEDIANTE U-PB EN CRISTALES DE CIRCÓN (VER FIG. 4).

\begin{tabular}{lllllll}
\hline Muestra & *Coord E-W & $\begin{array}{c}\text { Altura } \\
\text { (m s.n.m.) }\end{array}$ & $\begin{array}{c}\text { Edad U/Pb } \\
\text { en } \mathbf{~ Z r}\end{array}$ & $\begin{array}{c}\text { Tipo de } \\
\text { roca }\end{array}$ & \multicolumn{1}{c}{ Unidad } & Formación \\
\hline AL-4 & $369.089-6.434 .708$ & $3.015 \pm 7$ & $18,0 \pm 0,3$ & toba & Alicahue-Chepical & Farellones \\
AL-38 & $367.369-6.441 .672$ & $2.737 \pm 8$ & $20,9 \pm 0,3$ & toba & Las Llaretas & Abanico \\
AL-17 & $371.552-6.438 .968$ & $3.240 \pm 10$ & $21,2 \pm 0,3$ & toba & Estratos del Pañuelo & Abanico \\
AL-22 & $370.956-6.436 .656$ & $3.072 \pm 10$ & $22,0 \pm 0,3$ & arenisca & Estratos del Pañuelo & Abanico \\
AL-10 & $377.166-6.442 .294$ & $3.471 \pm 9$ & $23,5 \pm 0,4$ & toba & Estratos del Pañuelo & Abanico \\
CS-3 & $340.953-6.432 .237$ & $1.863 \pm 6$ & $81,5 \pm 1,1$ & toba & Cretácico Superior & Salamanca \\
AP-19 & $352.551-6.420 .380$ & $1.986 \pm 5$ & $87,7 \pm 1,2$ & lava & Cretácico Superior & Salamanca \\
RR-01 & $362.189-6.399 .909$ & $2.265 \pm 10$ & $26,5 \pm 2,3$ & lava & Alicahue-Chepical & Abanico \\
\hline
\end{tabular}

* Coordenadas en proyección UTM y datum Psad'56. 
En el sector del río Leiva (Fig. 4), las rocas volcanoclásticas de la unidad Las Llaretas se encuentran intensamente deformadas en pliegues volcados e incluso recumbentes. Hacia el este, en una franja de $\sim 4$ a $5 \mathrm{~km}$ de ancho, caracterizada por pliegues con rumbo cercano a NS a NNE (Fig. 7), se observan pliegues de longitudes de onda de $\sim 1 \mathrm{~km}$ a lo largo del río Chicharra y del estero Las Llaretas (Figs. 4 y 9), localizadas en zonas de no más de $15 \mathrm{~km}$ de largo. Se presenta también, sobrepuesta, en un ancho de $\sim 20 \mathrm{~km}$ hasta el límite fronterizo con Argentina, una estructuración de gran persistencia en el rumbo (longitudes de al menos $30 \mathrm{~km}$ ), con una orientación esencialmente NNW; ambos sets de estructuras (NNW y NS) afectan a rocas de las asociaciones de facies de predominio volcanoclástico (unidad Las Llaretas) y de predominio detrítico (unidad Estratos del Pañuelo).

La unidad Estratos del Pañuelo se encuentra intensamente plegada y fallada, lo que en algunos sectores ha causado la repetición de la secuencia, alcanzando espesores aparentes máximos de hasta $\sim 3.000 \mathrm{~m}$. Destaca la presencia de un pliegue anticlinal chevron buzante al sur (Fig. 9b) que, hacia el sur del estero Las Llaretas, presenta en su flanco oriental estratos de crecimiento, con capas inferiores

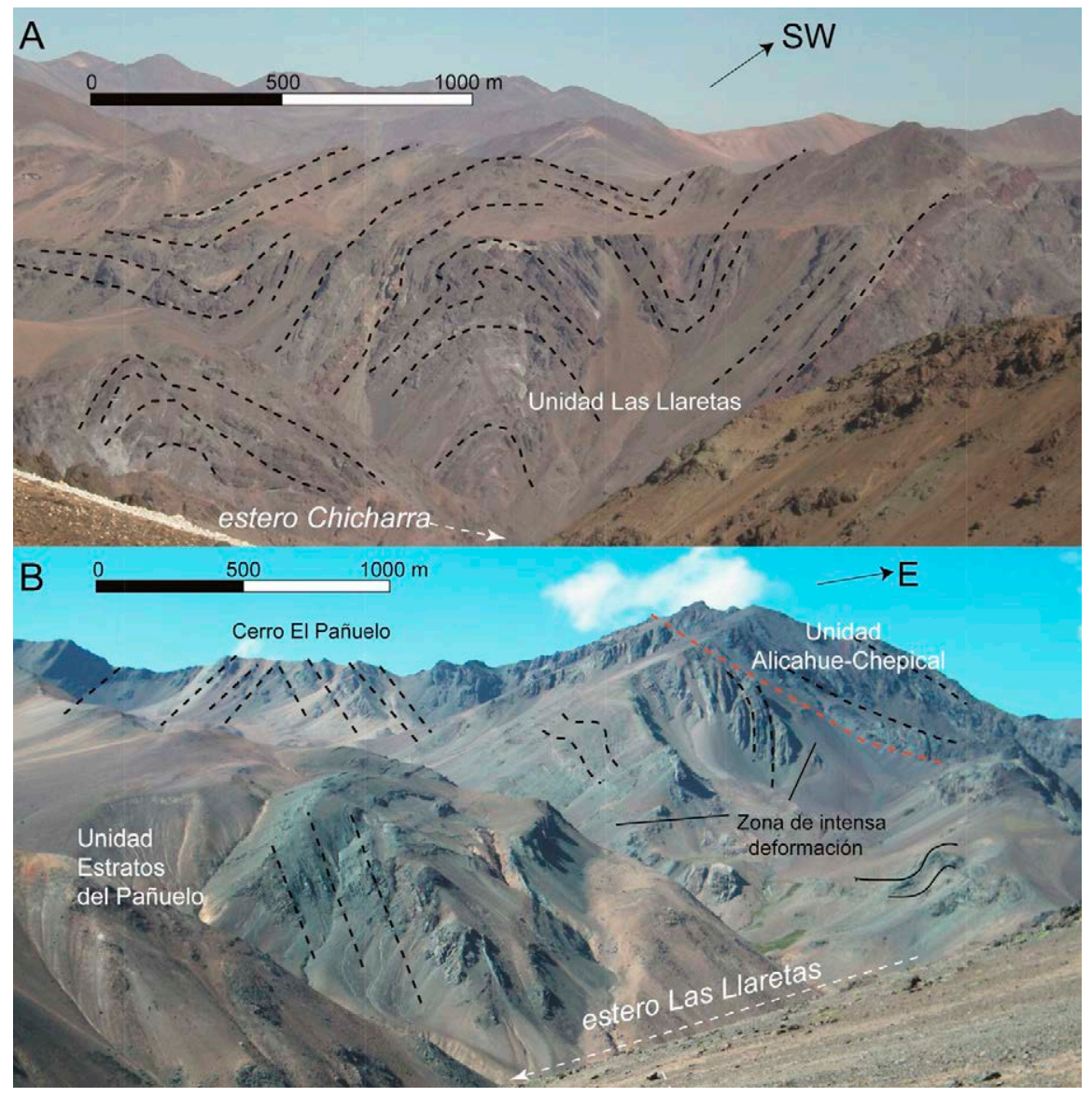

FIG. 9. Vistas de las estructuras que caracterizan la zona de intensa deformación con rumbos NS a NNE. En ambos casos, la amplitud del plegamiento es cercana a $1 \mathrm{~km}$ y se produce en rocas volcanoclásticas con intercalaciones de tobas. A. Vista al sur de pliegues anticlinal y sinclinal en ladera sur del valle superior del estero Chicharra, en rocas asignadas a las unidades distales. B. Vista al NNE hacia pliegue anticlinal en el cerro el Pañuelo, ladera norte al estero Las Llaretas. Nótese, al este de la estructura anticlinal, línea punteada roja que indica contacto discordante y por falla (ver mapa de figura 7) entre unidad Estratos del Pañuelo, a la izquierda (formando anticlinal chevron), y la unidad Alicahue-Chepical suprayacente, a la derecha (flanco occidental de suave sinclinal con mejor desarrollo hacia el oriente). 
de manteo creciente al poniente y relación de 'onlap' de los niveles superiores (Fig. 8). Se ha interpretado la traza de la falla que la bordea por el oriente sobre la base del límite de rumbo NS entre estas y un cuerpo intrusivo cuarzo feldespático del Mioceno inferior (Rivano et al., 1993). Rocas de 18 Ma de la unidad Alicahue-Chepical sobreyacen discordantemente en este sector a la unidad Estratos del Pañuelo y forman un pliegue sinclinal con un flanco oriental con manteos de $50^{\circ}$ a $70^{\circ} \mathrm{W}$ (Fig. 8).

$\mathrm{Al}$ este del paso fronterizo Las Llaretas (Fig. 4), en territorio argentino, una nueva datación $\mathrm{U}-\mathrm{Pb}$ en circón de 23,5 Ma confirma la edad oligocena superior de los niveles involucrados en la deformación de rumbo esencialmente NNW. Esta estructuración es principalmente de vergencia oriental, con manteos de $30^{\circ}$ a $60^{\circ} \mathrm{W}$. Cristallini (1996b) describe los pliegues de la región como cortos y con longitudes de onda en general menores a un kilómetro, lo cual es consistente con un nivel de despegue somero y con un mecanismo de propagación de falla para explicar su desarrollo (Cristallini, 1996b). Más allá del límite fronterizo (Figs. 2 y 7), la traza de la Falla del Río Teatinos-Río Volcán (Cristallini y Cangini,
1993; Cristallini et al., 1995), con manteo de $30^{\circ} \mathrm{W}$ (Mosquera y Zapata, 1991), fue descrita como un gran corrimiento fuera de secuencia con vergencia oriental de la faja plegada y corrida de La Ramada.

\section{Implicancias y correlaciones regionales}

Las nuevas dataciones y las relaciones de contacto observadas en el sector occidental de este estudio, evidencian que las rocas del Cretácico Superior, que afloran a ambos lados de la zona de Falla Pocuro, subyacen a rocas asignadas a las formaciones oligocenas a miocenas Abanico y Farellones.

Las rocas miocenas sobreyacentes a la secuencia cretácica deformada presentan manteos suaves a ambos lados de la Falla Pocuro, que indican que, si bien ha habido actividad posterior al Mioceno Inferior, la mayor parte de la deformación (plegamiento y alzamiento de rocas cretácicas) se habría generado entre el Cretácico Superior y el Paleógeno (Fig. 10).

Las rocas levemente deformadas del Eoceno Superior-Mioceno Inferior del sector occidental forman una secuencia monótona de, esencialmente, lavas andesíticas y escasas brechas volcanoclásticas.
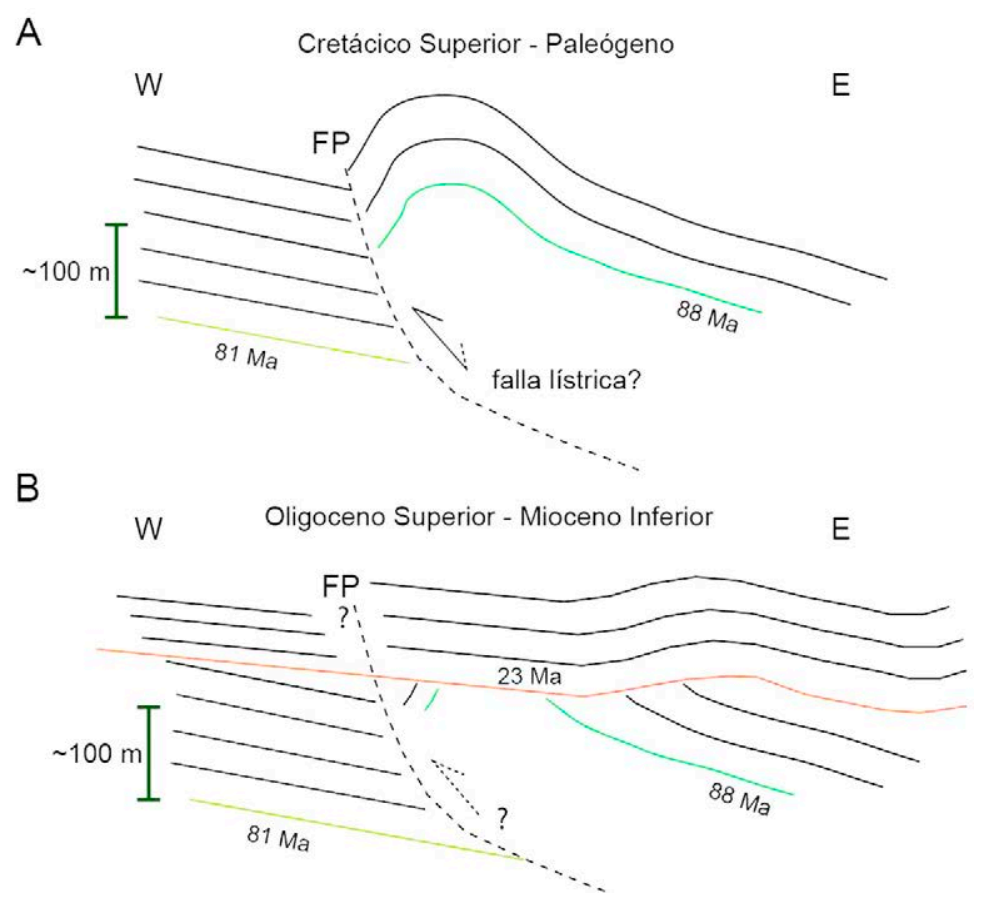

FIG. 10. Esquema de interpretación de la actividad principal de la Falla Pocuro (FP), entre el Cretácico Superior y el Paleógeno (A) y entre el Oligoceno Superior y el Mioceno Inferior (B). Se indican nuevas dataciones U-Pb en circón de este trabajo. 
Esta monotonía dificulta la distinción entre las dos formaciones cenozoicas ampliamente reconocidas al sur de $33^{\circ} \mathrm{S}$ : Abanico del Eoceno Medio a Mioceno Inferior, y Farellones del Mioceno (mayores antecedentes en Charrier et al., 2007).

A la latitud del río Alicahue, la presencia de grandes cuerpos intrusivos miocenos, junto a la monotonía de la secuencia de lavas con leve deformación, y la falta de otros estudios petrológicos detallados, no permiten realizar con certeza tal subdivisión. Sin embargo, hacia el sur, en el río Rocín, la nueva datación de 26,5 Ma en una zona donde se han reconocido discordancias progresivas (Campbell, 2005) atribuidas inicialmente al Cretácico y discordantes bajo la secuencia de lavas de la Formación Farellones (Rivano et al., 1993), permite también realizar esta subdivisión. De esta manera, la Formación Abanico corresponde a las unidades del Oligoceno Superior al Mioceno Inferior de más de $18 \mathrm{Ma}$, debido a que hacia el oriente estas se encuentran subyaciendo en contacto discordante a lavas de $18 \mathrm{Ma}$ (y más jóvenes) que han sido descritas como Formación Farellones (Rivano et al., 1993). La asociación de facies lávicas (unidad Alicahue-Chepical) pertenece en su parte inferior a la Formación Abanico y en su parte superior a la Formación Farellones, mientras que las asociaciones de facies de predominio volcanoclástico y detrítico (unidades Las Llaretas y Estratos del Pañuelo) pertenecen íntegramente a la Formación Abanico (Figs. 6 y 7).

En el Sector Oriental definido en este estudio no se observaron niveles cretácicos (Figs. 7 y 11). Las rocas más antiguas datadas tienen 23,5 Ma (Estratos del Pañuelo) y corresponden a los niveles más detríticos y orientales de la región de estudio.

Sobre la base de la litología que caracteriza a las unidades oligocenas-miocenas descritas (Fig. 6) y la distribución areal de estas, consideramos que las asociaciones de facies reconocidas representarían facies cercanas (proximales) o alejadas (distales), a los centros emisores del volcanismo oligocenomioceno en esta latitud; es decir, proximales o distales al arco volcánico ubicado en el sector occidental de la cordillera Principal en territorio chileno. En este sentido, la unidad Alicahue-Chepical representa las facies proximales, y las unidades Las Llaretas y Estratos del Pañuelo con mayor contenido volcanoclástico y sedimentario (Fig. 6), podrían corresponder a facies distales de la anterior debido al ambiente volcánico continental de amplia extensión que puede ser inferido de la estratigrafía observada (Fig. 12). Las características litológicas junto a las relaciones estratigráficas y de contacto y las edades presentadas en este trabajo para las unidades descritas permiten establecer una buena correlación con las unidades reconocidas por autores anteriores hacia el norte y sur de la región de estudio, sobre la base de la distribución, continuidad areal y las características estructurales y grado de deformación presentes en cada una.

La unidad Alicahue-Chepical (de predominio lávico), que corresponde a la más occidental de las unidades oligo-miocenas reconocidas, se presenta, en las cercanías de la Falla Pocuro, apoyada discordantemente sobre depósitos de edad cretácica, lo cual es congruente con lo observado por Mpodozis et al. (2009) al noroeste de la región de estudio. Esta unidad de predomino lávico presenta edades $\mathrm{K}$-Ar en roca total (Hojas Quillota y Portillo, Rivano et al., 1993) de 24,5 Ma (al poniente de laguna Chepical), mientras que hacia el oriente, en río Blanco, obtuvimos una edad U-Pb en circón de $18 \mathrm{Ma}$ (Tabla 1 y Apéndice). Entre $32^{\circ} \mathrm{S}$ y $33^{\circ} \mathrm{S}$, Rivano et al. (1993) presentan edades del Oligoceno Superior al Mioceno Medio para depósitos que están en continuidad con esta unidad volcánica, por lo que la correlación de estas con las formaciones Abanico y Farellones hacia el sur se hace más evidente.

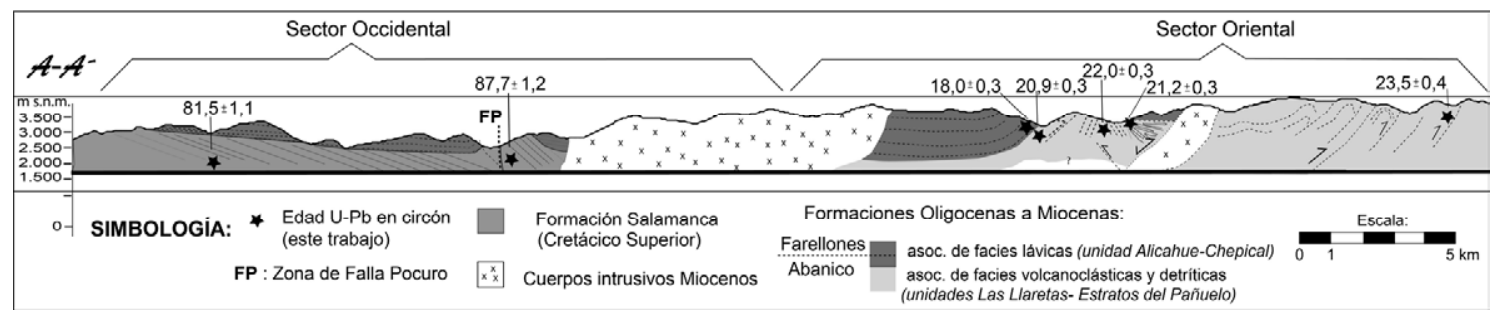

FIG. 11. Perfil esquemático integrado de unidades y estructuras observadas en la región de estudio (traza aproximada se indica en figura 4). 

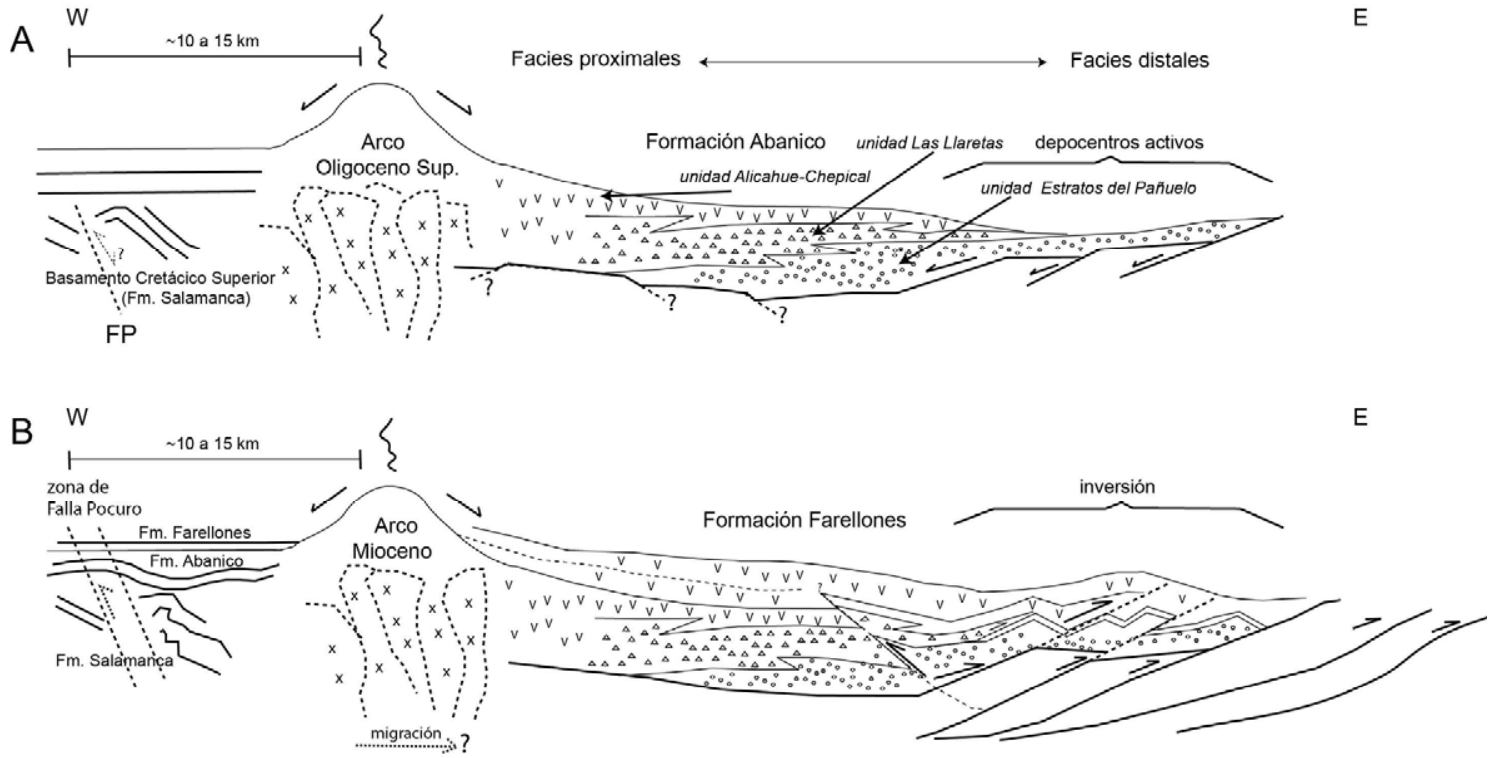

FIG. 12. Esquema paleogeográfico para la cordillera Principal de Chile central y límite occidental argentino, durante el Oligoceno Superior (A) y Mioceno (B), entre $32^{\circ} \mathrm{S}$ y $33^{\circ} \mathrm{S}$.

En el Sector Oriental de la cordillera Principal chilena, al este de los ríos Leiva y Blanco, y hasta el sector más occidental del territorio argentino (Fig. 4), se encuentran rocas cenozoicas (unidades Estratos del Pañuelo y Las Llaretas), con el mismo rango de edad (Oligoceno-Mioceno), pero caracterizadas por un mayor contenido volcanoclástico con intercalaciones tobáceas y niveles detríticos (Fig. 6), en comparación al de las gruesas secuencias volcánicas andesíticas que caracterizan el sector más occidental de la cordillera Principal a esta latitud. Las unidades distales Las Llaretas y Estratos del Pañuelo, pueden ser correlacionadas por sus características litológicas, distribución areal y por la prolongación hacia el sur de los dominios estructurales descritos por Mpodozis et al. (2009), con las formaciones Pachón ( 25-21 Ma) y Pelambres ( $\sim 33-25 \mathrm{Ma})$ que describen estos autores. Las dataciones obtenidas por estos autores muestran, sin embargo, un rango de edad mayor (al incluir las rocas más antiguas de la Formación Pelambres datadas al norte de $32^{\circ} \mathrm{S}$ ) que el obtenido y presentado aquí. Esto podría explicarse debido a que hacia el nororiente, más allá de los límites de la región estudiada en este trabajo, la deformación es de piel gruesa, por lo que fallas más profundas podrían haber alzado niveles más antiguos, que en esta región de deformación de piel fina no afloran en la superficie.
Las nuevas dataciones obtenidas para la unidad Estratos del Pañuelo (Tabla 1) muestran que los depósitos con mayor contenido detrítico y esporádicamente tobáceos se habrían acumulado entre $\sim 24$ y $21 \mathrm{Ma}$, en centros tectónicamente activos durante su depositación, ya que la relación de crecimiento observada en niveles de areniscas y brechas de esta unidad (Fig. 8), así como la observación de otras evidencias (por ejemplo presencia de diques clásticos y 'slumps'), sugieren que estos niveles no se encontraban completamente consolidados al momento de deformarse. Existe además una relación discordante entre esta unidad deformada y las lavas de la Formación Farellones de $18 \mathrm{Ma}$, las cuales, a su vez y en conjunto con las subyacientes, fueron deformadas pos-18 Ma (Fig. 8).

\section{Discusión}

Las rocas de la Formación Abanico, del Eoceno Medio-Superior hasta el Oligoceno Superior-Mioceno Inferior, reconocidas a lo largo de la cordillera Principal entre $\sim 28^{\circ}$ y $39^{\circ} \mathrm{S}$, se habrían depositado en una amplia cuenca extensional (cuenca de Abanico), posteriormente invertida en un proceso de inversión tectónica durante el Oligoceno Superior-Mioceno Inferior (Charrier et al., 2002, 2005, 2007 y referencias en ellos). 
En una región tan amplia como la que ocupa la cuenca de Abanico, se puede esperar que los efectos de un evento extensivo no sean homogéneos en toda su extensión. En efecto, en subcuencas limitadas por fallas normales podrían acumularse importantes espesores de relleno, mientras en zonas donde la extensión fue limitada se generarían depocentros menores. Lo anterior se puede dar, por ejemplo, en zonas de acomodación (rampas de relevo, fallas de transferencia) debido a que las fallas que limitan los hemigrábenes transfieren la diferencia de desplazamiento entre estos (Rosendahl, 1987). A causa de esta posible heterogeneidad latitudinal, un proceso posterior de inversión tectónica podría generar a su vez variaciones adicionales en las características estructurales y evolución tectónica de la región (Kley et al., 1999).

En la región de estudio, las rocas de la Formación Abanico en las asociaciones de facies con mayor contenido volcanoclástico (Estratos del Pañuelo y las Llaretas en figura 6) se interpretaron como facies distales, las cuales pudieron depositarse en subcuencas o depocentros, que en esta región habrían permitido la acumulación de los niveles alejados de los centros emisores. Los términos volcánicos distales que se encuentran en el Sector Oriental corresponden principalmente a los niveles tobáceos, que pudieron cubrir extensas áreas alejadas de los centros de origen, así como a los niveles volcanoclásticos más detríticos de la secuencia. La intensa deformación de las unidades Estratos del Pañuelo y las Llaretas se concentra en la zona de $\sim 4 \mathrm{~km}$ de ancho, de fallas y pliegues de rumbo esencialmente NS (Fig. 7), lo que sugiere, junto al espesor de estos depósitos en las zonas donde se observó relación de crecimiento, que esta es una dirección preferencial para la deformación en extensión (pre-21 Ma). En este sector, la unidad Alicahue-Chepical sobreyace discordantemente y por falla a la unidad Estratos del Pañuelo (Figs. 8 y 9). La falla que deforma los niveles superiores (línea punteada roja en Fig. 9B) se ha interpretado como rampa de pared colgante despegada sobre el 'synrift' de la unidad Las Llaretas, el cual se habría encontrado limitado por una falla NS posteriormente invertida (Figs. 8 y 11). Más aún, el estilo de plegamiento es congruente con el estilo de deformación que se genera por la interacción entre fallamiento extensional y subsecuente inversión tectónica, pues a pesar de que no se observaron directamente fallas normales preservadas, la zona tiene características que interpretamos como estructuras típicas de inversión, como 'synrift' deformado en estilo 'harpoon', 'backthrusting' y 'buttressing', así como rampa de pared colgante despegada sobre el 'synrift' (Coward et al., 1991) (Figs. 8 y 9).

Las evidencias locales de extensión en este estudio permiten interpretar que el desarrollo de depocentros activos sucedió solo en algunos sectores, lo que podría estar relacionado con el desarrollo de una cuenca con ancho mayor (Jara et al, 2009a, 2012) hacia el sur de $33^{\circ} \mathrm{S}$ durante el Oligoceno-Mioceno Inferior, y menor a la latitud de este estudio. Lo anterior, sumado a la intensa compresión posterior, podría explicar, en parte, algunas de las diferencias latitudinales observadas en perfiles transversales de la cordillera Principal hacia el sur de 31³0’S (Jara et al., 2009a; Godoy, 2011).

En el Sector Occidental de este estudio, donde afloran importantes espesores de material volcánico proximal a los centros emisores, se habrían generado depósitos volcanoclásticos y tobáceos que se habrían acumulado hacia el oriente (Fig. 12). Las fallas normales que limitaban los depocentros donde se acumularon los depósitos distales de la Formación Abanico tenían rumbo principal $\sim \mathrm{NS}$ y fueron activas desde antes de $21 \mathrm{Ma}$. Posteriormente fueron invertidas y se acumularon discordantemente las lavas de la Formación Farellones. Una deformación compresiva posterior a 18 Ma deformó el conjunto de rocas de las formaciones Abanico y Farellones en el sector oriental de la región estudiada.

La compleja relación de facies, así como la distribución de la deformación observada (mayor al oriente) y discordancias locales, sugiere que la deformación compresiva se habría concentrado en las rocas más incompetentes (localizadas al este de los centros volcánicos miocenos). La menor deformación que presentan los niveles volcánicos superiores (Formación Farellones) se explicaría tanto por una relación de mayor competencia (en comparación a los niveles distales clásticos de la Formación Abanico) como una probable migración del volcanismo hacia el oriente, que habría generado una cubierta volcánica pos-18 Ma no afectada por las primeras etapas de inversión (Fig. 12).

El reconocimiento de 3 facies (Figs. 6 y 12), entre las cuales las unidades de mayor contenido volcanoclástico representarían los sectores más distales en la paleogeografía del Oligoceno-Mioceno Inferior, fue observado con anterioridad por Cristallini y 
Cangini (1993) y Cristallini et al. (1994), quienes estudiaron estas secuencias en territorio argentino y propusieron un esquema de distribución de facies volcanoclásticas asociadas a un arco magmático, donde las facies volcánicas propiamente tales se encontrarían representadas por la Formación Juncal (y su equivalente volcánico la Formación Los Pelambres en Chile), las facies proximales por la Formación Cristo Redentor, y las distales por la Formación Diamante (Fig. 3), todas ellas asignadas inicialmente al Cretácico. Debido a la edad cenozoica de los niveles volcánicos descritos en este trabajo y la presencia de edades cenozoicas sobre la base de dataciones radiométricas $\mathrm{K}-\mathrm{Ar}$ en territorio argentino, en rocas inicialmente interpretadas como rejuvenecidas (Cristallini, 1996a, b), es necesario distinguir cuáles realmente corresponden al Cretácico y cuáles corresponderían a facies distales del volcanismo oligoceno-mioceno.

Por otra parte, las formaciones Los Pelambres y Juncal, así como sus equivalentes cronoestratigráficos que inicialmente se atribuyeron al Cretácico Inferior en Chile y Argentina, fueron vinculadas a un amplio arco magmático (de al menos $100 \mathrm{~km}$ de ancho sobre la base de las unidades consideradas), que se habría desarrollado desde la actual cordillera de la Costa (Fig. 2), en territorio chileno, hasta el territorio argentino (Sanguinetti y Ramos, 1993), afectado por una importante subsidencia producida por procesos extensionales en un margen convergente. En este contexto, las facies continentales y volcánicas de las formaciones Diamante, Cristo Redentor y Juncal en Argentina y Los Pelambres en Chile (Fig. 3) conformaban la parte más oriental (arco volcánico externo) del amplio arco mesozoico, el que incluía hacia el occidente el arco volcánico interno en territorio chileno. Con los nuevos estudios, la Formación Los Pelambres deja de representar un arco externo mesozoico, quedando por identificar si los niveles volcánicos de la Formación Juncal pueden corresponder a este arco externo. Charrier et al. (2007) indican para la etapa kimmeridgianatithoniana a albiana al sur de $30^{\circ} \mathrm{S}$, una paleogeografía caracterizada por tres dominios, entre los que el arco 'Lo Prado-Los Pelambres' separaría una cuenca de antearco (Lo Prado) de una de trasarco (Mendoza-Neuquén). Este arco de 'Lo Prado' se habría extendido desde la actual depresión central hasta el flanco oriental de la cordillera de la Costa (Fig. 2), a causa de la ubicación de los cuerpos intrusivos cretácicos. Estos autores, sin embargo, reconocen que, para esta etapa, se pueden claramente diferenciar, al sur de $32^{\circ} \mathrm{S}$, dos franjas de afloramientos del arco volcánico: uno en la región costera y otra en la alta cordillera Andina, cerca del límite fronterizo con Argentina.

$\mathrm{Al}$ concluir que el grueso de los niveles volcánicos de las formaciones Los Pelambres y Juncal en la región de estudio no son Cenozoicos, es necesario plantear una nueva interpretación paleogeográfica para el Mesozoico para esta región de los Andes centrales. Esta paleogeografía constaría de un solo arco volcánico en territorio chileno (Fig. 13), de menor extensión areal que la que se suponía al incluir en él los depósitos volcánicos de las formaciones Juncal y Pelambres, y una amplia cuenca de trasarco con profundos depocentros en Chile y Argentina. En esta cuenca se habría desarrollado actividad volcánica alejada del arco, aunque de mucho menor volumen, la que se encuentra formando las intercalaciones volcánicas conocidas en las secuencias de trasarco. Esta sería una situación similar a la observada en

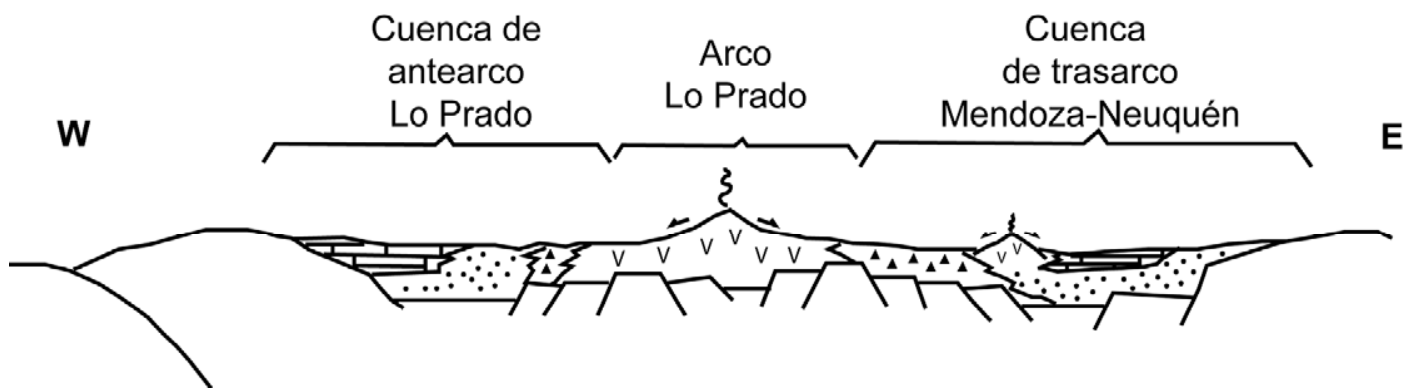

FIG. 13. Sección paleogeográfica esquemática de la segunda subetapa (Kimmeridgiano a Cretácico temprano) de la $1^{\underline{a}}$ Etapa del Ciclo Andino, entre $32^{\circ}$ y $33^{\circ} \mathrm{S}$. Modificado de Charrier et al. (2007). 
las unidades volcano-sedimentarias al norte de $31^{\circ} \mathrm{S}$ (Oliveros et al., 2012), donde existen evidencias de un volcanismo de trasarco a fines del Jurásico.

Hacia el oriente, el estudio de los depósitos sinorogénicos de la cuenca neógena de Manantiales $\left(32^{\circ}-32^{\circ} 30^{\prime} \mathrm{S}\right)$, en la provincia de San Juan, en Argentina (Pérez, 2001), indica que la base de esta puede ser datada en $20 \mathrm{Ma}$. Esto sugiere, según ese autor, que la deformación y el alzamiento de las áreas fuente de estos depósitos (de cordones al W de la cuenca) habrían comenzado en el Mioceno temprano. Esto, sumado a la presencia de lavas andesíticas que sobreyacen discordantemente sobre estructuras de la faja plegada y corrida de La Ramada, indicaría un rango para el alzamiento andino en estas latitudes entre 20 y $10 \mathrm{Ma}$ (Pérez y Ramos, 1996), con un último levantamiento ocurrido durante el Plioceno-Pleistoceno (Pérez, 2001). Las rocas fuentes identificadas para los depósitos sinorogénicos de la cuenca de Manantiales corresponden a las rocas andesíticas de la Formación Doña Ana $\left(29^{\circ}-30^{\circ} \mathrm{S}\right)$ del Mioceno Inferior, interpretadas como de ambiente de retroarco (Pérez, 2001). Este autor indica, además, que esta correlación permite inferir el inicio del volcanismo y el alzamiento de la cordillera Principal en la región de Manantiales cerca de $\sim 20 \mathrm{Ma}$. Posteriormente se han incluido las formaciones Tilito (27 a $23 \mathrm{Ma}$ ) y Escabroso (21,5 a 17,5 Ma) en el Grupo Doña Ana, y trabajos actuales presentan evidencias de un período extensional durante la acumulación de la formación inferior de este Grupo (Formación Tilito) (Winocur, 2010; Winocur y Ramos, 2008, 2012). Los nuevos datos geocronológicos aquí presentados permiten interpretar las rocas que afloran en la región de este estudio como posibles áreas fuente para estos depósitos sinorogénicos.

\section{Conclusiones}

\subsection{Estratigrafía y nuevos datos geocronológicos}

Se presentan en este estudio 8 nuevas dataciones radiométricas $\mathrm{U}-\mathrm{Pb}$ en circón, de las cuales 2 corresponden a rocas de la Formación Salamanca (Cretácico Superior), 5 a la Formación Abanico (Eoceno a Mioceno Inferior) y 1 a la Formación Farellones (Mioceno Superior temprano), lo que reafirma la ya sugerida edad cenozoica de gran parte de las rocas que conforman la cordillera
Principal de Chile central y límite con Argentina en esta latitud.

En el Sector Occidental de este estudio, al oeste de la Falla Pocuro, se obtuvo una edad de 81,5 $\pm 1,1 \mathrm{Ma}$, mientras que hacia el este, la Falla Pocuro habría alzado niveles inferiores de la Formación Salamanca (Cretácico Superior), en los cuales se obtuvo una

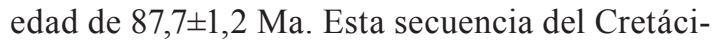
co Superior subyace de forma discordante a una secuencia de rocas volcánicas de la Formación Abanico.

Los depósitos volcánicos, volcanoclásticos y sedimentarios oligocenos a miocenos de la región cordillerana comprendida entre $32^{\circ}$ y $32^{\circ} 15^{\prime} \mathrm{S}$ se pueden agrupar en tres unidades que corresponden a asociaciones de facies relacionadas con el volcanismo oligoceno-mioceno: 1. unidad Alicahue-Chepical: corresponde a una asociación de facies con predominio lávico, 2. unidad Las Llaretas: asociación de facies con predominio volcanoclástico y $\mathbf{3}$. unidad Estratos del Pañuelo: asociación de facies con predominio detrítico. Las tres unidades forman parte de la Formación Abanico; mientras que la parte alta de algunos cerros está formada por lavas de la Formación Farellones, que en algunos sectores se presenta discordante sobre la anterior. Sin embargo, la monotonía litológica y la baja deformación en otros sectores donde la Formación Farellones se presenta concordante o pseudoconcordante sobre la Formación Abanico, no permite hacer una diferenciación certera entre ambas formaciones sin otras metodologías de estudio.

Las relaciones de contacto y la relación espacial (con los miembros más volcánicos en el sector occidental de la región y los más clásticos al oriente), junto a las evidencias de depósito sintectónico en la unidad de predominio detrítico, muestran una relación de facies para el volcanismo oligocenomioceno (proximales a distales de occidente a oriente), con probables depocentros limitados por fallas extensionales en el Sector Oriental. La distribución de estas unidades sugiere que la unidad Alicahue-Chepical, expuesta entre la Falla Pocuro al oeste y la línea de los ríos Leiva y Blanco al este, corresponde a los depósitos más proximales a los centros volcánicos, mientras que las otras dos unidades corresponden a depósitos distales. De la unidad distal Estratos del Pañuelo, se obtuvieron edades U-Pb en circón de 21,2 $\pm 0,3 \mathrm{Ma}, 22,0 \pm 0,3$ y $23,5 \pm 0,4 \mathrm{Ma}$; de la unidad Las Llaretas, se obtuvo 
una edad de 20,9 $\pm 0,3 \mathrm{Ma}$, y de la unidad proximal

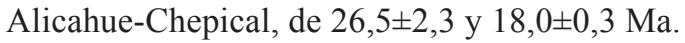

\subsection{Eventos de deformación inferidos}

En el Sector Occidental de la región de estudio, la Falla Pocuro habría tenido su actividad principal posterior a 81,5 Ma, generando el fallamiento, plegamiento y basculamiento de las rocas de la Formación Salamanca (Cretácico Superior), con movimientos inversos de vergencia occidental. Estos niveles subyacen una gruesa secuencia volcánica proximal del Mioceno Inferior, la que presenta un plegamiento suave afectado por movimientos tardíos y menos importantes de esta estructura. La presencia de discordancias angulares que separan ambas unidades permite inferir que las rocas miocenas 'sellan' la deformación principal en continuidad areal a ambos lados de la zona de Falla Pocuro. Es decir, se limita la actividad principal de la Falla Pocuro para períodos premiocenos.

El grado de deformación observado es creciente hacia el oriente. La estructuración de mayor persistencia y rumbo $\sim$ NNW tiene su límite oriental, en el lado argentino, en la Falla Río Teatinos-Río Volcán. En el sector oriental de este estudio, en territorio chileno, existe una interferencia entre las estructuras NNW anteriores y una serie de estructuras de rumbo $\sim$ NS. Esta orientación NS parece corresponder a una dirección preferencial para estructuras normales posteriormente invertidas, las cuales habrían limitado subcuencas o depocentros aislados en que se podían acumular las potentes secuencias volcanoclásticas distales del Oligoceno Superior-Mioceno Inferior; mientras que la orientación NNW ha sido descrita como una orientación preferencial para las estructuras de la faja plegada y corrida de La Ramada.

Sobre la base de los nuevos antecedentes aquí expuestos, es posible reconocer al menos tres etapas en la evolución de los productos volcánicos del Oligoceno-Mioceno: 1. Una etapa extensional del Oligoceno Superior en la región oriental de la zona de estudio, en los sectores que limitan los productos de la unidad distal Estratos del Pañuelo, evidenciada por las estructuras sintectónicas que fueron observadas en estos depósitos, 2 . Un evento compresivo previo a 18 y posterior a $21 \mathrm{Ma}$ y 3 . Una deformación tardía de vergencia oriental (pos-18 Ma) que afecta a las formaciones Abanico y Farellones, cuya intensidad es mayor en el sector oriental.

\section{Agradecimientos}

Esta contribución es parte del estudio financiado por la Beca de Doctorado en Chile de CONICYT. Se agradece el importante aporte del proyecto ACT-18 y el Advanced Mining Technology Center (AMTC) en el financiamiento de las campañas de terreno. También se agradece el financiamiento de las dataciones geocronológicas por la Beca de Apoyo a la Tesis Doctoral de CONICYT y a los investigadores V. Valencia (Washington State University) y M. Fanning (Australian National University) a cargo de los análisis. Los autores agradecen en especial la valiosa contribución en la discusión a los colegas C. Mpodozis (Antofagasta Minerals), C. Marquardt (Antofagasta Minerals), C. Venegas (Sernageomin), J. Piquer (Codelco), D. Sellés (AURUM), G. Pineda (Energía Andina), V. Ramos (Universidad de Buenos Aires), F. Barra (Universidad de Chile) y M.P. Rodríguez (Universidad de Chile), y en particular la minuciosa revisión de los editores M. Suárez (Sernageomin), L. Lara (Sernageomin), E.O. Cristallini (Universidad de Buenos Aires), L. Giambiagi (IANIGLA) y E. Godoy (Dirección de Obras Hidráulicas).

\section{Referencias}

Aguirre, L. 1960. Geología de los Andes de Chile Central, provincia de Aconcagua. Instituto de Investigaciones Geológicas, Boletín 9: 70 p. Santiago.

Aguirre, L.; Charrier, R.; Davidson, J.; Mpodozis, C.A.; Rivano, S.; Thiele, R.; Tidy, E.; Vergara, M.; Vicente, J.C. 1974. Andean magmatism: its paleogeographic and structural setting in the central part $\left(30^{\circ}-35^{\circ} \mathrm{S}\right)$ of the Southern Andes: Pacific. Geology 8: 1-38.

Aguirre, L.; Robinson, D.; Bevins, R.E.; Morata, D.; Vergara, M.; Fonseca, E.; Carrasco, J. 2000. A lowgrade metamorphic model for the Miocene volcanic sequences in the Andes of central Chile. New Zealand Journal of Geology and Geophysics 43: 83-93.

Arias, L. 1984. Geología y perspectivas económicas del área comprendida entre los ríos Rocín e Hidalgo, Provincia de San Felipe de Aconcagua. Memoria de Título (Inédito), Departamento de Geología, Universidad de Chile: $104 \mathrm{p}$.

Armijo, R.; Rauld, R.; Thiele, R.; Vargas, G.; Campos, J.; Lacassin, R.; Kausel, E. 2009. The West Andean Thrust (WAT), the San Ramón Fault and the seismic hazard for Santiago (Chile). Tectonics 29 (2): $34 \mathrm{p}$. doi: 10.1029/2008TC002427.

Astaburuaga, D.; Farías, M.; Charrier, R.; Tapia, F. 2012. Geología y estructuras del límite Mesozoico-Cenozoico de la Cordillera Principal entre $35^{\circ} 30^{\prime}$ y $36^{\circ}$ S, Región 
del Maule, Chile. In Congreso Geológico Chileno, No. 13, Actas: 250-252. Antofagasta.

Cahill, T.; Isacks, B. 1992. Seismicity and Shape of the Subducted Nazca Plate. Journal of Geophysical Research 97 (B12): 17503-17529.

Campbell, D. 2005. Termocronología del sector comprendido entre los ríos Rocín y Aconcagua: Implicancias en la evolución meso-cenozoica de la zona. Memoria de título (Inédito), Departamento de Geología, Universidad de Chile: $113 \mathrm{p}$.

Carter, W.; Aguirre, L. 1965. Structural Geology of Aconcagua province and its relationship to the central Valley Graben, Chile. Geological Society of America, Bulletin 76: 651-664.

Cegarra, M.; Ramos, V.A. 1996. La Falla Plegada y Corrida del Aconcagua. In Geología de la región del Aconcagua, provincias de San Juan y Mendoza (Ramos, V.A.; editor), Subsecretaría de Minería de la Nación, Dirección Nacional del Servicio Geológico, Anales 24: 387-422. Buenos Aires.

Chang, Z.; Vervoort, J.D.; McClelland, W.C.; Knaack, C. 2006. U-Pb dating of zircon by LA-ICP-MS. Geochemistry, Geophysics, Geosystems 7: 1-14.

Charrier, R. 1973. Geología de las Provincias O’Higgins y Colchagua. Instituto de Investigación de Recursos Naturales (IREN), Publicación 7: 69 p. Santiago.

Charrier, R. 1981. Mesozoic and Cenozoic stratigraphy of the central Argentinean-Chilean Andes (32-35 $\left.{ }^{\circ} \mathrm{S}\right)$ and chronology of their tectonic evolution. Zentralblatt Geologie Paläontologie 1: 344-355. Stuttgart.

Charrier, R. 1984. Áreas subsidentes en el borde occidental de la cuenca tras-arco jurásico-cretácica. Cordillera Principal Chilena entre $34^{\circ}$ y $34^{\circ} 30^{\prime} \mathrm{S}$. In Congreso Geológico Argentino, No. 9, Actas 2: 107-124. Buenos Aires.

Charrier, R.; Wyss, A.R.; Flynn, J.J.; Swisher, C.C. III; Norell, M.A.; Zapatta, F.; McKenna, M.C.; Novaceck, M.J. 1996. New evidence for late Mesozoic: early Cenozoic evolution of the Chilean Andes in the upper Tinguiririca valley $\left(35^{\circ} \mathrm{S}\right)$, Central Chile. Journal of South American Earth Sciences 9 (2): 1-30.

Charrier, R.; Baeza, O.; Elgueta, S.; Flynn, J.J.; Gans, P.; Kay, S.M.; Muñoz, N.; Wyss, A.R.; Zurita, E. 2002. Evidence for Cenozoic extensional basin development and tectonic inversion south of the flat-slab segment, southern Central Andes, Chile (33-36 ${ }^{\circ}$ S.L.). Journal of South American Earth Sciences 15: 117-139.

Charrier, R.; Bustamante, M.; Comte, D.; Elgueta, E.; Flyn, J.; Iturra, I.; Muñoz, N.; Pardo, M.; Thiele, R.; Wyss, A. 2005. The Abanico extensional basin:
Regional extension, chronology of tectonic inversion and relation to shallow seismic activity and Andean uplift. Neues Jahrbuch Fur Geologie Und Palaontologie-Abhandlungen 236 (1-2): 43-77.

Charrier, R.; Pinto, L.; Rodríguez, M.P. 2007. Tectonostratigraphic evolution of the Andean orogen in Chile. In Geology of Chile, Chapter 3 (Moreno, T.; Gibbons, W.; editors). The Geological Society, Special Publication: 21-116. London.

Coira, B.; Davidson, C.; Mpodozis, C.; Ramos, V. 1982. Tectonic and magmatic evolution of the Andes of northern Argentina and Chile. Earth-Science Reviews, Special Issue 18: 303-332.

Coward, M.P.; Gillcrist, R.; Trudgill, B. 1991. Extensional structures and their tectonic inversion in the Western Alps. Geological Society, Special Publications 56: 93-112. London.

Cristallini, E. 1996a. Estructura de la Alta Cordillera de San Juan. Tesis de Doctorado (Inédito), Departamento de Ciencias Geológicas, Universidad de Buenos Aires: 248 p.

Cristallini, E. 1996b. La Faja Plegada y Corrida de la Ramada. In Geología de la región del Aconcagua, provincias de San Juan y Mendoza (Ramos, V.A.; editor). Subsecretaría de Minería de la Nación, Dirección Nacional del Servicio Geológico, Anales 24: 349-386. Buenos Aires.

Cristallini, E.O.; Cangini, A. 1993. Estratigrafía y estructura de las nacientes del río Volcán, Alta cordillera de San Juan. In Congreso Geológico Argentino, No. 12 y Congreso de Exploración de Hidrocarburos, No. 2, Actas 3: 85-92. Buenos Aires.

Cristallini, E.; Ramos, V. 1996. Los depósitos continentales cretácicos y volcanitas asociadas. In Geología de la región del Aconcagua, provincias de San Juan y Mendoza (Ramos, V.A.; editor). Subsecretaría de Minería de la Nación, Dirección Nacional del Servicio Geológico, Anales 24: 231-273. Buenos Aires.

Cristallini, E.O.; Kay, S.M.; Ramos, V.A. 1994. Geoquímica de las volcanitas cretácicas y terciarias aflorantes en el límite argentino-chileno a los $32^{\circ}$ de latitud sur. In Congreso Geológico Chileno, No. 7, Actas 2: 1311-1315. Concepción.

Cristallini, E.; Álvarez, P.; Pérez, D.; Ramos, V. 1995. Estructura de la Alta Cordillera de San Juan. Asociación Geológica Argentina, Revista 49 (1-2): 165-183. Buenos Aires.

Cristallini, E.; Álvarez, P.; Pérez, D.; Ramos, V. 1996. Carta Geológica de la región de La Ramada. Servicio Geológico Nacional, mapa escala 1:100.000. Argentina. 
Dickinson, W.R.; Gehrels, G.E. 2003. U-Pb ages of detrital zircons from Permian and Jurassic eolianite sandstones of the Colorado Plateau, USA: Paleogeographic implications. Sedimentary Geology 163: 29-66.

Farías, M.; Comte, D.; Charrier, R.; Martinod, J.; David, C.; Tassara, A.; Tapia, F.; Fock, A. 2010. Crustal-scale structural architecture in central Chile based on seismicity and surface geology: Implications for Andean mountain building. Tectonics 29: TC3006. doi: 10.1029/2009TC002480.

Fock, A. 2005. Cronología y tectónica de la exhumación en el Neógeno de los Andes de Chile central entre los $33^{\circ}$ y los $34^{\circ} \mathrm{S}$. Tesis de Doctorado (Inédito), Departamento de Geología, Universidad de Chile: 235 p.

Fock, A.; Charrier, R.; Farías, M.; Maksaev, V.; Fanning, M.; Álvarez, P. 2005. Exhumation and uplift of the western Main Cordillera between $33^{\circ}$ and $34^{\circ} \mathrm{S}$. In International Symposium on Andean Geodynamics (ISAG), No. 6, Extended Abstracts: 273-276. Barcelona.

Fock, A.; Charrier, R.; Farías, M.; Muñoz, M. $2006 a$. Fallas de vergencia oeste en la Cordillera Principal de Chile Central: Inversión de la cuenca de Abanico $\left(33^{\circ}-34^{\circ} \mathrm{S}\right)$. Revista de la Asociación Geológica Argentina, Publicación Especial 6: 48-55.

Fock, A.; Charrier, R.; Maksaev, V.; Farías, M.; Álvarez, P. 2006b. Evolución cenozoica de los Andes de Chile

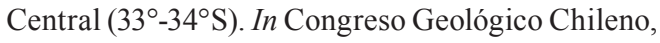
No. 11, Actas 2: 205-208. Antofagasta.

Fuentes, F. 2004. Petrología y metamorfismo de muy bajo grado de unidades volcánicas oligoceno-miocenas en la ladera occidental de los Andes de Chile central $\left(33^{\circ} \mathrm{S}\right)$. Tesis de Doctorado (Inédito), Departamento de Geología, Universidad de Chile: 398 p.

Fuentes, F.; Vergara, M.; Aguirre, L.; Féraud, G. 2002. Relaciones de contacto de unidades volcánicas terciarias de los Andes de Chile central $\left(33^{\circ} \mathrm{S}\right)$ : una reinterpretación sobre la base de dataciones ${ }^{40} \mathrm{Ar} /{ }^{39} \mathrm{Ar}$. Revista Geológica de Chile 29 (2): 207-225.

Godoy, E. 1988. Y Klohn tenía razón: La Formación Colimapu recupera sus miembros basales. In Congreso Geológico Chileno, No. 5, Proceedings 3: H101-H120. Santiago.

Giambiagi, L.B.; Ramos, V.A. 2002. Structural evolution of the Andes in a transitional zone between flat and

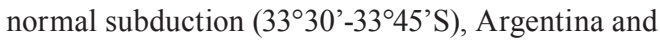
Chile. Journal of South American Earth Sciences 15: 101-116.

Giambiagi, L.B.; Ramos, V.A.; Godoy, E.; Álvarez, P.P. 2002. Deformational History of the Andes, between $33^{\circ}$ and $34^{\circ}$ South Latitude, Chile and Argentina. In
International Symposium on Andean Geodynamics (ISAG), No.5: 247-250. Toulouse.

Godoy, E. 1991. El corrimiento El Fierro reemplaza a la discordancia intrasenoniana en el río Cachapoal, Chile central. In Congreso Geológico Chileno, No. 6: 515-519. Viña del Mar.

Godoy, E. 2011. Structural setting and diachronism in the Central Andean Eocene to Miocene volcano tectonic basins. In Cenozoic geology of the Central Andes of Argentina (Salfity, J.A.; Marquillas, R.A.; editores). Instituto del Cenozoico, Universidad Nacional de Salta: $155-167$.

Godoy, E.; Lara, L. 1994. Segmentación estructural andina a los $33^{\circ}-34^{\circ}$ : nuevos datos en la Cordillera Principal. In Congreso Geológico Chileno, No. 7, Proceedings 2: 1344-1348. Concepción.

Godoy, E.; Navarro, M.; Rivera, O. 1996. Zonas triangulares en el borde occidental de la Cordillera Principal (32³0'-34³0'), Chile: una solución a la paradoja Abanico-Farellones. In Congreso Geológico Argentino, No. 13 y Congreso de Exploración de Hidrocarburos, No. 3, Actas 2: 373-381. Buenos Aires.

Godoy, E.; Yáñez, G.; Vera, E. 1999. Inversion of an Oligocene volcano-tectonic basin and uplifting of its superimposed Miocene magmatic arc in the Chilean Central Andes: first seismic and gravity evidences. Tectonophysics 306: 217-236.

Gutscher, M.A.; Spakman, W.; Bijwaard, H.; Engdahl, E.R. 2000. Geodynamics of flat subduction: Seismicity and tomographic constraints from the Andean margin. Tectonics 19: 814-833. doi: 10.1029/ 1999TC001152.

Jara, P.; Charrier, R. 2011. Perfil estructural en la Alta Cordillera de Chile central a $32^{\circ} 15^{\prime}$ S. In Congreso Geológico Argentino, No. 18, Sesión S12: 2 p. Neuquén.

Jara, P.; Piquer, J.; Pinto, L.; Arriagada, C.; Charrier, R.; Rivera, O. 2009a. Perfiles estructurales de la Cordillera Principal de Chile Central: resultados preliminares. In Congreso Geológico Chileno, No. 12, Sesión 9-038: 4 p. Santiago.

Jara, P.; Charrier, R.; Farías, M.; Arriagada, C. 2009 b. Geometric reconstruction and trishear model of folding: a case study in the western Principal Cordillera, Central Chile (34 $15^{\prime}$ 'S-34 $30^{\circ}$ 'S). Universidad de Oviedo, Trabajos de Geología 29: 413-418.

Jara, P.; Likerman, J.; Cristallini, E.; Ghiglione, M.; Pinto, L.; Charrier, R.; Jara, C. 2012. Analogue models of basins affected by differential deformation in extensional and compressional regimes. In Congreso Geológico Chileno, No. 13, Actas: 302-304. Antofagasta. 
Jordan, T.E.; Burns, W.M.; Veiga, R.; Pángaro, F.; Copeland, P.; Kelley, S.; Mpodozis, C. 2001. Extension and basin formation in the Southern Andes caused by increased convergence rate: A mid-Cenozoic trigger for the Andes. Tectonics 20: 308-324.

Kay, S.M.; Godoy, E.; Kurtz, A. 2005. Episodic arc migration, crustal thickening, subduction erosion, and magmatism in the south-central-Andes. Geological Society of America Bulletin 117: 67-88.

Kley, J.; Monaldi, C.R.; Salfity, J.A. 1999. Along-strike segmentation of the Andean foreland: causes and consequences. Tectonophysics 301: 75-94.

Klohn, C. 1960. Geología de la Cordillera de los Andes de Chile Central, Provincia de Santiago, Colchagua y Curicó. Instituto de Investigaciones Geológicas, Boletín 8: 95 p. Santiago.

Levi, B.; Aguirre, L. 1981. Ensialic spreading-subsidence in the Mesozoic and Paleogene Andes of central Chile. Journal of the Geological Society of London 138: 75-81.

Levi, B.; Nyström, J.O. 1982. Spreading subsidence and subduction in central Chile: a preliminary geochemical test in Mesozoic Paleogene rocks. In Congreso Geológico Chileno, No. 3, Actas I (B): 28-36. Concepción.

Ludwig, K.R. 2003. Isoplot 3.0 A geochronological toolkit for Microsoft Excel. Berkeley Geochronology Center. Special publication 4: 71 p. Berkeley.

Maksaev, V.; Zentilli, M.; Munizaga, F.; Charrier, R. 2003. Denudación/alzamiento del Mioceno SuperiorPlioceno Inferior de la Cordillera de Chile Central $\left(33^{\circ}-35^{\circ} \mathrm{S}\right)$ inferida por dataciones por trazas de fisión en apatito de plutones miocenos. In Congreso Geológico Chileno, No. 10, Sesión Temática, CD-Rom 1. Concepción.

Maksaev, V.; Munizaga, F.; Zentilli, M.; Charrier, R. 2009. Fission track thermochronology of Neogene plutons in the Principal Andean Cordillera of central Chile (33-35 $\left.{ }^{\circ} \mathrm{S}\right)$ : Implications for tectonic evolution and porphyry $\mathrm{Cu}-\mathrm{Mo}$ mineralization. Andean Geology 36 (2): 153-171.

Moscoso, R.; Padilla, H.; Rivano, S. 1982. Hoja Los Andes, Región de Valparaíso. Servicio Nacional de Geología y Minería, Carta Geológica de Chile 52: 67 p.

Mosquera, A.; Zapata, T. 1991. Análisis e interpretación estructural de las cordilleras casa de Piedra y del Medio, sur de la Cordillera Principal sanjuanina, Argentina. In Congreso Geológico Chileno, No. 6, Actas: 742-746. Viña del Mar.

Mpodozis, C.; Ramos, V.A. 1989. The Andes of Chile and Argentina. In Geology of the Andes and its relation to hydrocarbon and energy resources (Ericksen, G.E.;
Cañas, M.T.; Reinemund, J.A.; editores). Circum-Pacific Council for Energy and Hydrothermal Resources, American Association of Petroleum Geologists, Earth Science Series 11: 59-90. Houston.

Mpodozis, C.; Brockway, H.; Marquardt, C.; Perelló, J. 2009. Geocronología U-Pb y tectónica de la región Los Pelambres-Cerro Mercedario: Implicancias para la evolución cenozoica de los Andes del centro de Chile y Argentina. In Congreso Geológico Chileno, No. 12, Actas Digitales. Santiago.

Muñoz, M.; Fuentes, F.; Vergara, M.; Aguirre, L.; Nyström, J.O.; Feraud, G.; Demant, A. 2006. Abanico East Formation: petrology and geochemistry of volcanic rocks behind the Cenozoic arc front in the Andean Cordillera, central Chile (3350'S). Revista Geológica de Chile 33 (1): 109-140.

Munizaga, F.; Vicente, J.C. 1982. Acerca de la zonación plutónica y del volcanismo mioceno en los Andes del Aconcagua (La. $32-33^{\circ} \mathrm{S}$ ): Datos radiométricos K-Ar. Revista Geológica de Chile 16: 3-21.

Nyström, J.O.; Vergara, M.; Morata, D.; Levi, B. 2003. Tertiary volcanism during extension in the Andean

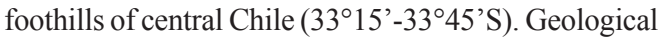
Society of America, Bulletin 115 (12): 1523-1537.

Oliveros, V.; Labbé, M.; Rossel P.; Charrier, R.; Encinas, A. 2012. Late Jurassic paleogeographic evolution of the Andean back-arc basin: New constrains from the Lagunillas Formation, northern Chile (2730'-28 $30^{\circ}$ 'S). Journal of South American Earth Sciences 37: 25-40.

Paces, J.; Miller, J. 1993. Precise U-Pb ages of Duluth complex and related mafic intrusions, northeastern Minnesota; geochronological insights to physical, petrogenetic, paleomagnetic, and tectonomagmatic processes associated with the 1.1 Ga midcontinent rift system. Journal of Geophysical Research 98 (B8): 13997-14013. doi: 10.1029/93JB01159.

Padilla, H. 1981. Contribución a la Geología y Petrología de las rocas volcánicas e intrusivas de los Andes Chilenos entre las latitudes $33^{\circ} 45^{\prime} \mathrm{S}$ y $33^{\circ} \mathrm{S}$. Memoria de Título (Inédito), Departamento de Geología, Universidad de Chile: 329 p.

Pardo-Casas, F.; Molnar, P. 1987. Relative motion of the Nazca (Farallón) and South American Plates since late cretaceous time. Tectonics 6 (3): 233-284.

Pérez, D.J.; Ramos, V.A. 1996. Los depósitos sinorogénicos. In Geología de la región del Aconcagua, provincias de San Juan y Mendoza (Ramos, V.A.; editor), Subsecretaría de Minería de la Nación, Dirección Nacional del Servicio Geológico, Anales 24: 387-422. Buenos Aires. 
Pérez, D.J. 2001. Tectonic and unroofing history of Neogene Manantiales foreland basin deposits, Cordillera Frontal (32³0’S), San Juan Province, Argentina. Journal of South American Earth Sciences 14: 693-705.

Ramos, V.A. 1988. The Tectonics of Central Andes: $30^{\circ}$ to $33^{\circ} \mathrm{S}$ latitude. In Processes in Continental Lithospheric Deformation (Clark, S.; Burchfiel, D.; editores). Geological Society of America, Special Paper 218: 31-54.

Ramos, V.A. 1996. Evolución Tectónica de la Alta Cordillera de San Juan y Mendoza. In Geología de la región del Aconcagua, provincias de San Juan y Mendoza (Ramos, V.A.; editor). Subsecretaría de Minería de la Nación, Dirección Nacional del Servicio Geológico, Anales 24: 447-460. Buenos Aires.

Ramos, V.A. 1999. El Segmento de Subducción Subhorizontal de los Andes Centrales Argentino-Chilenos. Acta Geológica Hispánica 32 (7): 5-16.

Ramos, V.A.; Cingolani, C. 1989. La granodiorita Matienzo, intrusivo mioceno de la Alta cordillera de Mendoza. Asociación Geológica Argentina, Revista 43 (3): 404-408. Buenos Aires.

Ramos, V.A.; Aguirre-Urreta, M.B. 1992. El Neocomiano de los Andes Centrales de Argentina y Chile. In Congreso Geológico de España, No. 3 y Congreso Latinoamericano de Geología, No. 8, Actas Simposios 4: 75-79. Salamanca.

Ramos, V.A.; Rivano, S.; Aguirre-Urreta, M.B.; Godoy, E.; Lo Forte, G.L. 1990. El Mesozoico del cordón del Límite entre Portezuelo Navarro y Monos de Agua (Chile-Argentina). In Congreso Geológico Argentino, No. 11, Actas 2: 43-46. San Juan.

Ramos, V.A.; Aguirre-Urreta, M.B.; Álvarez, P.P.; Cegarra, M.; Cristallini, E.O.; Kay, S.M.; Lo Forte, G.L.; Pereyra, F.; Pérez, D. 1996a. Geología de la región del Aconcagua, Provincias de San Juan y Mendoza. Dirección Nacional del Servicio Geológico, Subsecretaría de la Nación, Anales 24: 510 p. Buenos Aires.

Ramos, V.A.; Cegarra, M.; Cristallini, E. 1996b. Cenozoic tectonics of the High Andes of west-central Argentina (30-36 ${ }^{\circ} \mathrm{S}$ latitude). Tectonophysics 259: 185-200.

Ramos, V.A.; Cristallini, E.; Pérez, D.J. 2002. The Pampean flat-slab of the Central Andes. Journal of South American Earth Sciences 15: 59-78.

Rauld, R. 2011. Deformación cortical y peligro sísmico asociado a la falla San Ramón en el frente cordillerano de Santiago, Chile Central $\left(33^{\circ} \mathrm{S}\right)$. Tesis para el grado de Doctor en Ciencias, mención Geología (Inédito), Departamento de Geología, Universidad de Chile: 311 p. Santiago.
Rivano, S. 1984. Geología del Meso-Cenozoico entre los $31^{\circ}$ y $33^{\circ}$ Lat. Sur. In Seminario Actualización de la Geología de Chile, Apuntes. Servicio Nacional de Geología y Minería, Miscelánea 4: k1-k17. Santiago.

Rivano, S.; Sepúlveda, P. 1991. Hoja Illapel, Región de Coquimbo. Servicio Nacional de Geología y Minería, Carta Geológica de Chile 69: 132 p.

Rivano, S.; Godoy, E.; Vergara, M.; Villarroel, R. 1990. Redefinición de la Formación Farellones en la cordillera de los Andes de Chile Central $\left(32^{\circ}-34^{\circ} \mathrm{S}\right)$. Revista Geológica de Chile 17 (2): 205-214.

Rivano, S.; Sepúlveda, P.; Boric, R.; Espiñeira, D. 1993. Hoja Quillota y Portillo. V Región. Servicio Nacional de Geología y Minería, Carta Geológica de Chile 73, 1 mapa escala 1:250.000. Acompaña Informe Inédito 7644.

Rivera, O.; Cembrano, J. 2000. Modelo de formación de cuencas volcano-tectónicas en zonas de transferencia oblicuas a la cadena andina: el caso de las cuencas oligo-miocénicas de Chile central y su relación con

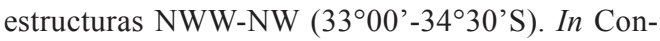
greso Geológico Chileno, No. 9, Actas 2: 631-636. Puerto Varas.

Rosendahl, B.R. 1987. Architecture of continental rifts with special reference to East Africa. Annual Review of Earth and Planetary Sciences 15: 445-503.

Sanguinetti, A.S.; Ramos, V.A. 1993. El volcanismo de arco mesozoico. In Geología y Recursos Naturales de Mendoza (Ramos, V.A.; editor). Congreso Geológico Argentino, No. 12 y Congreso de Exploración de Hidrocarburos, No. 2, Relatorio 1 (10): 115-122. Buenos Aires.

Sellés, D. 1999. La Formación Abanico en el Cuadrángulo Santiago (331' $\left.-33^{\circ} 30^{\prime} \mathrm{S}, 70^{\circ} 30^{\prime}-70^{\circ} 45^{\prime} \mathrm{O}\right)$, Chile Central. Estratigrafía y Geoquímica. Tesis de Doctorado (Inédito), Departamento de Geología, Universidad de Chile: 154 p.

Sellés, D. 2000. La relación discordante entre las Formaciones Abanico y Las Chilcas en la localidad de Angostura: implicancias regionales. In Congreso Geológico Chileno, No. 9, Actas 1: 555-558. Puerto Varas.

Sellés, D.; Gana, P. 2001. Geología del área Talagante-San Francisco de Mostazal. Servicio Nacional de Geología y Minería, Carta Geológica de Chile, Serie Geología Básica No 74: 30 p.

SERNAGEOMIN. 2002. Mapa Geológico de Chile. Servicio Nacional de Geología y Minería, Carta Geológica de Chile 75, 1 mapa en 3 hojas, escala 1:1.000.000.

Thiele, R. 1980. Hoja Santiago, Región Metropolitana. Servicio Nacional de Geología y Minería, Carta Geológica de Chile 29: 21 p. 
Tunik, M.; Álvarez, P. 2008. Análisis y edad de la sección calcárea de la Formación Las Chilcas (Chile) y sus implicancias para la correlación con unidades de Argentina. Revista Asociación Geológica Argentina 63 (3): 363-379.

Vergara, M.; Drake, R. 1978. Edades potasio-argón y su implicancia en la geología regional de Chile. Revista Comunicaciones 23: 1-11.

Vergara, M.; Morata, D.; Villarroel, R.; Nyström, J.; Aguirre, L. 1999. ${ }^{40} \mathrm{Ar} /{ }^{39} \mathrm{Ar}$ Ages, very low-grade metamorphism and geochemistry of the volcanic rock from 'Cerro El Abanico', Santiago Andean Cor-

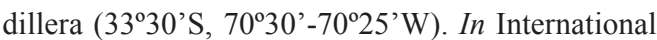
Symposium on Andean Geodynamics (ISAG), No. 4, Proceedings: 785-788. Göttingen.

Wall, R.; Sellés, D.; Gana, P. 1999. Mapa Geológico del Área Til-Til-Santiago. Servicio Nacional de Geología y Minería, Mapas Geológicos 11: 17 p

Williams, I.S. 1998. U-Th-Pb geochronology by Ion Microprobe. In Applications of microanalytical techniques to understanding mineralizing processes (McKibben, M.A.; Shanks, W.C.; Ridley, W.I.; editores). Reviews in Economic Geology 7: 1-35.
Winocur, D.; Ramos, V. 2008. Geología y Estructura del sector norte de la Alta Cordillera de la provincia de San Juan. In Congreso Geológico Argentino, No. 17, Actas 3: 166-167. Jujuy.

Winocur, D. 2010. Geología y estructura del Valle del Cura y el sector central del Norte Chico, provincia de San Juan y IV Región de Coquimbo, Argentina y Chile. Tesis de Doctorado (Inédito), Universidad de Buenos Aires: 354 p.

Winocur, D.; Ramos, V. 2012. Oligocene Extensional Tectonics at the Main Andes. Valle del Cura Basin, San Juan Province, Argentina. In Congreso Geológico Chileno, No. 13, Actas: 250-252. Antofagasta.

Yrigoyen, M.R. 1976. Observaciones geológicas alrededor del Aconcagua. In Congreso Geológico Chileno, No. 1, Actas 1: 168-190. Santiago.

Yrigoyen, M.R. 1979. Cordillera Principal. In Simposio Geología Regional, No 2 (Turner, J.C.M.; editor). Academia Nacional de Ciencias 1: 651-694. Córdoba.

Zurita, E. 1999. Historia de enterramiento y exhumación de la Formación Abanico=Coya-Machalí, Cordillera Principal, Chile Central. Memoria de título (Inédito), De partamento de Geología, Universidad de Chile: 156 p. 


\section{APÉNDICE \\ Resultados de dataciones U-Pb en circón.}

\section{Material Utilizado}

Se dataron 8 muestras (Tabla 1 y Apéndice), 6 de ellas (AL-4, AL-38, AL-17, AL-22, AL-10, RR-01) pertenecientes a las unidades oligocenas-miocenas descritas (Fig. 7) y 2 (CS-3 y AP-19) a niveles cretácicos en el Sector Occidental de la región estudiada (Fig. 4).

La muestra AL-4 corresponde a una toba cristalina intercalada en una secuencia de lavas andesíticas en el sector adyacente al río Blanco (Fig. 4), en los afloramientos orientales de la unidad Alicahue-Chepical, donde las rocas comienzan a involucrarse en la intensa deformación que se observa hacia el este de la línea formada por los ríos Leiva y Blanco (Fig. 7). La muestra AL-38 corresponde a una toba cristalina en el sector del río Leiva (Fig. 4) colectada a la cota de 2.737 m s.n.m y estratigráficamente bajo la unidad de predominio lávico en rocas de la unidad Las Llaretas, que se encuentran intensamente deformadas. La muestra proviene de una capa con manteo de $60^{\circ} \mathrm{W}$.

Se dataron 2 muestras de la unidad Estratos del Pañuelo, AL-17 corresponde a una toba vítrea intercalada en una secuencia deformada de $1 \mathrm{~km}$ de espesor de areniscas e intercalaciones tobáceas, ubicada a 3.240 m s.n.m. en el flanco oriental de un anticlinal (Fig. 4 y 9B); mientras que AL-22 corresponde a una arenisca de la cual se obtuvieron circones detríticos cuya edad presenta 95\% de confiabilidad para un grupo de 53 circones. Esta muestra se ubica en la ladera sur del estero Las Llaretas, bajo la discordancia que separa la unidad Estratos del Pañuelo de la unidad Alicahue-Chepical (Fig. 8).

La muestra AL-10, la más oriental datada en este estudio (Fig. 4), se encuentra en territorio argentino, al este del paso fronterizo Las Llaretas, y corresponde a una toba vítrea intercalada en una sucesión de areniscas rojas de la unidad Estratos del Pañuelo, que forma una delgada franja dentro de una lámina tectónica que mantea $\sim 55^{\circ} \mathrm{W}$, a una altura de $3.471 \mathrm{~m}$ s.n.m.

Hacia el SW, 10 km al este de la zona de Falla Pocuro, por el río Rocín, se colectó la muestra RR-01, a una altura de $\sim 2.265 \mathrm{~m}$ s.n.m., las cuales corresponden a lavas andesíticas porfíricas deformadas de la unidad Alicahue-Chepical de la Formación Abanico que forman el flanco oriental de un anticlinal, con cambios progresivos de manteo de $10^{\circ}$ hasta $\sim 50^{\circ} \mathrm{E}$. Sobreyacen a estas rocas niveles de la Formación Farellones subhorizontales (Rivano et al., 1993; Campbell, 2005).

Sumado a las 6 dataciones de rocas oligo-miocenas de las unidades anteriores, se obtuvieron 2 dataciones en rocas tobáceas colectadas en el sector occidental de la cordillera Principal a esta latitud (Fig. 4). La primera (AP-19) fue obtenida en la zona de Falla Pocuro, en la ladera sur del valle del río Alicahue, a la cota 1.986 m s.n.m. La segunda (CS-3), colectada a una altura de 1.863 m s.n.m., en el sector del valle del río Sobrante (Fig. 4), en la secuencia subyacente a la discordancia angular descrita en este sector (Fig. 5). 


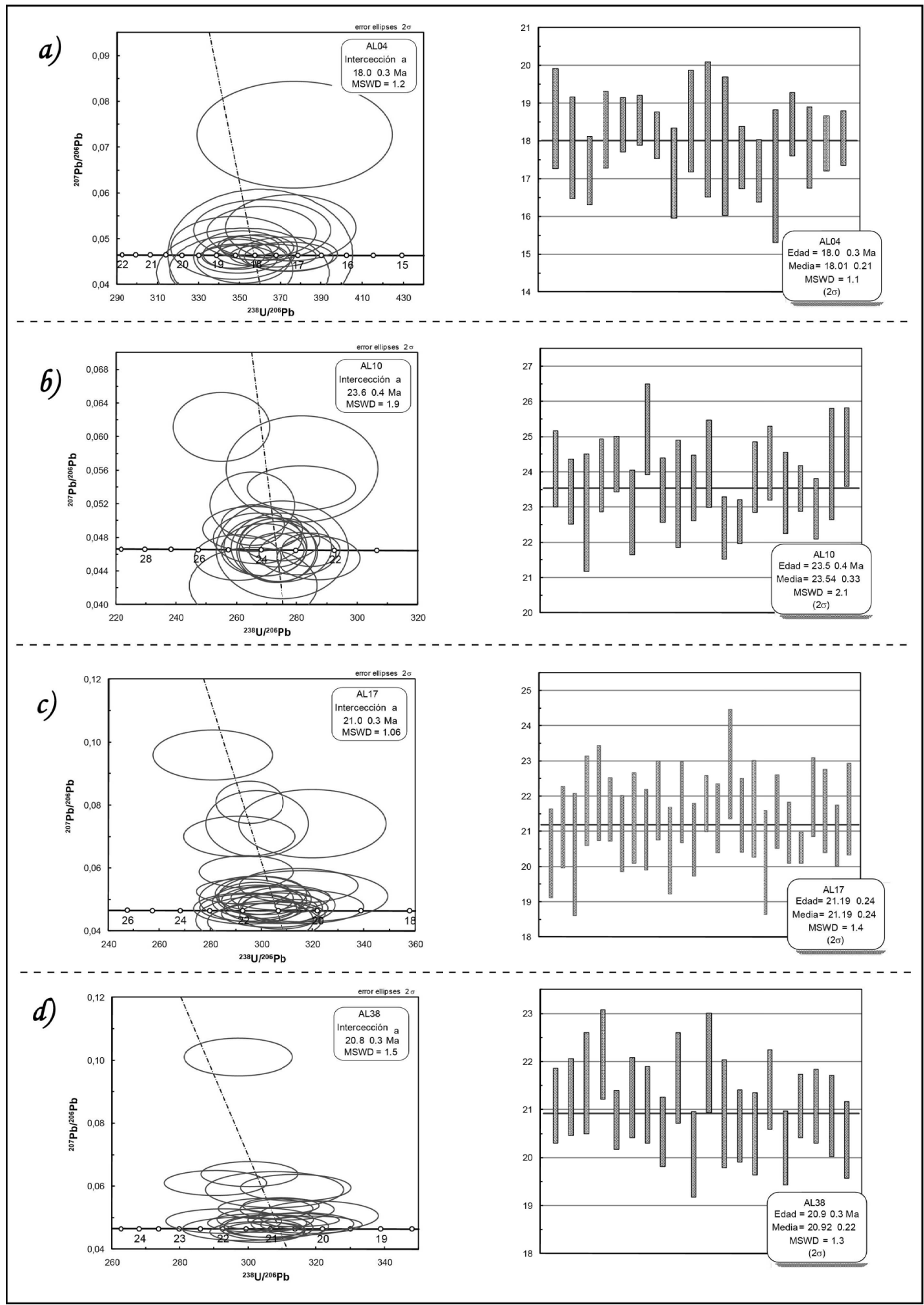

FIG. 1 apéndice. Izquierda: gráficos de concordia (Tera Wasserburg) con elipses a $2 \sigma$; Derecha: gráficos de distribución de edades promedio ponderado (error en $\pm 2 \sigma$ ), para las muestras oligo-miocenas datadas: a. AL-4, b. AL-10, c. AL-17 y d. AL-38. Para detalle de los datos ver también Tabla 2. 


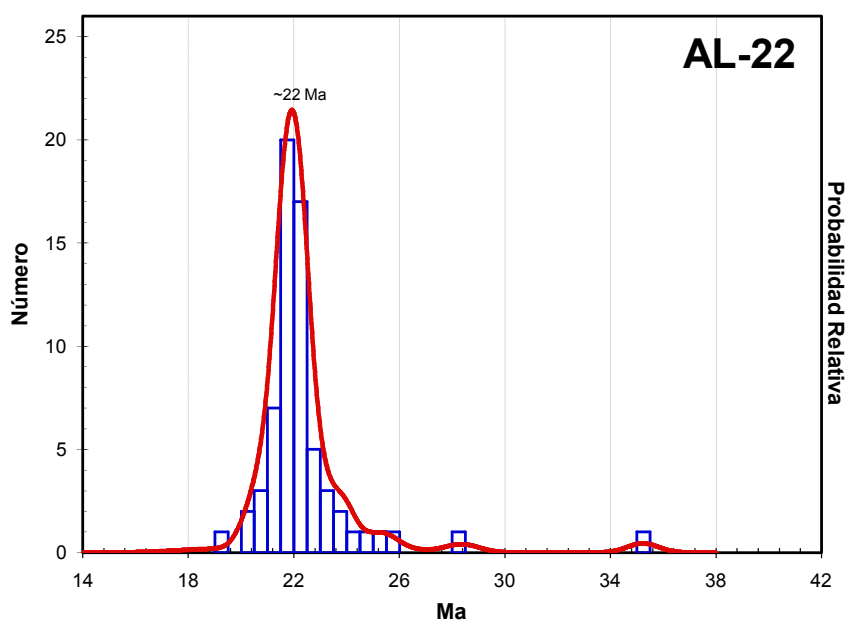

FIG. 2 apéndice. Distribución de edades mediante U-Pb en circón, para la muestra AL-22 de la unidad 'Estratos del Pañuelo'.

A)

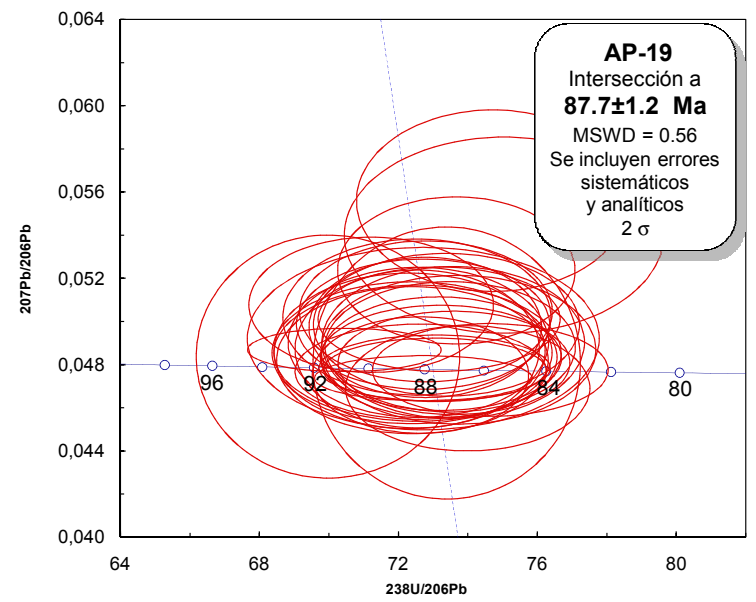

B)

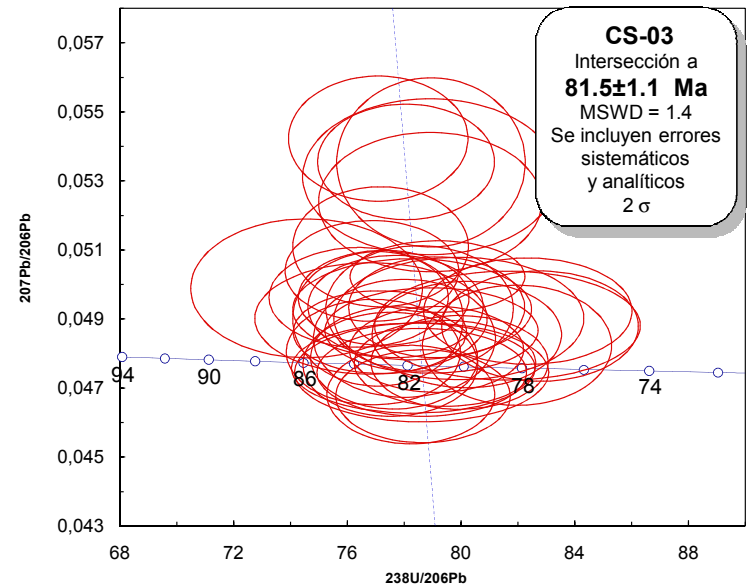

FIG. 3 apéndice. Gráficos de concordia (Tera Wasserburg) con elipses a 2 $\sigma$, para las dos muestras cretácicas datadas mediante U-Pb en

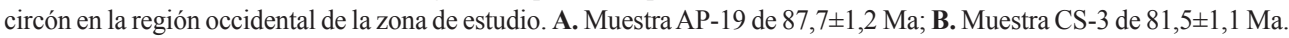


APÉNDICE TABLA 1. RESULTADOS ANALÍTICOS DE LAS DATACIONES U-PB EN CIRCÓN MEDIANTE LA-ICP-MS.

\begin{tabular}{|c|c|c|c|c|c|c|c|c|c|c|c|c|}
\hline Muestra & $\begin{array}{c}\mathrm{U} \\
\text { ppm }\end{array}$ & $\begin{array}{c}\text { Th } \\
\mathbf{U}\end{array}$ & $\begin{array}{c}238 \mathrm{U} \\
206 \mathrm{~Pb}\end{array}$ & $\begin{array}{c}1 \sigma \\
\% \text { error }\end{array}$ & $\begin{array}{l}207 \mathrm{~Pb} \\
206 \mathrm{~Pb}\end{array}$ & $\begin{array}{c}1 \sigma \\
\% \text { error }\end{array}$ & $\begin{array}{c}206 / 238 \\
\text { Edad }\end{array}$ & $\begin{array}{c}1 \sigma \\
\text { Error abs }\end{array}$ & $\begin{array}{c}\text { 207/206 } \\
\text { Edad }\end{array}$ & $\begin{array}{c}1 \sigma \\
\text { Error abs }\end{array}$ & Edad & $\begin{array}{c}1 \sigma \\
\text { Error abs } \\
\text { Ma }\end{array}$ \\
\hline AL04_23 & 137 & 0,47 & $3.461,617$ & $3,57 \%$ & 0,0432 & $6,91 \%$ & 18,6 & 0,7 & 0 & 8,7 & 18,6 & 0,7 \\
\hline AL04_22 & 159 & 0,82 & $3.612,312$ & $3,79 \%$ & 0,0519 & $5,22 \%$ & 17,8 & 0,7 & 279,6 & 115,2 & 17,8 & 0,7 \\
\hline AL04_21 & 454 & 0,49 & 373,927 & $2,64 \%$ & 0,0467 & $3,23 \%$ & 17,2 & 0,5 & 31,8 & 75,7 & 17,2 & 0,5 \\
\hline AL04_19 & 245 & 0,63 & $3.516,166$ & $2,78 \%$ & 0,046 & $5,06 \%$ & 18,3 & 0,5 & 0,5 & 117,1 & 18,3 & 0,5 \\
\hline AL04_18 & 621 & 0,78 & 349,131 & $1,96 \%$ & 0,0466 & $2,85 \%$ & 18,4 & 0,4 & 29,5 & 67 & 18,4 & 0,4 \\
\hline AL04_17 & 886 & 0,98 & $3.469,819$ & $1,78 \%$ & 0,0462 & $2,31 \%$ & 18,6 & 0,3 & 9,9 & 54,7 & 18,6 & 0,3 \\
\hline AL04_16 & 1187 & 0,47 & $3.544,396$ & $1,7 \%$ & 0,0485 & $1,95 \%$ & 18,2 & 0,3 & 121,9 & 45,4 & 18,2 & 0,3 \\
\hline AL04_15 & 210 & 0,76 & $3.751,448$ & $3,48 \%$ & 0,0524 & $5,61 \%$ & 17,2 & 0,6 & 302 & 123,1 & 17,2 & 0,6 \\
\hline AL04_14 & 181 & 0,45 & $3.473,688$ & $3,64 \%$ & 0,048 & $5,83 \%$ & 18,5 & 0,7 & 100,8 & 132,5 & 18,5 & 0,7 \\
\hline AL04_13 & 121 & 0,55 & 351,692 & $4,91 \%$ & 0,0426 & $9,34 \%$ & 18,3 & 0,9 & 0 & 26,6 & 18,3 & 0,9 \\
\hline AL04_12 & 70 & 0,66 & $3.602,207$ & $5,12 \%$ & 0,0465 & $12,5 \%$ & 17,9 & 0,9 & 0 & 301,3 & 17,9 & 0,9 \\
\hline AL04_11 & 1477 & 0,94 & $3.664,645$ & $2,35 \%$ & 0,0463 & $2,15 \%$ & 17,6 & 0,4 & 13,6 & 50,9 & 17,6 & 0,4 \\
\hline AL04_8 & 628 & 0,86 & $3.740,156$ & $2,38 \%$ & 0,0461 & $2,87 \%$ & 17,2 & 0,4 & 3 & 67,7 & 17,2 & 0,4 \\
\hline AL04_7 & 184 & 0,49 & $3.769,704$ & $5,16 \%$ & 0,0727 & $6,54 \%$ & 17,1 & 0,9 & 1005,2 & 127,4 & 17,1 & 0,9 \\
\hline AL04_6 & 753 & 1,02 & $3.489,493$ & $2,28 \%$ & 0,0455 & $2,75 \%$ & 18,4 & 0,4 & 0 & 35,9 & 18,4 & 0,4 \\
\hline AL04_3 & 308 & 0,61 & $3.609,426$ & $3,03 \%$ & 0,0515 & $4,45 \%$ & 17,8 & 0,5 & 262,2 & 99,1 & 17,8 & 0,5 \\
\hline AL04_2 & 960 & 0,65 & $3.587,771$ & $2,05 \%$ & 0,048 & $2,36 \%$ & 17,9 & 0,4 & 101,7 & 54,9 & 17,9 & 0,4 \\
\hline AL04_1 & 1064 & 0,66 & $3.561,006$ & $2,00 \%$ & 0,0465 & $2,12 \%$ & 18,1 & 0,4 & 25,5 & 50,1 & 18,1 & 0,4 \\
\hline AL10_24 & 531 & 0,69 & $2.670,501$ & $2,24 \%$ & 0,0479 & $2,57 \%$ & 24,1 & 0,5 & 93,6 & 59,8 & 24,1 & 0,5 \\
\hline AL10_23 & 689 & 0,72 & $2.743,617$ & $1,98 \%$ & 0,0478 & $2,18 \%$ & 23,5 & 0,5 & 87 & 50,8 & 23,5 & 0,5 \\
\hline AL10_22 & 265 & 0,48 & $2.817,258$ & $3,65 \%$ & 0,0562 & $4,61 \%$ & 22,8 & 0,8 & 458,8 & 99,1 & 22,8 & 0,8 \\
\hline AL10_21 & 659 & 0,71 & 269,111 & $2,16 \%$ & 0,0465 & $2,74 \%$ & 23,9 & 0,5 & 25,8 & 64,5 & 23,9 & 0,5 \\
\hline AL10_20 & 885 & 0,8 & $2.655,089$ & $1,63 \%$ & 0,0495 & $1,99 \%$ & 24,2 & 0,4 & 169,8 & 45,9 & 24,2 & 0,4 \\
\hline AL10_19 & 1475 & 0,73 & $2.815,084$ & $2,61 \%$ & 0,0539 & $2,02 \%$ & 22,9 & 0,6 & 365,7 & 45 & 22,9 & 0,6 \\
\hline AL10_18 & 621 & 0,7 & 255,053 & $2,55 \%$ & 0,0612 & $2,72 \%$ & 25,2 & 0,6 & 644,7 & 57,5 & 25,2 & 0,6 \\
\hline AL10_17 & 449 & 0,63 & $2.738,814$ & $1,96 \%$ & 0,0463 & $3,16 \%$ & 23,5 & 0,5 & 15,7 & 74,2 & 23,5 & 0,5 \\
\hline AL10_16 & 161 & 0,82 & $2.751,661$ & $3,25 \%$ & 0,0465 & $5,14 \%$ & 23,4 & 0,8 & 24,7 & 118,8 & 23,4 & 0,8 \\
\hline AL10_15 & 457 & 0,75 & $2.732,414$ & $1,98 \%$ & 0,0465 & $3,38 \%$ & 23,5 & 0,5 & 21,3 & 79,3 & 23,5 & 0,5 \\
\hline AL10_14 & 806 & 0,63 & $2.653,757$ & $2,56 \%$ & 0,049 & $2,22 \%$ & 24,2 & 0,6 & 147,6 & 51,2 & 24,2 & 0,6 \\
\hline AL10_13 & 665 & 0,74 & 287,128 & $1,97 \%$ & 0,0455 & $2,32 \%$ & 22,4 & 0,4 & 0 & 26,6 & 22,4 & 0,4 \\
\hline AL10_12 & 469 & 0,46 & $2.846,863$ & $1,38 \%$ & 0,0465 & $1,75 \%$ & 22,6 & 0,3 & 25,5 & 41,4 & 22,6 & 0,3 \\
\hline AL10_11 & 611 & 0,98 & $2.696,367$ & $2,1 \%$ & 0,0469 & $3,02 \%$ & 23,9 & 0,5 & 42,8 & 70,8 & 23,9 & 0,5 \\
\hline AL10_9 & 1089 & 0,77 & $2.652,861$ & $2,17 \%$ & 0,0518 & $3,11 \%$ & 24,3 & 0,5 & 278,5 & 69,7 & 24,3 & 0,5 \\
\hline AL10_8 & 757 & 0,78 & $2.749,401$ & $2,48 \%$ & 0,0468 & $3,61 \%$ & 23,4 & 0,6 & 38,2 & 84,1 & 23,4 & 0,6 \\
\hline AL10_7 & 435 & 0,67 & $2.733,108$ & $1,37 \%$ & 0,0465 & $1,79 \%$ & 23,5 & 0,3 & 22,4 & 42,4 & 23,5 & 0,3 \\
\hline AL10_6 & 342 & 0,98 & $2.801,689$ & $1,87 \%$ & 0,046 & $2,22 \%$ & 23 & 0,4 & 0,1 & 52,3 & 23 & 0,4 \\
\hline AL10_5 & 206 & 0,74 & $2.656,039$ & $3,26 \%$ & 0,0423 & $4,41 \%$ & 24,2 & 0,8 & 0 & 0 & 24,2 & 0,8 \\
\hline AL10_1 & 520 & 0,6 & $2.604,225$ & $2,26 \%$ & 0,0456 & $2,45 \%$ & 24,7 & 0,6 & 0 & 34,5 & 24,7 & 0,6 \\
\hline
\end{tabular}


continuación apéndice tabla 1 .

\begin{tabular}{|c|c|c|c|c|c|c|c|c|c|c|c|c|}
\hline Muestra & $\begin{array}{c}\mathrm{U} \\
\text { ppm }\end{array}$ & $\begin{array}{c}\text { Th } \\
\mathbf{U}\end{array}$ & $\begin{array}{c}238 \mathrm{U} \\
206 \mathrm{~Pb}\end{array}$ & $\begin{array}{c}1 \sigma \\
\% \text { error }\end{array}$ & $\begin{array}{l}207 \mathrm{~Pb} \\
206 \mathrm{~Pb}\end{array}$ & $\begin{array}{c}1 \sigma \\
\% \text { error }\end{array}$ & $\begin{array}{c}206 / 238 \\
\text { Edad }\end{array}$ & $\begin{array}{c}1 \sigma \\
\text { Error abs }\end{array}$ & $\begin{array}{c}\text { 207/206 } \\
\text { Edad }\end{array}$ & $\begin{array}{c}1 \sigma \\
\text { Error abs }\end{array}$ & Edad & $\begin{array}{c}1 \sigma \\
\text { Error abs } \\
\text { Ma }\end{array}$ \\
\hline AL38_26 & 578 & 0,55 & $3.052,107$ & $1,86 \%$ & 0,0529 & $2,55 \%$ & 21,1 & 0,4 & 325,5 & 56,9 & 21,1 & 0,4 \\
\hline AL38_25 & 558 & 0,58 & $3.026,923$ & $1,88 \%$ & 0,0455 & $2,96 \%$ & 21,3 & 0,4 & 0 & 40,7 & 21,3 & 0,4 \\
\hline AL38_22 & 386 & 0,5 & $2.985,765$ & $2,44 \%$ & 0,0465 & $3,21 \%$ & 21,6 & 0,5 & 22 & 75,3 & 21,6 & 0,5 \\
\hline AL38_21 & 451 & 0,51 & $2.904,132$ & $2,1 \%$ & 0,061 & $2,68 \%$ & 22,2 & 0,5 & 638,7 & 56,7 & 22,2 & 0,5 \\
\hline AL38_20 & 887 & 0,56 & 309,594 & $1,49 \%$ & 0,0538 & $1,99 \%$ & 20,8 & 0,3 & 362,1 & 44,4 & 20,8 & 0,3 \\
\hline AL38_19 & 576 & 0,56 & $3.027,488$ & $1,97 \%$ & 0,0483 & $2,44 \%$ & 21,3 & 0,4 & 116,1 & 56,5 & 21,3 & 0,4 \\
\hline AL38_18 & 496 & 0,48 & $3.050,233$ & $1,9 \%$ & 0,0494 & $2,92 \%$ & 21,1 & 0,4 & 168 & 66,8 & 21,1 & 0,4 \\
\hline AL38_17 & 1099 & 0,86 & $3.133,163$ & $1,76 \%$ & 0,0493 & $1,77 \%$ & 20,5 & 0,4 & 160,5 & 40,9 & 20,5 & 0,4 \\
\hline AL38_15 & 486 & 0,58 & $2.971,295$ & $2,18 \%$ & 0,101 & $2,42 \%$ & 21,7 & 0,5 & 1642,3 & 44,2 & 21,7 & 0,5 \\
\hline AL38_13 & 545 & 0,53 & $3.206,843$ & $2,23 \%$ & 0,0506 & $3,76 \%$ & 20,1 & 0,4 & 220,4 & 84,7 & 20,1 & 0,4 \\
\hline AL38_12 & 370 & 0,6 & $2.928,485$ & $2,36 \%$ & 0,0489 & $3,26 \%$ & 22 & 0,5 & 142,9 & 74,8 & 22 & 0,5 \\
\hline AL38_10 & 578 & 0,49 & $3.077,281$ & $2,69 \%$ & 0,0589 & $3,99 \%$ & 20,9 & 0,6 & 564 & 84,7 & 20,9 & 0,6 \\
\hline AL38_9 & 512 & 0,53 & $3.114,401$ & $1,83 \%$ & 0,0527 & $2,64 \%$ & 20,7 & 0,4 & 314,4 & 58,9 & 20,7 & 0,4 \\
\hline AL38_8 & 362 & 0,49 & $3.139,589$ & $2,1 \%$ & 0,0595 & $2,94 \%$ & 20,5 & 0,4 & 585,7 & 62,6 & 20,5 & 0,4 \\
\hline AL38_4 & 581 & 0,58 & $3.003,787$ & $1,94 \%$ & 0,0639 & $2,56 \%$ & 21,4 & 0,4 & 738,3 & 53,2 & 21,4 & 0,4 \\
\hline AL38_7 & 1044 & 0,91 & $3.186,014$ & $1,91 \%$ & 0,0478 & $2,3 \%$ & 20,2 & 0,4 & 87,1 & 53,7 & 20,2 & 0,4 \\
\hline AL38_6 & 922 & 0,69 & $3.052,714$ & $1,56 \%$ & 0,0462 & $2,07 \%$ & 21,1 & 0,3 & 0 & 57 & 21,1 & 0,3 \\
\hline AL38_5 & 430 & 0,44 & $3.054,342$ & $1,83 \%$ & 0,0469 & $3,43 \%$ & 21,1 & 0,4 & 45,7 & 80 & 21,1 & 0,4 \\
\hline AL38_3 & 453 & 0,56 & $3.083,812$ & $2,03 \%$ & 0,0472 & $3,13 \%$ & 20,9 & 0,4 & 61,3 & 72,9 & 20,9 & 0,4 \\
\hline AL38_1 & 539 & 0,64 & $3.159,347$ & $1,96 \%$ & 0,048 & $2,97 \%$ & 20,4 & 0,4 & 100,5 & 68,8 & 20,4 & 0,4 \\
\hline AL17_30 & 258 & 0,97 & $3.158,059$ & $3,1 \%$ & 0,0477 & $4,49 \%$ & 20,4 & 0,6 & 83,2 & 103,3 & 20,4 & 0,6 \\
\hline AL17_28 & 331 & 0,83 & $3.045,767$ & $2,73 \%$ & 0,0454 & $3,78 \%$ & 21,1 & 0,6 & 0 & 54,6 & 21,1 & 0,6 \\
\hline AL17_27 & 340 & 0,94 & 316,165 & $4,27 \%$ & 0,051 & $6,49 \%$ & 20,4 & 0,9 & 242,7 & 143 & 20,4 & 0,9 \\
\hline AL17_26 & 230 & 0,81 & $2.941,668$ & $2,9 \%$ & 0,0472 & $4,27 \%$ & 21,9 & 0,6 & 57,8 & 98,7 & 21,9 & 0,6 \\
\hline AL17_25 & 259 & 0,83 & $2.912,708$ & $3,05 \%$ & 0,07 & $3,77 \%$ & 22,1 & 0,7 & 927,6 & 75,5 & 22,1 & 0,7 \\
\hline AL17_24 & 244 & 0,97 & $2.974,564$ & $2,07 \%$ & 0,0503 & $4,14 \%$ & 21,6 & 0,4 & 207,8 & 93,2 & 21,6 & 0,4 \\
\hline AL17_23 & 432 & 0,76 & $3.073,281$ & $2,59 \%$ & 0,0506 & $3,25 \%$ & 20,9 & 0,5 & 223,8 & 73,5 & 20,9 & 0,5 \\
\hline AL17_22 & 170 & 0,69 & $3.009,677$ & $3,01 \%$ & 0,0429 & $5,53 \%$ & 21,4 & 0,6 & 0 & 0 & 21,4 & 0,6 \\
\hline AL17_21 & 242 & 0,79 & $3.056,397$ & $2,71 \%$ & 0,0472 & $4,25 \%$ & 21,1 & 0,6 & 61,2 & 98,3 & 21,1 & 0,6 \\
\hline AL17_20 & 354 & 1,16 & $2.940,596$ & $2,57 \%$ & 0,0588 & $3,52 \%$ & 21,9 & 0,6 & 560,9 & 75 & 21,9 & 0,6 \\
\hline AL17_19 & 248 & 0,76 & $3.145,097$ & $3,02 \%$ & 0,0544 & $4,08 \%$ & 20,5 & 0,6 & 386,1 & 89,1 & 20,5 & 0,6 \\
\hline AL17_16 & 276 & 0,88 & $2.947,752$ & $2,65 \%$ & 0,0475 & $3,73 \%$ & 21,8 & 0,6 & 73 & 86,3 & 21,8 & 0,6 \\
\hline AL17_15 & 234 & 0,9 & 309,779 & $2,5 \%$ & 0,0482 & $4,91 \%$ & 20,8 & 0,5 & 109,1 & 112 & 20,8 & 0,5 \\
\hline AL17_14 & 267 & 0,89 & $2.953,451$ & $1,84 \%$ & 0,0809 & $3,41 \%$ & 21,8 & 0,4 & 1219,4 & 65,5 & 21,8 & 0,4 \\
\hline AL17_13 & 258 & 0,64 & $3.009,818$ & $2,28 \%$ & 0,0497 & $3,7 \%$ & 21,4 & 0,5 & 179,4 & 84,1 & 21,4 & 0,5 \\
\hline AL17_11 & 233 & 0,66 & $2.807,976$ & $3,4 \%$ & 0,0959 & $3,38 \%$ & 22,9 & 0,8 & 1545,7 & 62,1 & 22,9 & 0,8 \\
\hline AL17_10 & 218 & 0,8 & 299,782 & $2,44 \%$ & 0,0519 & $4,35 \%$ & 21,5 & 0,5 & 279,2 & 96,6 & 21,5 & 0,5 \\
\hline AL17_9 & 127 & 0,73 & 297,273 & $3,17 \%$ & 0,0434 & $6,94 \%$ & 21,6 & 0,7 & 0 & 20,7 & 21,6 & 0,7 \\
\hline AL17_8 & 372 & 1,05 & $3.198,751$ & $3,68 \%$ & 0,0741 & $6,02 \%$ & 20,1 & 0,7 & 1044 & 117 & 20,1 & 0,7 \\
\hline
\end{tabular}


continuación apéndice tabla 1 .

\begin{tabular}{|c|c|c|c|c|c|c|c|c|c|c|c|c|}
\hline Muestra & $\begin{array}{c}\mathrm{U} \\
\mathrm{ppm}\end{array}$ & $\begin{array}{c}\text { Th } \\
\mathbf{U}\end{array}$ & $\begin{array}{c}238 \mathrm{U} \\
206 \mathrm{~Pb}\end{array}$ & $\begin{array}{c}1 \sigma \\
\% \text { error }\end{array}$ & $\begin{array}{l}207 \mathrm{~Pb} \\
206 \mathrm{~Pb}\end{array}$ & $\begin{array}{c}1 \sigma \\
\% \text { error }\end{array}$ & $\begin{array}{c}206 / 238 \\
\text { Edad }\end{array}$ & $\begin{array}{c}1 \sigma \\
\text { Error abs }\end{array}$ & $\begin{array}{c}\text { 207/206 } \\
\text { Edad }\end{array}$ & $\begin{array}{c}1 \sigma \\
\text { Error abs }\end{array}$ & Edad & $\begin{array}{c}1 \sigma \\
\text { Error abs } \\
\text { Ma }\end{array}$ \\
\hline AL17_7 & 212 & 0,61 & $2.984,054$ & $2,42 \%$ & 0,0493 & $4,38 \%$ & 21,6 & 0,5 & 164,5 & 99,3 & 21,6 & 0,5 \\
\hline AL17_5 & 332 & 0,97 & $3.068,849$ & $2,07 \%$ & 0,045 & $3,98 \%$ & 21 & 0,4 & 0 & 36,4 & 21 & 0,4 \\
\hline AL17_4 & 1700 & 2,47 & $3.133,715$ & $1,08 \%$ & 0,0479 & $1,77 \%$ & 20,5 & 0,2 & 94,7 & 41,3 & 20,5 & 0,2 \\
\hline AL17_6 & 377 & 0,7 & 292,865 & $2,55 \%$ & 0,0525 & $3,08 \%$ & 22 & 0,6 & 307,5 & 68,7 & 22 & 0,6 \\
\hline AL17_3 & 143 & 0,93 & $2.982,528$ & $2,76 \%$ & 0,074 & $5,81 \%$ & 21,6 & 0,6 & 1042,4 & 113 & 21,6 & 0,6 \\
\hline AL17_2 & 235 & 0,75 & $3.081,953$ & $2,08 \%$ & 0,0475 & $4,37 \%$ & 20,9 & 0,4 & 74,2 & 100,7 & 20,9 & 0,4 \\
\hline AL17_1 & 198 & 0,85 & $2.975,142$ & $3,01 \%$ & 0,05 & $5,96 \%$ & 21,6 & 0,6 & 196,4 & 133 & 21,6 & 0,6 \\
\hline AP19_40 & 89 & 0,6 & 686,281 & $2,23 \%$ & 0,0556 & $2,92 \%$ & 93,3 & 2,1 & 435,3 & 63,7 & 93,3 & 2,1 \\
\hline AP19_39 & 150 & 0,73 & 731,758 & $1,89 \%$ & 0,0483 & $2,36 \%$ & 87,5 & 1,6 & 115,9 & 54,8 & 87,5 & 1,6 \\
\hline AP19_38 & 850 & 0,29 & 704,478 & $1,61 \%$ & 0,0487 & $0,84 \%$ & 90,9 & 1,5 & 132,3 & 19,6 & 90,9 & 1,5 \\
\hline AP19_37 & 126 & 0,69 & 725,507 & $2,33 \%$ & 0,0485 & $2,65 \%$ & 88,2 & 2 & 124,9 & 61,3 & 88,2 & 2 \\
\hline AP19_35 & 77 & 0,57 & 72,393 & $2,27 \%$ & 0,0485 & $2,77 \%$ & 88,4 & 2 & 125,9 & 63,9 & 88,4 & 2 \\
\hline AP19_34 & 486 & 0,29 & 607,855 & $1,88 \%$ & 0,0487 & $3,22 \%$ & 105,2 & 2 & 135,3 & 74 & 105,2 & 2 \\
\hline AP19_33 & 960 & 1,07 & 730,461 & $1,79 \%$ & 0,0478 & $1,25 \%$ & 87,7 & 1,6 & 87,1 & 29,5 & 87,7 & 1,6 \\
\hline AP19_32 & 152 & 0,85 & 733,887 & $2,14 \%$ & 0,0481 & $5,36 \%$ & 87,2 & 1,9 & 102,8 & 122 & 87,2 & 1,9 \\
\hline AP19_31 & 353 & 0,91 & 566,339 & $1,74 \%$ & 0,0484 & $1,33 \%$ & 112,8 & 1,9 & 119,6 & 31 & 112,8 & 1,9 \\
\hline AP19_30 & 87 & 0,62 & 725,724 & $2,11 \%$ & 0,049 & $2,89 \%$ & 88,2 & 1,8 & 149,1 & 66,4 & 88,2 & 1,8 \\
\hline AP19_29 & 148 & 0,83 & 734,936 & $2,00 \%$ & 0,0488 & $2,52 \%$ & 87,1 & 1,7 & 139,2 & 58,2 & 87,1 & 1,7 \\
\hline AP19_28 & 157 & 0,68 & 732,262 & $1,93 \%$ & 0,0483 & $2,06 \%$ & 87,4 & 1,7 & 114,6 & 47,9 & 87,4 & 1,7 \\
\hline AP19_27 & 80 & 0,62 & 723,224 & $2,2 \%$ & 0,0486 & $3,03 \%$ & 88,5 & 1,9 & 130,3 & 69,7 & 88,5 & 1,9 \\
\hline AP19_26 & 54 & 0,11 & 699,738 & $2,21 \%$ & 0,0484 & $4,75 \%$ & 91,5 & 2 & 117,3 & 108,4 & 91,5 & 2 \\
\hline AP19_25 & 463 & 1,15 & 730,394 & $1,86 \%$ & 0,0478 & $1,3 \%$ & 87,7 & 1,6 & 91,2 & 30,6 & 87,7 & 1,6 \\
\hline AP19_24 & 119 & 0,74 & 727,107 & $2,04 \%$ & 0,0499 & $2,47 \%$ & 88,1 & 1,8 & 188,8 & 56,5 & 88,1 & 1,8 \\
\hline AP19_23 & 122 & 0,8 & 712,176 & $2,02 \%$ & 0,0508 & $2,52 \%$ & 89,9 & 1,8 & 230,3 & 57,1 & 89,9 & 1,8 \\
\hline AP19_22 & 137 & 0,67 & 739,928 & $1,94 \%$ & 0,0469 & $2,53 \%$ & 86,5 & 1,7 & 44,1 & 59,3 & 86,5 & 1,7 \\
\hline AP19_21 & 156 & 0,84 & 726,344 & $1,75 \%$ & 0,0475 & $2,32 \%$ & 88,1 & 1,5 & 77,3 & 52,5 & 88,1 & 1,5 \\
\hline AP19_20 & 117 & 0,7 & 735,777 & $2,1 \%$ & 0,049 & $2,93 \%$ & 87 & 1,8 & 149 & 67,4 & 87 & 1,8 \\
\hline AP19_19 & 229 & 0,75 & 660,118 & $1,73 \%$ & 0,0489 & $1,91 \%$ & 96,9 & 1,7 & 143,9 & 44,2 & 96,9 & 1,7 \\
\hline AP19_18 & 98 & 0,82 & 727,919 & $2,04 \%$ & 0,0505 & $2,65 \%$ & 88 & 1,8 & 216,3 & 60,1 & 88 & 1,8 \\
\hline AP19_17 & 127 & 0,81 & 724,014 & $2,2 \%$ & 0,0482 & $2,89 \%$ & 88,4 & 1,9 & 109,2 & 66,9 & 88,4 & 1,9 \\
\hline AP19_16 & 98 & 0,77 & 737,292 & $2,19 \%$ & 0,0487 & $2,89 \%$ & 86,8 & 1,9 & 132,7 & 66,7 & 86,8 & 1,9 \\
\hline AP19_14 & 96 & 0,73 & 614,242 & $3,29 \%$ & 0,0515 & $6,01 \%$ & 104,1 & 3,4 & 261,3 & 132,5 & 104,1 & 3,4 \\
\hline AP19_13 & 117 & 0,65 & 733,801 & $2,13 \%$ & 0,0498 & $2,71 \%$ & 87,3 & 1,8 & 187,8 & 61,9 & 87,3 & 1,8 \\
\hline AP19_12 & 594 & 1,7 & 726,436 & $2,03 \%$ & 0,0477 & $1,89 \%$ & 88,1 & 1,8 & 82,9 & 44,2 & 88,1 & 1,8 \\
\hline AP19_11 & 79 & 0,66 & 725,316 & $2,17 \%$ & 0,0502 & $2,94 \%$ & 88,3 & 1,9 & 204 & 66,9 & 88,3 & 1,9 \\
\hline AP19_10 & 102 & 0,75 & 750,372 & $2,5 \%$ & 0,054 & $3,44 \%$ & 85,3 & 2,1 & 370,8 & 75,6 & 85,3 & 2,1 \\
\hline AP19_9 & 202 & 0,92 & 736,011 & $1,85 \%$ & 0,0481 & $2,03 \%$ & 87 & 1,6 & 103 & 47,4 & 87 & 1,6 \\
\hline AP19_8 & 115 & 0,77 & 727,756 & $1,88 \%$ & 0,0497 & $2,67 \%$ & 88 & 1,6 & 181,9 & 61 & 88 & 1,6 \\
\hline AP19_7 & 100 & 0,77 & 747,167 & $2,14 \%$ & 0,0556 & $3,09 \%$ & 85,7 & 1,8 & 436,1 & 67,4 & 85,7 & 1,8 \\
\hline
\end{tabular}


continuación apéndice tabla 1 .

\begin{tabular}{|c|c|c|c|c|c|c|c|c|c|c|c|c|}
\hline Muestra & $\begin{array}{c}\mathrm{U} \\
\mathrm{ppm}\end{array}$ & $\begin{array}{c}\text { Th } \\
\mathbf{U}\end{array}$ & $\begin{array}{c}238 \mathrm{U} \\
206 \mathrm{~Pb}\end{array}$ & $\begin{array}{c}1 \sigma \\
\% \text { error }\end{array}$ & $\begin{array}{l}207 \mathrm{~Pb} \\
206 \mathrm{~Pb}\end{array}$ & $\begin{array}{c}1 \sigma \\
\% \text { error }\end{array}$ & $\begin{array}{c}206 / 238 \\
\text { Edad }\end{array}$ & $\begin{array}{c}1 \sigma \\
\text { Error abs }\end{array}$ & $\begin{array}{c}\text { 207/206 } \\
\text { Edad }\end{array}$ & $\begin{array}{c}1 \sigma \\
\text { Error abs }\end{array}$ & Edad & $\begin{array}{c}1 \sigma \\
\text { Error abs } \\
\text { Ma }\end{array}$ \\
\hline AP19_6 & 100 & 0,61 & 72,54 & $1,98 \%$ & 0,0487 & $3,07 \%$ & 88,3 & 1,7 & 134,5 & 70,6 & 88,3 & 1,7 \\
\hline AP19_5 & 232 & 0,85 & 746,429 & $1,85 \%$ & 0,0478 & $1,84 \%$ & 85,8 & 1,6 & 87 & 43 & 85,8 & 1,6 \\
\hline AP19_4 & 152 & 0,92 & 736,674 & $1,89 \%$ & 0,0524 & $2,66 \%$ & 86,9 & 1,6 & 301,1 & 59,6 & 86,9 & 1,6 \\
\hline AP19_3 & 165 & 0,7 & 73,17 & $1,94 \%$ & 0,0501 & $1,97 \%$ & 87,5 & 1,7 & 199,8 & 45,1 & 87,5 & 1,7 \\
\hline AP19_2 & 1525 & 0,11 & 727,165 & $1,76 \%$ & 0,0474 & $0,9 \%$ & 88 & 1,5 & 67,9 & 21,2 & 88 & 1,5 \\
\hline AP19_1 & 79 & 0,6 & 727,173 & $2,84 \%$ & 0,0492 & $3,51 \%$ & 88 & 2,5 & 157,5 & 80,1 & 88 & 2,5 \\
\hline AL22_68 & 2612 & 1,01 & $3.057,611$ & $1,81 \%$ & 0,0464 & $1,53 \%$ & 21 & 0,4 & 0,3 & 55,2 & 21 & 0,4 \\
\hline AL22_67 & 589 & 0,53 & $3.104,439$ & $1,91 \%$ & 0,0499 & $2,1 \%$ & 20,7 & 0,4 & 190,9 & 48 & 20,7 & 0,4 \\
\hline AL22_66 & 727 & 0,65 & $3.008,516$ & $1,83 \%$ & 0,0503 & $2,1 \%$ & 21,4 & 0,4 & 209,2 & 48 & 21,4 & 0,4 \\
\hline AL22_65 & 1126 & 0,89 & $2.888,245$ & $1,76 \%$ & 0,0714 & $1,69 \%$ & 22,3 & 0,4 & 967,7 & 34,1 & 22,3 & 0,4 \\
\hline AL22_64 & 535 & 0,6 & $2.615,263$ & $2,64 \%$ & 0,0625 & $2,59 \%$ & 24,6 & 0,6 & 692,5 & 54,2 & 24,6 & 0,6 \\
\hline AL22_63 & 822 & 0,69 & 308,025 & $1,76 \%$ & 0,0511 & $1,59 \%$ & 20,9 & 0,4 & 243,1 & 36,2 & 20,9 & 0,4 \\
\hline AL22_62 & 1045 & 0,78 & $2.882,938$ & $1,96 \%$ & 0,0533 & $1,87 \%$ & 22,3 & 0,4 & 343,3 & 41,9 & 22,3 & 0,4 \\
\hline AL22_61 & 459 & 0,36 & $2.515,571$ & $3,99 \%$ & 0,0525 & $5,86 \%$ & 25,6 & 1 & 308,4 & 128,3 & 25,6 & 1 \\
\hline AL22_60 & 3199 & 0,99 & $2.720,591$ & $1,72 \%$ & 0,0592 & $1,08 \%$ & 23,7 & 0,4 & 574 & 23,4 & 23,7 & 0,4 \\
\hline AL22_59 & 548 & 0,91 & $1.824,733$ & $1,67 \%$ & 0,0482 & $14,92 \%$ & 35,2 & 0,6 & 110,3 & 318,9 & 35,2 & 0,6 \\
\hline AL22_58 & 1546 & 1,01 & $2.928,291$ & $1,69 \%$ & 0,0576 & $1,67 \%$ & 22 & 0,4 & 516,1 & 36,2 & 22 & 0,4 \\
\hline AL22_57 & 1559 & 0,53 & $2.906,926$ & $1,64 \%$ & 0,0479 & $1,41 \%$ & 22,1 & 0,4 & 92,8 & 33 & 22,1 & 0,4 \\
\hline AL22_56 & 1281 & 0,99 & $2.987,882$ & $1,72 \%$ & 0,0477 & $1,58 \%$ & 21,5 & 0,4 & 86 & 37,1 & 21,5 & 0,4 \\
\hline AL22_55 & 790 & 0,64 & $3.159,382$ & $2,32 \%$ & 0,0599 & $1,83 \%$ & 20,4 & 0,5 & 598,8 & 39,1 & 20,4 & 0,5 \\
\hline AL22_54 & 615 & 0,97 & $2.267,225$ & $2,32 \%$ & 0,0464 & $2,3 \%$ & 28,4 & 0,7 & 15,8 & 56 & 28,4 & 0,7 \\
\hline AL22_53 & 906 & 0,59 & $2.856,839$ & $4,45 \%$ & 0,0497 & $2,32 \%$ & 22,5 & 1 & 179,8 & 53,3 & 22,5 & 1 \\
\hline AL22_52 & 551 & 0,73 & 295,644 & $2,05 \%$ & 0,0471 & $2,12 \%$ & 21,8 & 0,4 & 54,6 & 49,7 & 21,8 & 0,4 \\
\hline AL22_51 & 879 & 0,71 & $2.869,942$ & $1,7 \%$ & 0,0539 & $1,92 \%$ & 22,4 & 0,4 & 365 & 42,7 & 22,4 & 0,4 \\
\hline AL22_50 & 623 & 0,55 & 286,876 & $1,89 \%$ & 0,0463 & $2,08 \%$ & 22,4 & 0,4 & 0 & 62,8 & 22,4 & 0,4 \\
\hline AL22_49 & 2126 & 0,6 & $2.975,616$ & $1,7 \%$ & 0,0476 & $1,3 \%$ & 21,6 & 0,4 & 77,7 & 30,5 & 21,6 & 0,4 \\
\hline AL22_48 & 1501 & 0,56 & $2.874,951$ & $1,55 \%$ & 0,0518 & $1,35 \%$ & 22,4 & 0,3 & 274,4 & 30,6 & 22,4 & 0,3 \\
\hline AL22_47 & 837 & 1,16 & $2.926,823$ & $2,09 \%$ & 0,0504 & $2,00 \%$ & 22 & 0,5 & 214,5 & 45,7 & 22 & 0,5 \\
\hline AL22_46 & 863 & 0,58 & $2.939,841$ & $1,93 \%$ & 0,0506 & $2,02 \%$ & 21,9 & 0,4 & 222,5 & 46 & 21,9 & 0,4 \\
\hline AL22_45 & 611 & 0,63 & $2.843,699$ & $2,02 \%$ & 0,05 & $2,54 \%$ & 22,6 & 0,5 & 193,9 & 58 & 22,6 & 0,5 \\
\hline AL22_44 & 709 & 0,63 & 296,646 & $1,86 \%$ & 0,0473 & $2,05 \%$ & 21,7 & 0,4 & 65,4 & 48,2 & 21,7 & 0,4 \\
\hline AL22_43 & 1141 & 1,09 & $3.021,392$ & $3,84 \%$ & 0,0589 & $2,41 \%$ & 21,3 & 0,8 & 561,6 & 51,7 & 21,3 & 0,8 \\
\hline AL22_42 & 1283 & 0,59 & $2.980,766$ & $2,03 \%$ & 0,0466 & $2,4 \%$ & 21,6 & 0,4 & 28,3 & 56,5 & 21,6 & 0,4 \\
\hline AL22_41 & 1041 & 0,74 & $2.787,932$ & $2,08 \%$ & 0,0653 & $1,94 \%$ & 23,1 & 0,5 & 785 & 40,2 & 23,1 & 0,5 \\
\hline AL22_40 & 952 & 0,64 & $2.923,544$ & $1,94 \%$ & 0,0497 & $1,83 \%$ & 22 & 0,4 & 182,7 & 42,1 & 22 & 0,4 \\
\hline AL22_39 & 604 & 0,85 & $2.985,571$ & $1,92 \%$ & 0,0526 & $2,39 \%$ & 21,6 & 0,4 & 311,1 & 53,5 & 21,6 & 0,4 \\
\hline AL22_38 & 821 & 0,49 & $2.956,729$ & $1,88 \%$ & 0,0524 & $1,9 \%$ & 21,8 & 0,4 & 303,9 & 42,6 & 21,8 & 0,4 \\
\hline AL22_37 & 1281 & 0,67 & $2.901,599$ & $1,74 \%$ & 0,0603 & $1,46 \%$ & 22,2 & 0,4 & 614,3 & 31,3 & 22,2 & 0,4 \\
\hline AL22_36 & 538 & 0,73 & $2.917,603$ & $1,93 \%$ & 0,0707 & $2,45 \%$ & 22,1 & 0,4 & 948,8 & 49,3 & 22,1 & 0,4 \\
\hline
\end{tabular}


continuación apéndice tabla 1.

\begin{tabular}{|c|c|c|c|c|c|c|c|c|c|c|c|c|}
\hline Muestra & $\begin{array}{c}\mathrm{U} \\
\mathrm{ppm}\end{array}$ & $\begin{array}{c}\text { Th } \\
\text { U }\end{array}$ & $\begin{array}{c}238 \mathrm{U} \\
206 \mathrm{~Pb}\end{array}$ & $\begin{array}{c}1 \sigma \\
\% \text { error }\end{array}$ & $\begin{array}{l}207 \mathrm{~Pb} \\
206 \mathrm{~Pb}\end{array}$ & $\begin{array}{c}1 \sigma \\
\% \text { error }\end{array}$ & $\begin{array}{c}206 / 238 \\
\text { Edad }\end{array}$ & $\begin{array}{c}1 \sigma \\
\text { Error abs }\end{array}$ & $\begin{array}{c}\text { 207/206 } \\
\text { Edad }\end{array}$ & $\begin{array}{c}1 \sigma \\
\text { Error abs }\end{array}$ & Edad & $\begin{array}{c}1 \sigma \\
\text { Error abs } \\
\text { Ma }\end{array}$ \\
\hline AL22_34 & 941 & 0,7 & $2.898,555$ & $1,88 \%$ & 0,0519 & $1,73 \%$ & 22,2 & 0,4 & 283 & 39,1 & 22,2 & 0,4 \\
\hline AL22_33 & 721 & 0,72 & $2.916,156$ & $1,72 \%$ & 0,0485 & $1,98 \%$ & 22,1 & 0,4 & 125,1 & 45,9 & 22,1 & 0,4 \\
\hline AL22_32 & 871 & 0,73 & $2.677,674$ & $1,82 \%$ & 0,0667 & $1,74 \%$ & 24 & 0,4 & 827,6 & 35,9 & 24 & 0,4 \\
\hline AL22_31 & 772 & 0,53 & $3.107,105$ & $1,92 \%$ & 0,0478 & $1,84 \%$ & 20,7 & 0,4 & 90 & 43 & 20,7 & 0,4 \\
\hline AL22_30 & 1044 & 0,62 & $2.904,665$ & $1,72 \%$ & 0,048 & $1,77 \%$ & 22,2 & 0,4 & 98,5 & 41,5 & 22,2 & 0,4 \\
\hline AL22_29 & 496 & 0,51 & $2.802,055$ & $1,93 \%$ & 0,0453 & $2,66 \%$ & 23 & 0,4 & 0 & 23,5 & 23 & 0,4 \\
\hline AL22_28 & 771 & 0,62 & $2.953,871$ & $1,86 \%$ & 0,0503 & $1,9 \%$ & 21,8 & 0,4 & 210,4 & 43,6 & 21,8 & 0,4 \\
\hline AL22_27 & 1294 & 0,53 & $2.999,355$ & $1,97 \%$ & 0,0561 & $2,02 \%$ & 21,5 & 0,4 & 456 & 44,2 & 21,5 & 0,4 \\
\hline AL22_26 & 410 & 1,15 & $2.789,859$ & $1,96 \%$ & 0,0455 & $2,73 \%$ & 23,1 & 0,5 & 0 & 36,6 & 23,1 & 0,5 \\
\hline AL22_25 & 649 & 0,48 & 296,091 & $2,03 \%$ & 0,0551 & $2,77 \%$ & 21,7 & 0,4 & 418,3 & 60,8 & 21,7 & 0,4 \\
\hline AL22_24 & 1447 & 0,65 & $2.527,844$ & $2,03 \%$ & 0,0481 & $1,56 \%$ & 25,5 & 0,5 & 105,3 & 36,5 & 25,5 & 0,5 \\
\hline AL22_23 & 880 & 0,66 & $3.371,795$ & $7,78 \%$ & 0,0508 & $3,02 \%$ & 19,1 & 1,5 & 231,1 & 68,2 & 19,1 & 1,5 \\
\hline AL22_22 & 3479 & 1,75 & $2.966,049$ & $1,71 \%$ & 0,0517 & $1,1 \%$ & 21,7 & 0,4 & 272,4 & 25 & 21,7 & 0,4 \\
\hline AL22_21 & 1523 & 0,7 & $2.827,356$ & $2,11 \%$ & 0,056 & $2,21 \%$ & 22,8 & 0,5 & 452,1 & 48,3 & 22,8 & 0,5 \\
\hline AL22_20 & 664 & 0,55 & $2.937,238$ & $1,95 \%$ & 0,064 & $2,31 \%$ & 21,9 & 0,4 & 740,8 & 48,2 & 21,9 & 0,4 \\
\hline AL22_19 & 691 & 0,59 & $2.967,345$ & $2,28 \%$ & 0,0499 & $2,41 \%$ & 21,7 & 0,5 & 188,8 & 55,2 & 21,7 & 0,5 \\
\hline AL22_18 & 1679 & 1,12 & $3.010,418$ & $1,65 \%$ & 0,0495 & $1,53 \%$ & 21,4 & 0,4 & 172,7 & 35,3 & 21,4 & 0,4 \\
\hline AL22_17 & 1020 & 0,87 & $2.885,187$ & $1,73 \%$ & 0,0463 & $1,92 \%$ & 22,3 & 0,4 & 11 & 45,5 & 22,3 & 0,4 \\
\hline AL22_16 & 1639 & 0,64 & $3.013,258$ & $1,7 \%$ & 0,052 & $1,57 \%$ & 21,4 & 0,4 & 286,2 & 35,5 & 21,4 & 0,4 \\
\hline AL22_15 & 1181 & 0,58 & $2.967,172$ & $1,72 \%$ & 0,0507 & $1,76 \%$ & 21,7 & 0,4 & 228,5 & 40,2 & 21,7 & 0,4 \\
\hline AL22_14 & 643 & 0,6 & $2.944,795$ & $1,9 \%$ & 0,0453 & $2,17 \%$ & 21,9 & 0,4 & 0 & 13 & 21,9 & 0,4 \\
\hline AL22_13 & 824 & 0,64 & $2.885,105$ & $1,94 \%$ & 0,0464 & $2,00 \%$ & 22,3 & 0,4 & 17 & 47,3 & 22,3 & 0,4 \\
\hline AL22_12 & 1680 & 0,71 & $2.979,985$ & $2,08 \%$ & 0,0484 & $1,71 \%$ & 21,6 & 0,4 & 119,5 & 39,8 & 21,6 & 0,4 \\
\hline AL22_11 & 750 & 0,71 & $2.903,559$ & $1,71 \%$ & 0,0465 & $2,02 \%$ & 22,2 & 0,4 & 24,9 & 47,7 & 22,2 & 0,4 \\
\hline AL22_10 & 1605 & 0,77 & $2.988,323$ & $1,65 \%$ & 0,051 & $1,49 \%$ & 21,5 & 0,4 & 242,3 & 34,1 & 21,5 & 0,4 \\
\hline AL22_9 & 381 & 0,76 & $2.901,411$ & $2,12 \%$ & 0,047 & $3,2 \%$ & 22,2 & 0,5 & 51 & 74,6 & 22,2 & 0,5 \\
\hline AL22_8 & 1130 & 1,59 & $3.184,621$ & $2,00 \%$ & 0,0598 & $2,09 \%$ & 20,2 & 0,4 & 597,7 & 44,7 & 20,2 & 0,4 \\
\hline AL22_7 & 2395 & 1,95 & $2.689,704$ & $1,65 \%$ & 0,0452 & $1,11 \%$ & 23,9 & 0,4 & 0 & 0 & 23,9 & 0,4 \\
\hline AL22_6 & 950 & 0,79 & $2.787,391$ & $2,79 \%$ & 0,0525 & $2,3 \%$ & 23,1 & 0,6 & 305,9 & 51,6 & 23,1 & 0,6 \\
\hline AL22_5 & 928 & 0,64 & $2.888,235$ & $1,75 \%$ & 0,0552 & $2,12 \%$ & 22,3 & 0,4 & 418,8 & 46,6 & 22,3 & 0,4 \\
\hline AL22_4 & 721 & 0,47 & $2.971,477$ & $1,97 \%$ & 0,0737 & $1,89 \%$ & 21,7 & 0,4 & 1032,6 & 37,8 & 21,7 & 0,4 \\
\hline AL22_3 & 1115 & 0,72 & $2.857,772$ & $1,85 \%$ & 0,0499 & $1,77 \%$ & 22,5 & 0,4 & 188,1 & 40,7 & 22,5 & 0,4 \\
\hline AL22_2 & 1405 & 0,68 & $3.017,576$ & $2,29 \%$ & 0,0503 & $2,23 \%$ & 21,3 & 0,5 & 208,4 & 51 & 21,3 & 0,5 \\
\hline CS03_53 & 499 & 0,66 & 789,091 & $2,32 \%$ & 0,0531 & $1,73 \%$ & 81,2 & 1,9 & 333,8 & 38,8 & 81,2 & 1,9 \\
\hline CS03_51 & 6079 & 1,84 & 739,087 & $2,16 \%$ & 0,0511 & $0,89 \%$ & 86,6 & 1,9 & 245,6 & 20,3 & 86,6 & 1,9 \\
\hline CS03_49 & 632 & 0,7 & 768,309 & $2,17 \%$ & 0,049 & $1,34 \%$ & 83,4 & 1,8 & 148,5 & 31,2 & 83,4 & 1,8 \\
\hline $\mathrm{CS} 03 \_48$ & 698 & 0,64 & 78,612 & $2,32 \%$ & 0,0475 & $1,23 \%$ & 81,5 & 1,9 & 71,9 & 29,1 & 81,5 & 1,9 \\
\hline CS03_47 & 659 & 0,52 & 782,779 & $2,19 \%$ & 0,0493 & $1,21 \%$ & 81,8 & 1,8 & 161,1 & 28,1 & 81,8 & 1,8 \\
\hline $\mathrm{CS} 03 \_46$ & 632 & 0,6 & 816,303 & $2,34 \%$ & 0,0488 & $1,32 \%$ & 78,5 & 1,8 & 138,4 & 30,7 & 78,5 & 1,8 \\
\hline CS03_45 & 963 & 0,67 & 783,169 & $2,23 \%$ & 0,0476 & $1,12 \%$ & 81,8 & 1,8 & 78,1 & 26,4 & 81,8 & 1,8 \\
\hline
\end{tabular}


continuación apéndice tabla 1.

\begin{tabular}{|c|c|c|c|c|c|c|c|c|c|c|c|c|}
\hline Muestra & $\begin{array}{c}\mathrm{U} \\
\mathrm{ppm}\end{array}$ & $\begin{array}{c}\text { Th } \\
\text { U }\end{array}$ & $\begin{array}{c}238 \mathrm{U} \\
206 \mathrm{~Pb}\end{array}$ & $\begin{array}{c}1 \sigma \\
\% \text { error }\end{array}$ & $\begin{array}{l}207 \mathrm{~Pb} \\
206 \mathrm{~Pb}\end{array}$ & $\begin{array}{c}1 \sigma \\
\% \text { error }\end{array}$ & $\begin{array}{c}206 / 238 \\
\text { Edad }\end{array}$ & $\begin{array}{c}1 \sigma \\
\text { Error abs }\end{array}$ & $\begin{array}{c}207 / 206 \\
\text { Edad }\end{array}$ & $\begin{array}{c}1 \sigma \\
\text { Error abs }\end{array}$ & Edad & $\begin{array}{c}1 \sigma \\
\text { Error abs } \\
\text { Ma }\end{array}$ \\
\hline CS03_44 & 544 & 0,61 & 799,237 & $2,24 \%$ & 0,049 & $1,48 \%$ & 80,2 & 1,8 & 148,3 & 34,3 & 80,2 & 1,8 \\
\hline CSO3_43 & 1367 & 0,72 & 823,458 & $1,82 \%$ & 0,0492 & $1,28 \%$ & 77,8 & 1,4 & 158,4 & 29,6 & 77,8 & 1,4 \\
\hline CSO3_42 & 359 & 0,47 & 789,398 & $1,72 \%$ & 0,0535 & $1,87 \%$ & 81,1 & 1,4 & 351,4 & 41,7 & 81,1 & 1,4 \\
\hline CS03_41 & 401 & 0,55 & 785,384 & $1,71 \%$ & 0,0493 & $1,51 \%$ & 81,6 & 1,4 & 162,2 & 34,8 & 81,6 & 1,4 \\
\hline $\mathrm{CS} 03 \_40$ & 696 & 0,6 & 768,629 & $1,62 \%$ & 0,0504 & $1,18 \%$ & 83,3 & 1,3 & 213 & 27,2 & 83,3 & 1,3 \\
\hline CS03_39 & 1020 & 0,88 & 786,153 & $1,91 \%$ & 0,0475 & $1,09 \%$ & 81,5 & 1,5 & 71,9 & 25,9 & 81,5 & 1,5 \\
\hline $\mathrm{CS} 03 \_38$ & 92 & 0,83 & 732,231 & $2,16 \%$ & 0,091 & $2,66 \%$ & 87,4 & 1,9 & 1446,9 & 49,9 & 87,4 & 1,9 \\
\hline CS03_37 & 786 & 0,71 & 786,606 & $1,59 \%$ & 0,0468 & $1,17 \%$ & 81,4 & 1,3 & 36,9 & 28 & 81,4 & 1,3 \\
\hline CS03_35 & 442 & 0,56 & 771,678 & $1,63 \%$ & 0,0511 & $1,39 \%$ & 83 & 1,3 & 244,8 & 31,7 & 83 & 1,3 \\
\hline CS03_34 & 654 & 0,55 & 791,414 & $1,6 \%$ & 0,0493 & $1,21 \%$ & 80,9 & 1,3 & 163,8 & 28 & 80,9 & 1,3 \\
\hline CS03_33 & 364 & 0,58 & 717,396 & $1,95 \%$ & 0,0678 & $1,64 \%$ & 89,2 & 1,7 & 863,8 & 33,7 & 89,2 & 1,7 \\
\hline $\mathrm{CS} 03 \_32$ & 493 & 0,68 & 827,755 & $1,71 \%$ & 0,0488 & $1,34 \%$ & 77,4 & 1,3 & 137,7 & 31,1 & 77,4 & 1,3 \\
\hline CSO3_31 & 1147 & 1,03 & 789,106 & $2,03 \%$ & 0,0524 & $1,57 \%$ & 81,2 & 1,6 & 302,1 & 35,5 & 81,2 & 1,6 \\
\hline CS03_30 & 591 & 0,6 & 764,009 & $1,69 \%$ & 0,0496 & $1,19 \%$ & 83,8 & 1,4 & 177,4 & 27,5 & 83,8 & 1,4 \\
\hline CS03_29 & 437 & 0,51 & 780,067 & $1,67 \%$ & 0,0484 & $1,44 \%$ & 82,1 & 1,4 & 120,7 & 33,6 & 82,1 & 1,4 \\
\hline CS03_28 & 1994 & 1,00 & 791,679 & $1,58 \%$ & 0,0502 & $0,84 \%$ & 80,9 & 1,3 & 205,4 & 19,5 & 80,9 & 1,3 \\
\hline CS03_27 & 425 & 0,51 & 819,671 & $1,66 \%$ & 0,0482 & $1,47 \%$ & 78,2 & 1,3 & 110,9 & 34,4 & 78,2 & 1,3 \\
\hline CS03_26 & 702 & 0,58 & 791,325 & $1,58 \%$ & 0,0481 & $1,05 \%$ & 81 & 1,3 & 104,8 & 24,7 & 81 & 1,3 \\
\hline CS03_25 & 531 & 0,53 & 776,428 & $1,54 \%$ & 0,0479 & $1,26 \%$ & 82,5 & 1,3 & 92,8 & 29,6 & 82,5 & 1,3 \\
\hline CS03_23 & 685 & 0,62 & 772,748 & $1,59 \%$ & 0,0496 & $1,13 \%$ & 82,9 & 1,3 & 176,7 & 26,2 & 82,9 & 1,3 \\
\hline CS03_22 & 531 & 0,64 & 770,857 & $1,67 \%$ & 0,0542 & $1,36 \%$ & 83,1 & 1,4 & 380,3 & 30,4 & 83,1 & 1,4 \\
\hline CS03_21 & 433 & 0,64 & 780,649 & $1,63 \%$ & 0,0535 & $1,28 \%$ & 82,1 & 1,3 & 352 & 28,6 & 82,1 & 1,3 \\
\hline CS03_20 & 458 & 0,55 & 802,012 & $1,7 \%$ & 0,0485 & $1,3 \%$ & 79,9 & 1,3 & 125,9 & 30,2 & 79,9 & 1,3 \\
\hline CS03_19 & 73 & 0,7 & 846,209 & $3,14 \%$ & 0,0504 & $3,52 \%$ & 75,7 & 2,4 & 214,7 & 79,6 & 75,7 & 2,4 \\
\hline CS03_17 & 965 & 0,63 & 794,371 & $1,64 \%$ & 0,0477 & $1,07 \%$ & 80,6 & 1,3 & 84,9 & 25,1 & 80,6 & 1,3 \\
\hline CS03_16 & 948 & 0,94 & 79,942 & $1,59 \%$ & 0,0477 & $1,16 \%$ & 80,1 & 1,3 & 86,4 & 27,3 & 80,1 & 1,3 \\
\hline CS03_15 & 633 & 0,55 & 727,037 & $1,82 \%$ & 0,0488 & $1,34 \%$ & 88,1 & 1,6 & 140,1 & 31,2 & 88,1 & 1,6 \\
\hline CS03_14 & 567 & 0,62 & 769,162 & $1,63 \%$ & 0,048 & $1,3 \%$ & 83,3 & 1,3 & 101,1 & 30,4 & 83,3 & 1,3 \\
\hline CS03_13 & 435 & 0,59 & 744,647 & $1,74 \%$ & 0,0471 & $1,48 \%$ & 86 & 1,5 & 52,5 & 34,9 & 86 & 1,5 \\
\hline CS03_11 & 645 & 0,54 & 78,233 & $1,54 \%$ & 0,0468 & $1,24 \%$ & 81,9 & 1,3 & 39,4 & 29,5 & 81,9 & 1,3 \\
\hline CS03_10 & 767 & 0,7 & 771,407 & $1,61 \%$ & 0,0486 & $1,00 \%$ & 83 & 1,3 & 129,4 & 23,5 & 83 & 1,3 \\
\hline CSO3_9 & 407 & 0,48 & 770,759 & $1,59 \%$ & 0,049 & $1,62 \%$ & 83,1 & 1,3 & 147,8 & 37,6 & 83,1 & 1,3 \\
\hline CSO3_8 & 469 & 0,88 & 681,089 & $3,49 \%$ & 0,0554 & $1,85 \%$ & 94 & 3,3 & 427,3 & 40,7 & 94 & 3,3 \\
\hline CS03_6 & 493 & 0,45 & 760,558 & $1,61 \%$ & 0,0507 & $1,25 \%$ & 84,2 & 1,3 & 228,7 & 28,6 & 84,2 & 1,3 \\
\hline $\mathrm{CS} 03 \_5$ & 760 & 0,81 & 700,815 & $2,65 \%$ & 0,053 & $3,95 \%$ & 91,3 & 2,4 & 328,5 & 87,2 & 91,3 & 2,4 \\
\hline CS03_4 & 387 & 0,46 & 745,674 & $2,23 \%$ & 0,0499 & $1,65 \%$ & 85,9 & 1,9 & 189,6 & 37,9 & 85,9 & 1,9 \\
\hline CS03_3 & 531 & 0,58 & 776,906 & $1,62 \%$ & 0,0494 & $1,22 \%$ & 82,4 & 1,3 & 164,9 & 28,4 & 82,4 & 1,3 \\
\hline CS03_2 & 937 & 0,76 & 789,584 & $1,94 \%$ & 0,0487 & $1,04 \%$ & 81,1 & 1,6 & 131,6 & 24,2 & 81,1 & 1,6 \\
\hline CS03_1 & 601 & 0,45 & 775,138 & $1,62 \%$ & 0,0477 & $1,29 \%$ & 82,6 & 1,3 & 83,6 & 30,3 & 82,6 & 1,3 \\
\hline
\end{tabular}


APÉNDICE TABLA 2. RESUMEN DE RESULTADOS PARA LA MUESTRA RR-01 MEDIANTE U/PB SHRIMP.

\begin{tabular}{|c|c|c|c|c|c|c|c|c|c|c|c|c|c|c|}
\hline \multirow{3}{*}{$\begin{array}{l}\text { RR-01 } \\
\text { Puntos }\end{array}$} & \multirow{3}{*}{$\begin{array}{c}\mathbf{U} \\
\mathbf{p p m}\end{array}$} & \multirow{3}{*}{$\begin{array}{c}\text { Th } \\
\text { ppm }\end{array}$} & \multirow[t]{2}{*}{$\mathbf{T h} / \mathbf{U}$} & \multirow[t]{2}{*}{${ }^{206} \mathrm{~Pb}^{*}$} & \multirow[t]{2}{*}{${ }^{204} \mathrm{~Pb} /$} & \multirow[t]{2}{*}{$\mathbf{f}^{206}$} & \multicolumn{4}{|c|}{ Total } & \multicolumn{4}{|c|}{ Edad (Ma) } \\
\hline & & & & & & & ${ }^{238} \mathrm{U} /$ & \pm & ${ }^{207} \mathrm{U} /$ & & ${ }^{206} \mathrm{~Pb}$ & & ${ }^{206} \mathrm{~Pb}$ & \\
\hline & & & & $(\mathrm{ppm})$ & ${ }^{206} \mathrm{~Pb}$ & $\%$ & ${ }^{206} \mathrm{~Pb}$ & & ${ }^{206} \mathrm{~Pb}$ & \pm & ${ }^{238} \mathbf{U} /$ & \pm & ${ }^{238} \mathrm{U} /$ & \pm \\
\hline 1,1 & 108 & 82 & 0,76 & 0,4 & 0,002652 & 3,9 & 229,3 & 5,3 & 0,0774 & 0,0044 & 0,0042 & 0,0001 & 27,0 & 0,6 \\
\hline 2,1 & 163 & 131 & 0,8 & 0,6 & 0,005645 & 2,86 & 240,9 & 4,1 & 0,0691 & 0,0032 & 0,004 & 0,0001 & 25,9 & 0,4 \\
\hline 3,1 & 100 & 65 & 0,66 & 0,4 & - & 2,53 & 237,0 & 4,7 & 0,0666 & 0,0041 & 0,0041 & 0,0001 & 26,5 & 0,5 \\
\hline 4,1 & 133 & 87 & 0,65 & 0,5 & 0,001408 & 2,43 & 240,5 & 4,4 & 0,0657 & 0,0037 & 0,0041 & 0,0001 & 26,1 & 0,5 \\
\hline 5,1 & 97 & 55 & 0,57 & 0,4 & 0,004189 & 3,44 & 229,1 & 4,6 & 0,0738 & 0,0044 & 0,0042 & 0,0001 & 27,1 & 0,6 \\
\hline 6,1 & 143 & 89 & 0,62 & 0,5 & - & 2,96 & 238,0 & 4,4 & 0,07 & 0,0039 & 0,0041 & 0,0001 & 26,2 & 0,5 \\
\hline 7,1 & 117 & 71 & 0,61 & 0,4 & 0,003873 & 4,7 & 241,9 & 5,1 & 0,0837 & 0,005 & 0,0039 & 0,0001 & 25,3 & 0,6 \\
\hline 8,1 & 126 & 79 & 0,63 & 0,5 & 0,005249 & 4,69 & 233,3 & 4,8 & 0,0836 & 0,0049 & 0,0041 & 0,0001 & 26,3 & 0,6 \\
\hline 9,1 & 652 & 724 & 1,11 & 2,3 & 0,00019 & 0,15 & 244,0 & 2,9 & 0,0477 & 0,0016 & 0,0041 & 0,0000 & 26,3 & 0,3 \\
\hline 10,1 & 347 & 396 & 1,14 & 1,3 & 0,001512 & 0,93 & 230,1 & 3,1 & 0,0539 & 0,0018 & 0,0043 & 0,0001 & 27,7 & 0,4 \\
\hline 11,1 & 148 & 115 & 0,78 & 0,5 & 0,004512 & 1,39 & 237,3 & 4,1 & 0,0575 & 0,003 & 0,0042 & 0,0001 & 26,7 & 0,5 \\
\hline 12,1 & 97 & 75 & 0,77 & 0,4 & 0,002819 & 2,53 & 234,6 & 4,6 & 0,0666 & 0,0042 & 0,0042 & 0,0001 & 26,7 & 0,5 \\
\hline 13,1 & 463 & 590 & 1,27 & 1,7 & 0,001281 & 0,6 & 235,8 & 3,0 & 0,0513 & 0,0017 & 0,0042 & 0,0001 & 27,1 & 0,4 \\
\hline 14,1 & 156 & 101 & 0,65 & 0,6 & 0,00151 & 2,58 & 236,7 & 4,0 & 0,0669 & 0,0033 & 0,0041 & 0,0001 & 26,5 & 0,5 \\
\hline
\end{tabular}

